\title{
REACTIVITY OF LESIONS DERIVED FROM ABASIC (AP) SITES IN DNA
}

\author{
A Dissertation \\ presented to \\ the Faculty of the Graduate School \\ at the University of Missouri-Columbia \\ In Partial Fulfillment \\ of the Requirements for the Degree \\ Doctor of Philosophy \\ by \\ Kurt L. Housh \\ Dr. Kent S. Gates, Dissertation Supervisor \\ May, 2021
}


The undersigned, appointed by the dean of the Graduate School, have examined the dissertation entitled

\section{REACTIVITY OF LESIONS DERIVED FROM ABASIC (AP) SITES IN DNA}

Presented by Kurt L. Housh

a candidate for the degree of Doctor of Philosophy

and hereby certify that, in their opinion, it is worthy of acceptance.

Professor Kent Gates

Professor Michael Harmata

Professor Justin Walensky

Professor Timothy Hoffman 


\section{ACKNOWLEDGEMENTS}

I would like to begin by thanking the two most important people in my life; my wife, Ali, and my mom, Cara. Their support through this process is beyond words, and my love for them knows no depths. Going through the $\mathrm{PhD}$ process with Ali has been nothing short of amazing. I am lucky to have someone who is there for me who both understands and is supportive of this process. She is my rock.

Behind every well-oiled research group, there is an advisor derailing group meeting with topics that allow us to grow as scientists and as people. I am thankful for Dr. Gates for fostering a cohesive team in which I had the opportunity be a part. While I may not have always been the easiest graduate student to coach, I sincerely appreciate all his time and effort in order to mold me into being a better scientist and a better person. Our lengthy conversations are invaluable to me.

To that, I am thankful for being a part of this research group, and thankful to all Gates members past and present for helping me through some of my research challenges and for their input regarding this work. I would like to personally thank Chris Nel and Tuhin Haldar. In these two, I sought to make friends, and ending up finding a family.

A very special thanks to Dr. Mike Harmata, for helping me gain a firm understanding of organic chemistry through the courses he taught. I am also beyond thankful because he has been a personal mentor to me.

I would also like to thank Drs. Walensky and Hoffman for accepting to be a part of my thesis committee and asking me questions throughout my tenure. Our conversations have helped mold me into becoming a better scientist. 


\section{Table of Contents}

Acknowledgements ii

List of Schemes $\quad$ v

List of Figures vii vii v v vis

$\begin{array}{ll}\text { Abstract } & \text { x } \\ & \end{array}$

Chapter One: An introduction to relevant DNA chemistry

$\begin{array}{ll}\text { 1.1 Introduction } & 1\end{array}$

1.2 The abasic (Ap) site and the 3'dRP end group 4

1.3 Ap sites and the 3'dRP end groups are reactive species 6

1.4 Conclusion 9

$\begin{array}{ll}\text { References } & \mathbf{1 0}\end{array}$

Chapter Two: Adducts with Ap sites and their derivatives

2.1 Introduction $\quad 16$

2.2 Formation of Ap adduct with glutathione $\quad 18$

2.3 Formation of Ap adduct with 1-aminohydantoin 21

2.4 Formation of Ap adduct with carbidopa $\quad \mathbf{2 5}$

2.5 Formation of the 3'dRP adduct with dGTP 30

$\begin{array}{ll}\text { 2.6 Formation of the } 3 \text { ' dRP adduct with dGMP } & 37\end{array}$

2.7 Conclusion $\quad 41$

2.8 Experimental $\quad \mathbf{4 2}$

References 
Chapter Three: A complex interstrand DNA cross-link arising from a common endogenous lesion

3.1 Introduction

3.2 Evidence that amine-catalyzed strand cleavage gives rise to a complex ICL in duplex DNA

3.3 Unhooking of the dG-dRP cross-link by human apurinic endonuclease I (hAPE1) has the potential to initiate repair of the $\mathrm{dG}-\mathrm{dRP} \mathrm{ICL}$

3.4 Scope and generality of the cross-linking reaction: formation of the dG-dRP ICL in various sequences and conditions

3.5 Conclusion

3.6 Experimental

References

Chapter Four: Facile synthesis of DNA duplexes containing a chemically defined, derivatizable covalent cross-link

4.1 Introduction

4.2 Interstrand cross-link formation

4.3 Cross-link formation with derivatizable amino handle

122

4.4 Conjugating a biotin tag onto the interstrand cross-link

126

4.5 Conclusions

130

4.6 Experimental

131

References

136

Chapter Five: Conclusion and directionality of research

5.1 Introduction

5.2 Directionality of research

References 


\section{LIST OF SCHEMES}

\section{Chapter One Schemes}

1.1.1 Central dogma of biology 4

1.2.1 Depurination of guanine and the enzymatic cleavage of uridine 5

1.2.2 Cleavage of the Ap site to form the 3'dRP end group 6

1.3.1 Formation of interstrand cross-link with adenine and guanine from Ap sites 7

1.3.2 Formation of 3'dRP and subsequent cross-link formation $\quad 8$

\section{Chapter Two Schemes}

2.1.1 Initiating the repair of an Ap site by the enzyme, APE1 17

2.2.1 Formation of GSH adduct with an Ap site $\quad 19$

2.3.1 Formation of 1-aminohydantoin adduct with an Ap site 23

2.4.1 Formation of carbidopa adduct with an Ap site $\quad 27$

2.5.1 Formation of dGTP adduct with the 3'dRP site 30

$\begin{array}{ll}\text { 2.6.1 Formation of dGMP adduct with the 3'dRP site } & 37\end{array}$

\section{Chapter Three Schemes}

3.1.1 $\beta$-Elimination at an AP site in DNA generates a strand break with electrophilic $\alpha, \beta$-unsaturated sugar remnants on the 3'-terminus.

3.1.2 Amine-catalyzed strand cleavage at an AP site in duplex DNA gives rise to a complex ICL via reaction of the $\alpha, \beta$-unsaturated iminium ion intermediate with a guanine residue on the opposing strand

3.1.3 Architecture of nicked duplex and ICLs generated at an AP site in duplex DNA 54 


\section{Chapter Four Schemes}

4.1.1 Synthesis of a DNA interstrand cross-link containing an ethylamine handle that is tagged with biotin

4.2.1. Formation of interstrand cross-link with a 1,4-diaminobutane linker

4.3.1. Synthesis of an interstrand cross-link containing the tris(2-aminoethyl)amine linker

4.4.1. Formation of interstrand cross-link with a Tris(2-aminoethyl)amine linker and subsequent formation of interstrand cross-link with a biotin label

\section{Chapter Five Schemes}

5.1.1 Fpg removes damaged base and leaves a single strand break with its lyase activity 


\section{LIST OF FIGURES}

\section{Chapter One Figures}

1.1.1 Structure of DNA. PDB code: 1BDNA 2

1.1.2 Structure of backbone and nitrogenous bases of DNA 3

\section{Chapter Two Figures}

$\begin{array}{ll}\text { 2.1.1 DNA duplexes used in these studies } & \mathbf{1 8}\end{array}$

2.2.1 Formation of the capped Ap site with glutathione $\quad 20$

2.3.1 Formation of the capped Ap site with 1-aminohydantoin 23

2.3.2 ESI(-)-TOF-MS analysis of the 1-aminohydantoin adduct $\mathbf{2 5}$

2.4.1 Formation of the capped Ap site with carbidopa 27

2.4.2 ESI(-)-TOF-MS analysis of the carbidopa adduct 29

2.5.1 HPLC analysis of the dGTP adduct with the 3'dRP end group 32

2.5.2 Time course for the formation of the dGTP adduct with the 3 ' $d R P$ end group33

2.5.3 ESI(-)-TOF-MS analysis of the dGTP adduct 36

2.6.1 HPLC analysis of the dGMP adduct with the 3'dRP end group 38

2.6.2 ESI(-)-TOF-MS analysis of the dGMP adduct 40

\section{Chapter Three Figures}

3.1.1 Sequences used in these studies

3.2.1 Gel electrophoretic evidence for an interstrand cross-link generated by sperminecatalyzed strand cleavage at the AP site in duplex A

3.2.2. Time course for the formation of cross-linked DNA generated by amine-catalyzed cleavage of the AP site in duplex A

3.2.3 Evidence that the cross-link generated by spermine-catalyzed strand cleavage in duplex A arises from the 3'dRP iminium ion and not the 3'dRP cleavage product $\mathbf{6 3}$

3.2.4 Iron-EDTA- $\mathrm{H}_{2} \mathrm{O}_{2}$ footprinting of the cross-linked DNA generated by sperminecatalyzed strand cleavage of the AP site in duplex A

3.2.5 ESI(-)-QTOF-LC-MS analysis of the cross-linked DNA generated by sperminemediated cleavage of the AP-containing duplex A 
3.2.6 Stability of the cross-linked DNA arising from spermine-mediated strand cleavage of the AP site in duplex A

3.2.7 This Figure provides gel electrophoretic evidence for the stability of interstrand cross-link duplex $\mathrm{C}$ for both reduced and unreduced cross-link

3.2.8 LC-MS/MS and LC-MS/MS/MS analyses of the cross-linked DNA generated by spermine-mediated strand cleavage of the AP site in duplex A

3.3.1 Unhooking of the dG-dRP ICL by the DNA repair enzyme apurinic endonuclease (APE1)

3.3.2 Unhooking of the dG-dRP ICL by APE1 in a gapped substrate is more effective than in a resected substrate (lacking the duplex region on the 3'-side of the strand break)

3.3.3 Two left-hand panels: Unhooking of the (resected) dG-dRP ICL by APE1 is more effective in exonuclease-specific buffer than in the traditional AP endonuclease buffer

3.3.4 Trimming of the 3 ' $d R$ end group from a gapped substrate by APE1

3.3.5 The BER glycosylase FPG does not unhook the dG-dRP ICL

3.4.1 Yield of ICLs resulting from amine-catalyzed strand cleavage of an AP site in various sequence contexts

3.4.2 Amine-catalyzed cross-link generation in AP-containing duplexes with differing numbers of base pairs on the 3'-side of the AP site

3.4.3 Formation of the nicked cross-linked duplex F

3.4.5 Formation of the nicked cross-linked duplex $\mathrm{R}$

3.4.6 Formation of the nicked cross-linked duplex L

3.4.7 Interstrand cross-link formation in duplex A in various buffers

3.4.8 Interstrand cross-link formation in duplex A by various amines

3.4.9 ESI(-)-QTOF-LC-MS analysis of the cross-linked DNA generated by sperminemediated cleavage of the AP-containing duplex

\section{Chapter Four Figures}

$\begin{array}{ll}\text { 4.2.1 Duplexes used in this study } & 114\end{array}$

4.2.2 Effect of linker size on cross-link formation

4.2.3 Effect of Distance between opposing Ap sites on cross-link formation 
4.2.5 ESI(-)-TOF-MS analysis of the 1,4-diaminobutane interstrand cross-link

4.3.1 Formation of the cross-linked duplex

124

4.3.2 ESI(-)-TOF-MS analysis of the Tris(2-aminoethyl)amine interstrand cross-link 125

4.4.1 ESI(-)-TOF-MS analysis of the biotin tagged Tris(2-aminoethyl)amine interstrand cross-link

128

4.4.2 Pulldown of biotin containing cross-linked duplex B with streptavidin

129 


\title{
Reactivity of Lesions Derived from Abasic Sites (Ap) in DNA Kurt L. Housh \\ Dr. Kent Gates, Dissertation Advisor
}

\begin{abstract}
DNA is vital to cellular function. Therefore, maintaining the integrity of the structure of DNA is of the utmost importance. Damage to the DNA is unavoidable and can be detrimental to organisms. Abasic (Ap) sites are the most abundant form of DNA damage and are present in steady state levels of 10,000 Ap sites per cell per day. These lesions have been studied in the past, but there is still much to know about these noxious, electrophilic lesions. This thesis attempts to use the tools of organic and bio-organic chemistry to study the reactivity, structure, and repair of the Ap site and its derivatives.
\end{abstract}




\section{Chapter 1}

\section{An introduction to relevant DNA chemistry}

\subsection{Introduction}

DNA provides the blueprint and instructions for every living organism. ${ }^{1}$ The genetic information encoded in the sequence of DNA nucleobases must be maintained for every cell. ${ }^{2}$ DNA can be transcribed into messenger RNA that can further be translated into amino acids, which are the building blocks of proteins. ${ }^{3}$ DNA can also be replicated to form identical strands of DNA which is an important precursor to cellular replication (Scheme 1.1.1). The faithful reading and replication of DNA is important to the safety of the organism involved. ${ }^{2}$ Damage to the DNA can result in widespread consequences. ${ }^{4,5,6}$ This dissertation will discuss some of the damage that can happen to DNA.

DNA is a double stranded biopolymer held together via hydrogen-bonding interactions between the nitrogenous bases (Figure 1.1.1). ${ }^{7,8}$ DNA consists of several elements including a 2'-deoxyribose sugar, a phosphodiester backbone linking each sugar backbone to the next, and one of four nitrogenous bases (adenine, thymine, cytosine, and guanine) (Figure 1.1.2). ${ }^{7,8}$

Even with the stability of DNA, it continually undergoes low levels of unavoidable DNA damage produced by water, reactive oxygen species, and endogenous species. ${ }^{9,10,11}$ The human genome is quite large with 12.8 billion nucleobases, so even slow reactions can induce a significant amount of DNA lesions. The spontaneous loss of purine residues by water, for example, occurs with a half-life of 730 years- yet it generates more than 10,000 apurinic (Ap) sites per cell per day. ${ }^{10,12,13}$ 


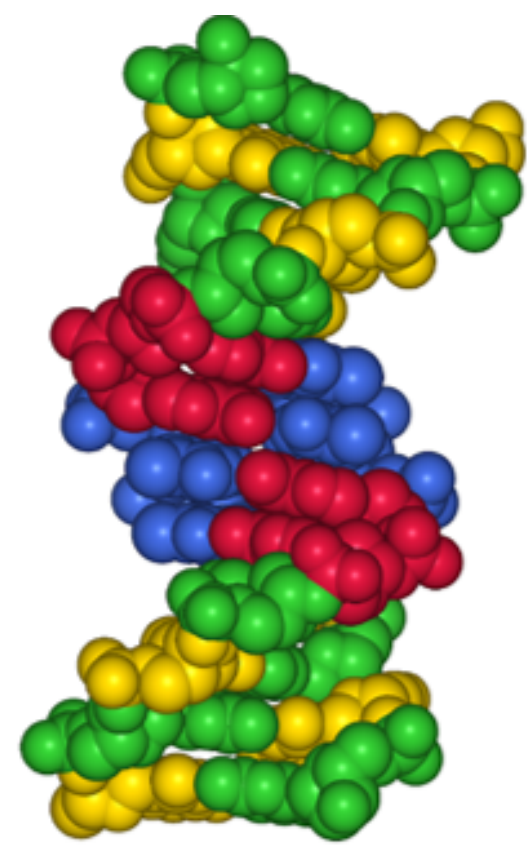

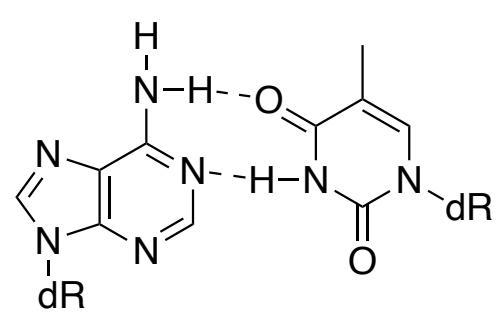

Adenine - Thymine Base Pair

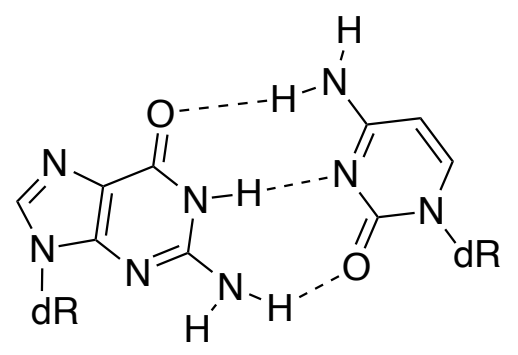

Guanine - Cytosine Base Pair

Figure 1.1.1 Structure of DNA. PBD code: 1BDNA. 

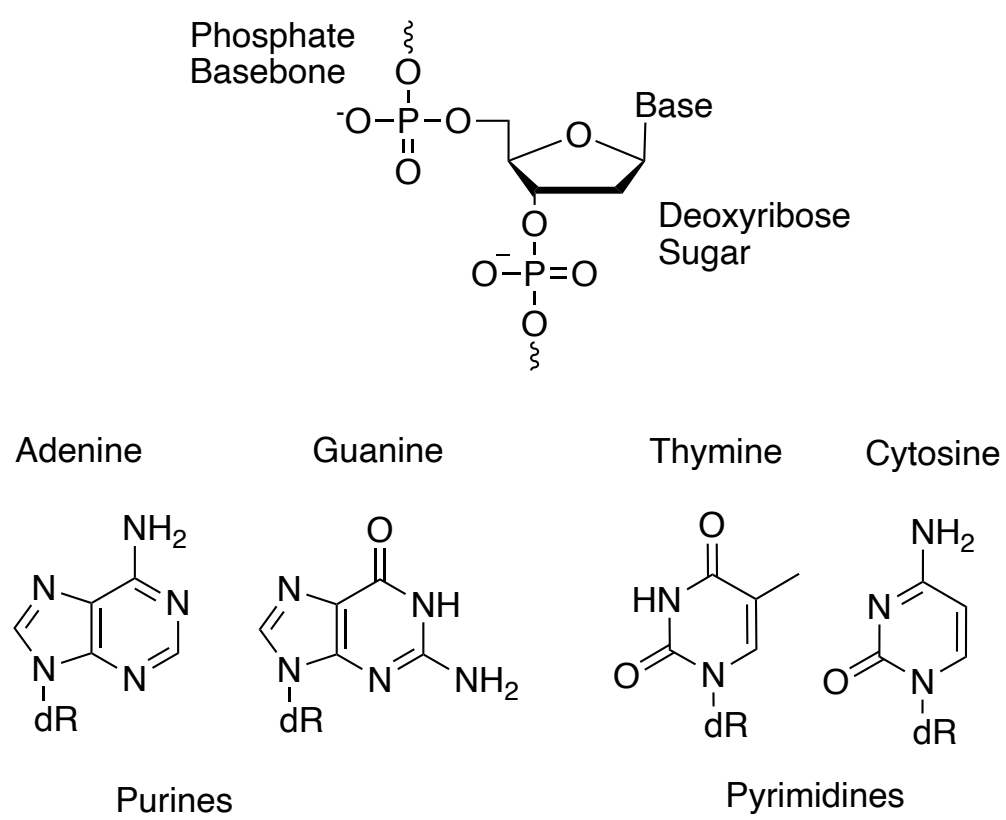

Figure 1.1.2 Structure of backbone and nitrogenous bases of DNA. 


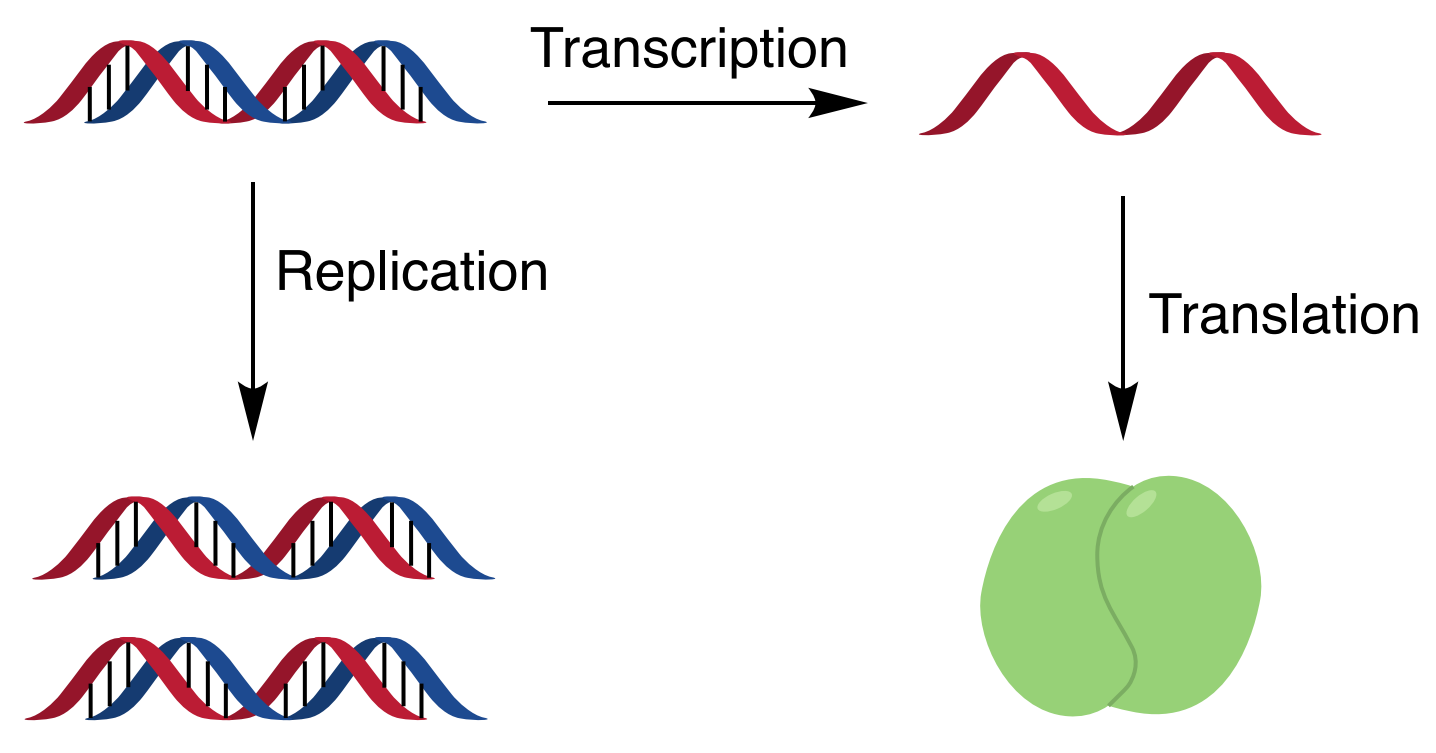

Scheme 1.1.1 Central dogma of biology.

\subsection{The abasic (Ap) site and the 3'dRP end group}

Ap sites can be formed by several mechanisms including depurination via alkylation/protonation and enzymatic cleavage of the nitrogenous base (Scheme 1.2.1). ${ }^{14,15}$ This cleavage is normally done by the elimination of the nitrogenous base, leaving in its place a reactive oxocarbenium ion. This reactive intermediate is readily attacked by water to form the Ap site (Scheme 1.2.1). Ap sites have been shown to be present at $\sim 10,000$ Ap sites per cell per day- making it one of the most ubiquitous forms of DNA damage. ${ }^{10,12,13}$ 
The Ap site exists as an equilibrium mixture of a ring-closed hemiacetal (99\%) and a ring open aldehyde $(1 \%) .{ }^{16,17}$ The ring open aldehyde is a reactive lesion that can undergo $\beta$-elimination to form an $\alpha, \beta$-unsaturated aldehyde, the dRP end group (Scheme 1.2.2). ${ }^{18,19}$ The dRP end group always occurs with a single strand break in the DNA. The Ap site and the dRP end group both are reactive lesions that can form multiple adducts within the cell. If these adducts are not repaired properly then it will lead to consequences such as neurodegeneration, aging, cancer, or mutagenesis. ${ }^{20,21,22,23,24,25,26}$

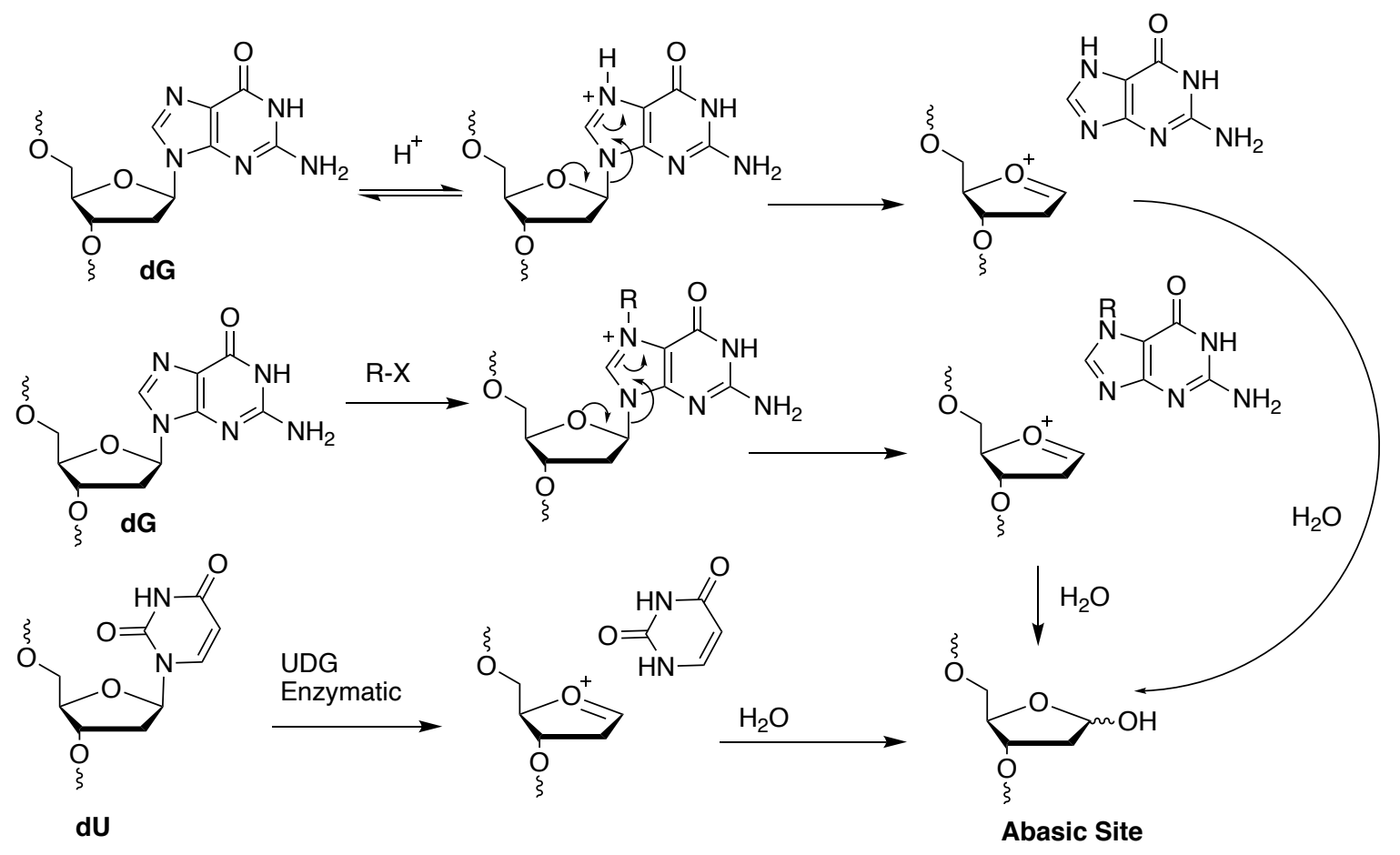

Scheme 1.2.1 Depurination of guanine and the enzymatic cleavage of uridine. 


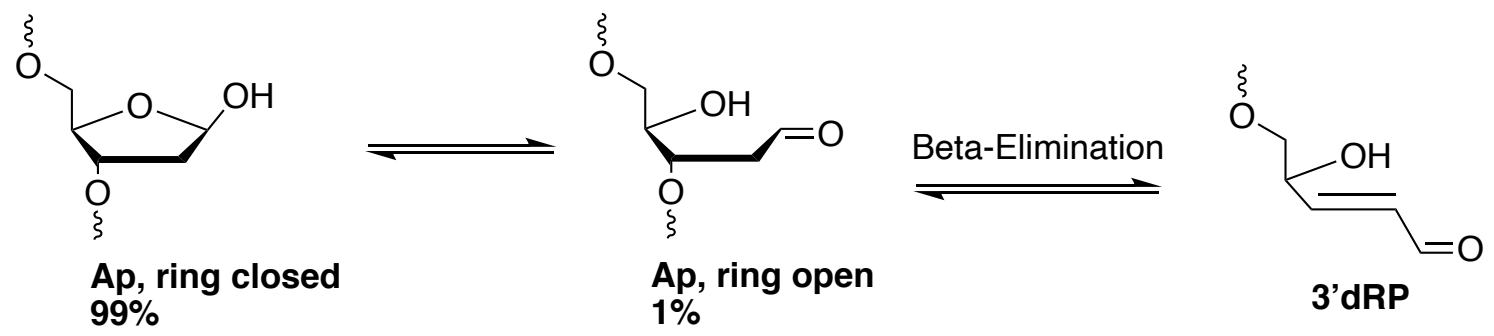

Scheme 1.2.2 Cleavage of Ap site to form the 3'dRP end group.

\subsection{Ap sites and the 3'dRP end groups are reactive species}

Aldehyde functional groups are electrophilic residues that can covalently modify DNA. Due to the reactivity of aldehydes, they are commonly known for their toxicity within organisms. ${ }^{27,28,29}$

Due to the ring-opened aldehyde form of the Ap site, it places a high, local concentration of the highly electrophilic aldehyde functional group inside the double helix of DNA. ${ }^{30}$ Our group has previously shown that nucleophilic attack of an opposing amine group of a nitrogenous base (adenine, guanine, or cytosine) can form an imine with the Ap site, covalently linking the two strands together forming an interstrand cross-link (Scheme 1.3.1). ${ }^{30,31}$ These imines can further be reduced to the corresponding alkylamine by treatment with a reducing agent, such as sodium cyanoborohydride, greatly increasing the stability of the cross-link (Scheme 1.3.1). ${ }^{32,33,30}$ 

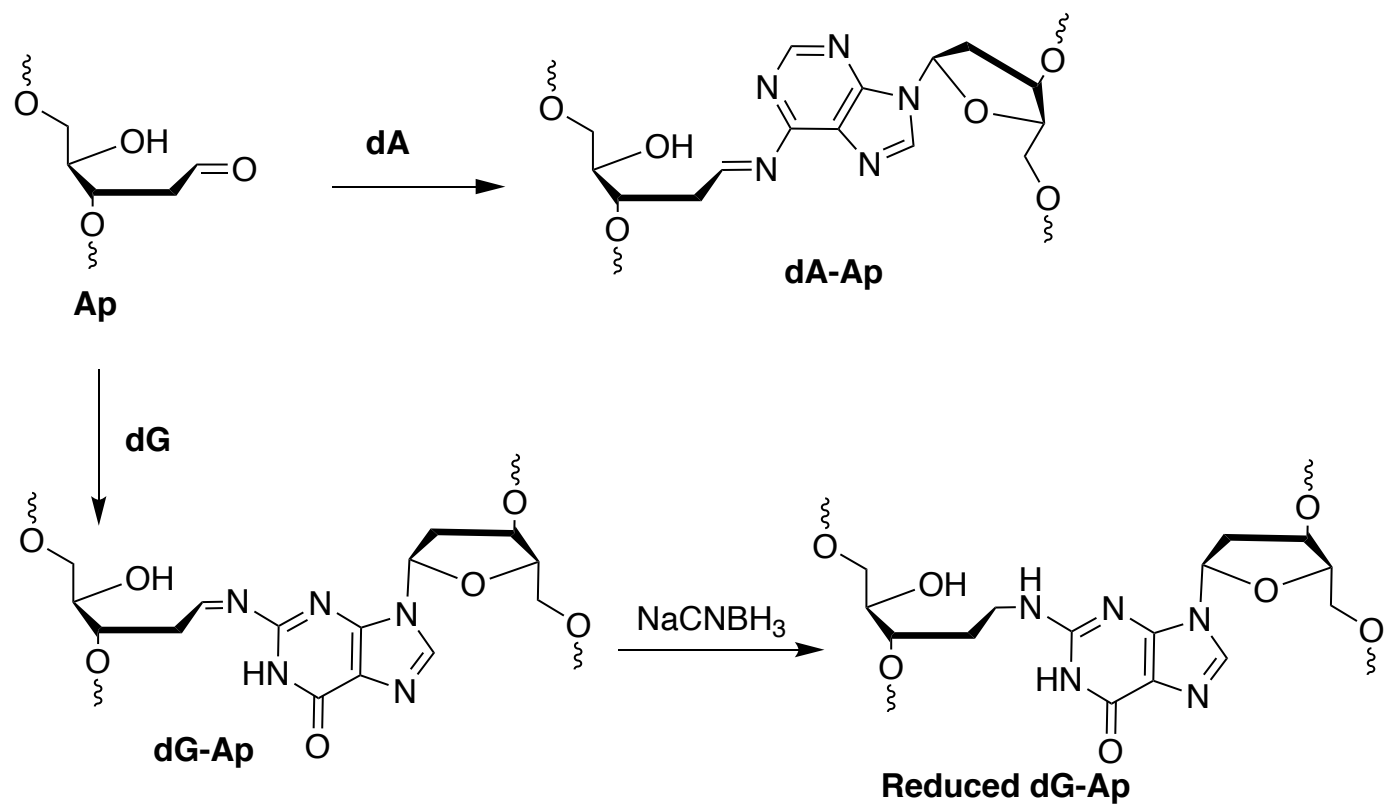

\section{Scheme 1.3.1 Formation of interstrand cross-links with adenine and guanine from Ap sites.}

$\alpha, \beta$-unsaturated aldehydes have been shown to react with the amino groups of nucleobases in DNA. ${ }^{18,34,35,36}$ These nucleophilic additions can occur either via a conjugate, 1,4-addition of the double bond or through a 1,2-addition of the aldehyde. ${ }^{18,34,35,36}$

Single strand breaks can occur in the double helix of DNA at Ap sites by the $\beta$ elimination of the 3'-phosphate group (Scheme 1.2.2) ${ }^{37}$ This reaction can occur under various conditions, including via the catalytic cleavage by the polyamine, spermine, which is present in high concentrations in the nucleus. ${ }^{18,37,38,39}$ This $\beta$-elimination reaction may proceed through an iminium ion intermediate to yield an $\alpha, \beta$-unsaturated 
remnant on the 3'-side of the strand break (3'dRP). ${ }^{18}$ Mass spectroscopic studies have shown the presence of the 3 ' dRP group in cellular DNA. ${ }^{40,41}$

The single strand break at an Ap site in DNA results in an electrophilic $\alpha, \beta-$ unsaturated aldehyde (or a more reactive iminium ion) embedded in the DNA. Our group has shown that this reactive 3 'dRP lesion can react with an opposing adenine residue on the complimentary strand to generate a complex lesion consisting of an interstrand crosslink at a single strand break in DNA (Scheme 1.3.2). ${ }^{18}$

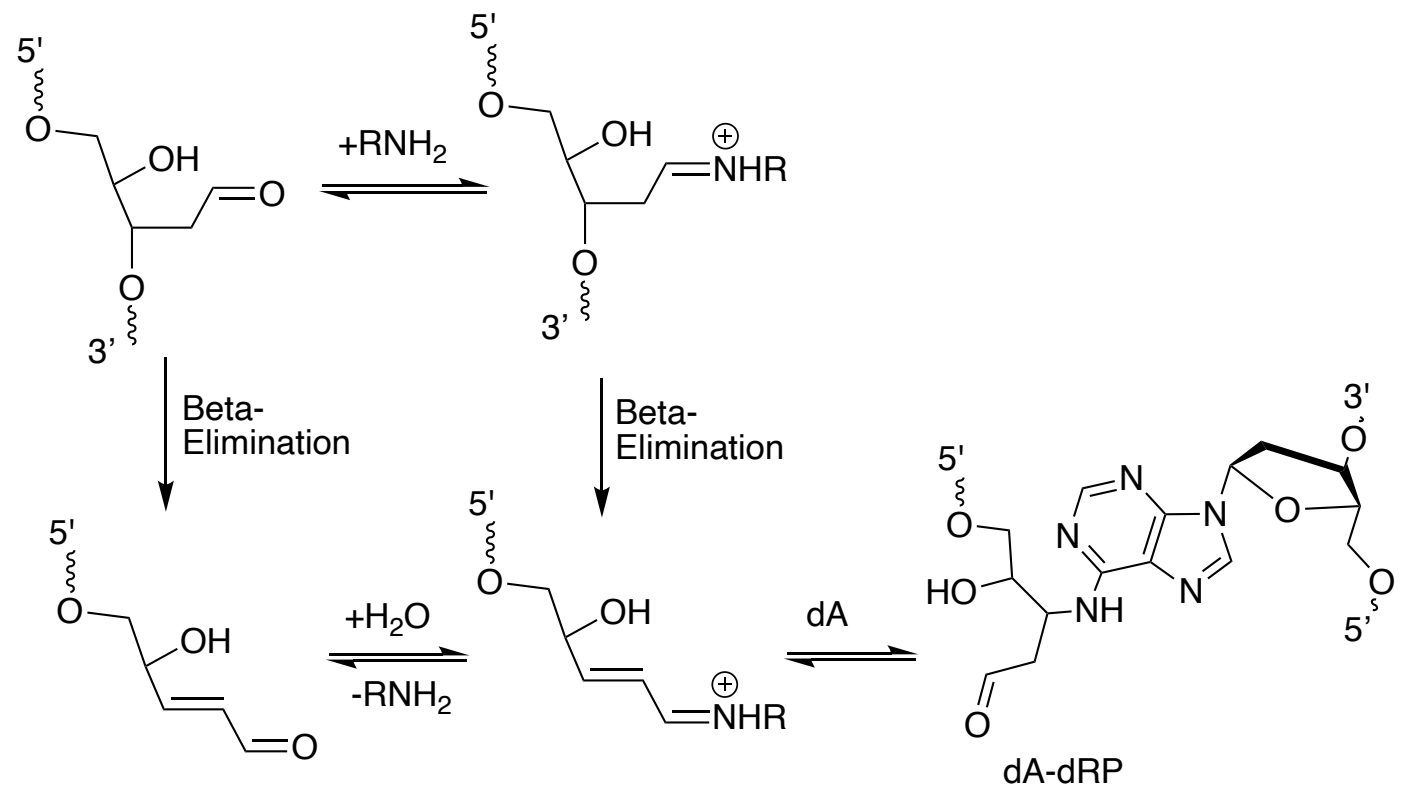

Scheme 1.3.2 Formation of 3'dRP and subsequent cross-link formation. 


\subsection{Conclusion}

Given the prominence of DNA in the cell it is important to understand the types of DNA damage that can occur. The most common form of DNA damage is the Ap site. While there are studies showing some of the chemistry of the Ap site from strand cleavage, generation of interstrand cross-links (ICL's), and adduct formation- there is still quite a bit left unanswered. This dissertation will cover some more of the adducts, including formation of novel ICL's and novel covalent monoadducts that arise from the Ap site and the 3'dRP end group as well as potential repair of the lesions that can arise from these Ap sites. 


\section{References}

(1) Crick, F. Central Dogma of Molecular Biology. Nature 1970, 227 (5258), 561-563. https://doi.org/10.1038/227561a0.

(2) Arrojo E Drigo, R.; Lev-Ram, V.; Tyagi, S.; Ramachandra, R.; Deerinck, T.; Bushong, E.; Phan, S.; Orphan, V.; Lechene, C.; Ellisman, M. H.; Hetzer, M. W. Age Mosaicism across Multiple Scales in Adult Tissues. Cell Metab. 2019, 30 (2), 343-351.e3. https://doi.org/10.1016/j.cmet.2019.05.010.

(3) CHAFFEY, N. Alberts, B., Johnson, A., Lewis, J., Raff, M., Roberts, K. and Walter, P. Molecular Biology of the Cell. 4th Edn. Ann. Bot. 2003, 91 (3), 401. https://doi.org/10.1093/aob/mcg023.

(4) Helleday, T.; Eshtad, S.; Nik-Zainal, S. Mechanisms Underlying Mutational Signatures in Human Cancers. Nat. Rev. Genet. 2014, 15 (9), 585-598. https://doi.org/10.1038/nrg3729.

(5) Friedberg, E. C.; McDaniel, L. D.; Schultz, R. A. The Role of Endogenous and Exogenous DNA Damage and Mutagenesis. Curr. Opin. Genet. Dev. 2004, 14 (1), 5-10. https://doi.org/10.1016/j.gde.2003.11.001.

(6) Kucab, J. E.; Zou, X.; Morganella, S.; Joel, M.; Nanda, A. S.; Nagy, E.; Gomez, C.; Degasperi, A.; Harris, R.; Jackson, S. P.; Arlt, V. M.; Phillips, D. H.; Nik-Zainal, S. A Compendium of Mutational Signatures of Environmental Agents. Cell 2019, 177 (4), 821-836.e16. https://doi.org/10.1016/j.cell.2019.03.001.

(7) Ar, T. CHEMICAL STRUCTURE OF THE NUCLEIC ACIDS. Proc. Natl. Acad. Sci. U. S. A. 1954, 40 (8), 748-755. https://doi.org/10.1073/pnas.40.8.748. 
(8) Watson, J. D.; Crick, F. H. C. Molecular Structure of Nucleic Acids: A Structure for Deoxyribose Nucleic Acid. Nature 1953, 171 (4356), 737-738. https://doi.org/10.1038/171737a0.

(9) Lindahl, T. Instability and Decay of the Primary Structure of DNA. Nature 1993, 362 (6422), 709-715. https://doi.org/10.1038/362709a0.

(10) Gates, K. S. An Overview of Chemical Processes That Damage Cellular DNA: Spontaneous Hydrolysis, Alkylation, and Reactions with Radicals. Chem. Res. Toxicol. 2009, 22 (11), 1747-1760. https://doi.org/10.1021/tx900242k.

(11) De Bont, R.; van Larebeke, N. Endogenous DNA Damage in Humans: A Review of Quantitative Data. Mutagenesis 2004, 19 (3), 169-185. https://doi.org/10.1093/mutage/geh025.

(12) Lindahl, T.; Nyberg, B. Rate of Depurination of Native Deoxyribonucleic Acid. Biochemistry 1972, 11 (19), 3610-3618. https://doi.org/10.1021/bi00769a018.

(13) Chen, H.; Yao, L.; Brown, C.; Rizzo, C. J.; Turesky, R. J. Quantitation of Apurinic/Apyrimidinic Sites in Isolated DNA and in Mammalian Tissue with a Reduced Level of Artifacts. Anal. Chem. 2019, 91 (11), 7403-7410. https://doi.org/10.1021/acs.analchem.9b01351.

(14) Lawley, P. D.; Brookes, P. Further Studies on the Alkylation of Nucleic Acids and Their Constituent Nucleotides. Biochem. J. 1963, 89 (1), 127-138.

(15) Gates, K. S.; Nooner, T.; Dutta, S. Biologically Relevant Chemical Reactions of N7Alkylguanine Residues in DNA. Chem. Res. Toxicol. 2004, 17 (7), 839-856. https://doi.org/10.1021/tx049965c. 
(16) Zhou, B.-B. S.; Elledge, S. J. The DNA Damage Response: Putting Checkpoints in Perspective. Nature 2000, 408 (6811), 433-439. https://doi.org/10.1038/35044005.

(17) Norbury, C. J.; Hickson, I. D. Cellular Responses to DNA Damage. Annu. Rev. Pharmacol. Toxicol. 2001, 41, 367-401. https://doi.org/10.1146/annurev.pharmtox.41.1.367.

(18) Yang, Z.; Price, N. E.; Johnson, K. M.; Wang, Y.; Gates, K. S. Interstrand CrossLinks Arising from Strand Breaks at True Abasic Sites in Duplex DNA. Nucleic Acids Res. 2017, 45 (11), 6275-6283. https://doi.org/10.1093/nar/gkx394.

(19) Bailly, V.; Verly, W. G. Possible Roles of Beta-Elimination and Delta-Elimination Reactions in the Repair of DNA Containing AP (Apurinic/Apyrimidinic) Sites in Mammalian Cells. Biochem. J. 1988, 253 (2), 553-559.

(20) McKinnon, P. J. DNA Repair Deficiency and Neurological Disease. Nat. Rev. Neurosci. 2009, 10 (2), 100-112. https://doi.org/10.1038/nrn2559.

(21) Madabhushi, R.; Pan, L.; Tsai, L.-H. DNA Damage and Its Links to Neurodegeneration. Neuron 2014, 83 (2), 266-282. https://doi.org/10.1016/j.neuron.2014.06.034.

(22) Borgesius, N. Z.; de Waard, M. C.; van der Pluijm, I.; Omrani, A.; Zondag, G. C. M.; van der Horst, G. T. J.; Melton, D. W.; Hoeijmakers, J. H. J.; Jaarsma, D.; Elgersma, Y. Accelerated Age-Related Cognitive Decline and Neurodegeneration, Caused by Deficient DNA Repair. J. Neurosci. Off. J. Soc. Neurosci. 2011, 31 (35), 12543-12553. https://doi.org/10.1523/JNEUROSCI.1589-11.2011. 
(23) Schumacher, B.; Garinis, G. A.; Hoeijmakers, J. H. J. Age to Survive: DNA Damage and Aging. Trends Genet. TIG 2008, 24 (2), 77-85. https://doi.org/10.1016/j.tig.2007.11.004.

(24) Menck, C. F.; Munford, V. DNA Repair Diseases: What Do They Tell Us about Cancer and Aging? Genet. Mol. Biol. 2014, 37 (1 Suppl), 220-233.

(25) Hoeijmakers, J. H. J. DNA Damage, Aging, and Cancer. N. Engl. J. Med. 2009, 361 (15), 1475-1485. https://doi.org/10.1056/NEJMra0804615.

(26) Cline, S. D. Mitochondrial DNA Damage and Its Consequences for Mitochondrial Gene Expression. Biochim. Biophys. Acta 2012, 1819 (9-10), 979-991. https://doi.org/10.1016/j.bbagrm.2012.06.002.

(27) Fritz, K. S.; Petersen, D. R. An Overview of the Chemistry and Biology of Reactive Aldehydes. Free Radic. Biol. Med. 2013, 59, 85-91. https://doi.org/10.1016/j.freeradbiomed.2012.06.025.

(28) O’Brien, P. J.; Siraki, A. G.; Shangari, N. Aldehyde Sources, Metabolism, Molecular Toxicity Mechanisms, and Possible Effects on Human Health. Crit. Rev. Toxicol. 2005, 35 (7), 609-662. https://doi.org/10.1080/10408440591002183.

(29) LoPachin, R. M.; Gavin, T. Molecular Mechanisms of Aldehyde Toxicity: A Chemical Perspective. Chem. Res. Toxicol. 2014, 27 (7), 1081-1091. https://doi.org/10.1021/tx5001046.

(30) Dutta, S.; Chowdhury, G.; Gates, K. S. Interstrand Cross-Links Generated by Abasic Sites in Duplex DNA. J. Am. Chem. Soc. 2007, 129 (7), 1852-1853. https://doi.org/10.1021/ja067294u. 
(31) Price, N. E.; Johnson, K. M.; Wang, J.; Fekry, M. I.; Wang, Y.; Gates, K. S. Interstrand DNA-DNA Cross-Link Formation Between Adenine Residues and Abasic Sites in Duplex DNA. J. Am. Chem. Soc. 2014, $136(9), 3483-3490$. https://doi.org/10.1021/ja410969x.

(32) Borch, R. F.; Bernstein, M. D.; Durst, H. D. Cyanohydridoborate Anion as a Selective Reducing Agent. J. Am. Chem. Soc. 1971, 93 (12), 2897-2904. https://doi.org/10.1021/ja00741a013.

(33) Johnson, K. M.; Price, N. E.; Wang, J.; Fekry, M. I.; Dutta, S.; Seiner, D. R.; Wang, Y.; Gates, K. S. On the Formation and Properties of Interstrand DNA-DNA CrossLinks Forged by Reaction of an Abasic Site with the Opposing Guanine Residue of 5'-CAp Sequences in Duplex DNA. J. Am. Chem. Soc. 2013, 135 (3), 1015-1025. https://doi.org/10.1021/ja308119q.

(34) Zhang, S.; Villalta, P. W.; Wang, M.; Hecht, S. S. Analysis of Crotonaldehyde- and Acetaldehyde-Derived 1,n(2)-Propanodeoxyguanosine Adducts in DNA from Human Tissues Using Liquid Chromatography Electrospray Ionization Tandem Mass Spectrometry. Chem. Res. Toxicol. 2006, 19 (10), 1386-1392. https://doi.org/10.1021/tx060154d.

(35) Stone, M. P.; Cho, Y.-J.; Huang, H.; Kim, H.-Y.; Kozekov, I. D.; Kozekova, A.; Wang, H.; Minko, I. G.; Lloyd, R. S.; Harris, T. M.; Rizzo, C. J. Interstrand DNA Cross-Links Induced by $\alpha, \beta$-Unsaturated Aldehydes Derived from Lipid Peroxidation and Environmental Sources. Acc. Chem. Res. 2008, 41 (7), 793-804. https://doi.org/10.1021/ar700246x. 
(36) Eder, E.; Hoffman, C. Identification and Characterization of Deoxyguanosine Adducts of Mutagenic .Beta.-Alkyl-Substituted Acrolein Congeners. Chem. Res. Toxicol. 1993, 6 (4), 486-494. https://doi.org/10.1021/tx00034a015.

(37) Lindahl, T.; Andersson, A. Rate of Chain Breakage at Apurinic Sites in DoubleStranded Deoxyribonucleic Acid. Biochemistry 1972, 11 (19), 3618-3623. https://doi.org/10.1021/bi00769a019.

(38) Ochs, S.; Severin, T. Reaction of 2'-Deoxyguanosine with Glucose. Carbohydr. Res. 1995, 266 (1), 87-94. https://doi.org/10.1016/0008-6215(94)00254-D.

(39) Hopkins, P. B.; Millard, J. T.; Woo, J.; Weidner, M. F.; Kirchner, J. J.; Sigurdsson, S. Th.; Raucher, S. Sequence Preferences of DNA Interstrand Cross-Linking Agents: Importance of Minimal DNA Structural Reorganization in the CrossLinking Reactions of Mechlorethamine, Cisplatin and Mitomycin C. Tetrahedron 1991, 47 (14), 2475-2489. https://doi.org/10.1016/S0040-4020(01)81782-8.

(40) Ma, W.; Westmoreland, J. W.; Gordenin, D. A.; Resnick, M. A. Alkylation Base Damage Is Converted into Repairable Double-Strand Breaks and Complex Intermediates in G2 Cells Lacking AP Endonuclease. PLoS Genet. 2011, 7 (4), e1002059. https://doi.org/10.1371/journal.pgen.1002059.

(41) Guillet, M.; Boiteux, S. Origin of Endogenous DNA Abasic Sites in Saccharomyces Cerevisiae. Mol. Cell. Biol. 2003, 23 (22), 8386-8394. https://doi.org/10.1128/MCB.23.22.8386-8394.2003. 


\section{Chapter 2}

\section{Adducts with Ap sites and their derivatives}

\subsection{Introduction}

Damage to cellular DNA is both unavoidable and detrimental to human health and it contributes to cancer, aging, and neurodegeneration. ${ }^{1,2,3,4,5,6}$ As mentioned previously, one of the most common types of DNA damage is the abasic (Ap) site. ${ }^{7}$ Ap sites are generated spontaneously by hydrolysis of the glycosidic bond which connects the nitrogenous bases to the sugar backbone. Ap sites are part of an equilibrium between a ring closed hemiacetal and a ring-opened aldehyde. ${ }^{8,9}$ This ring open aldehyde has been known to form adducts with nucleophiles. ${ }^{10,11,12}$

The Ap site is a labile lesion that can be degraded to an $\alpha, \beta$-unsaturated aldehyde via a $\beta$-elimination of the 3'-phosphate group to give the 3'dRP remnant. ${ }^{13,14}$ This reactive 3 'dRP lesion has been known to form interstrand cross-links with amino groups on the nucleobase of an adenine residue on the opposing strand. ${ }^{13}$ Giving rise to the question if other molecules present in the nucleus can form adducts with the electrophilic aldehyde functional group.

The repair of DNA damage is vital for cellular function. ${ }^{15,16,17,18,19}$ When an Ap site is present, repair can be initiated by the enzyme APE1, which results in a single strand break leaving behind a 5'-deoxyribosephosphate and a 3'OH at the break (Scheme 2.1.1). ${ }^{20}$ If the Ap site is not effectively repaired it can result in mutation upon DNA replication. ${ }^{21,22}$ 
Studies have shown that the Ap site is capable of forming adducts when nucleophiles are present. ${ }^{23,24,25,13}$ In this chapter several compounds are explored that can form adducts with both Ap sites and the 3'dRP derivative.
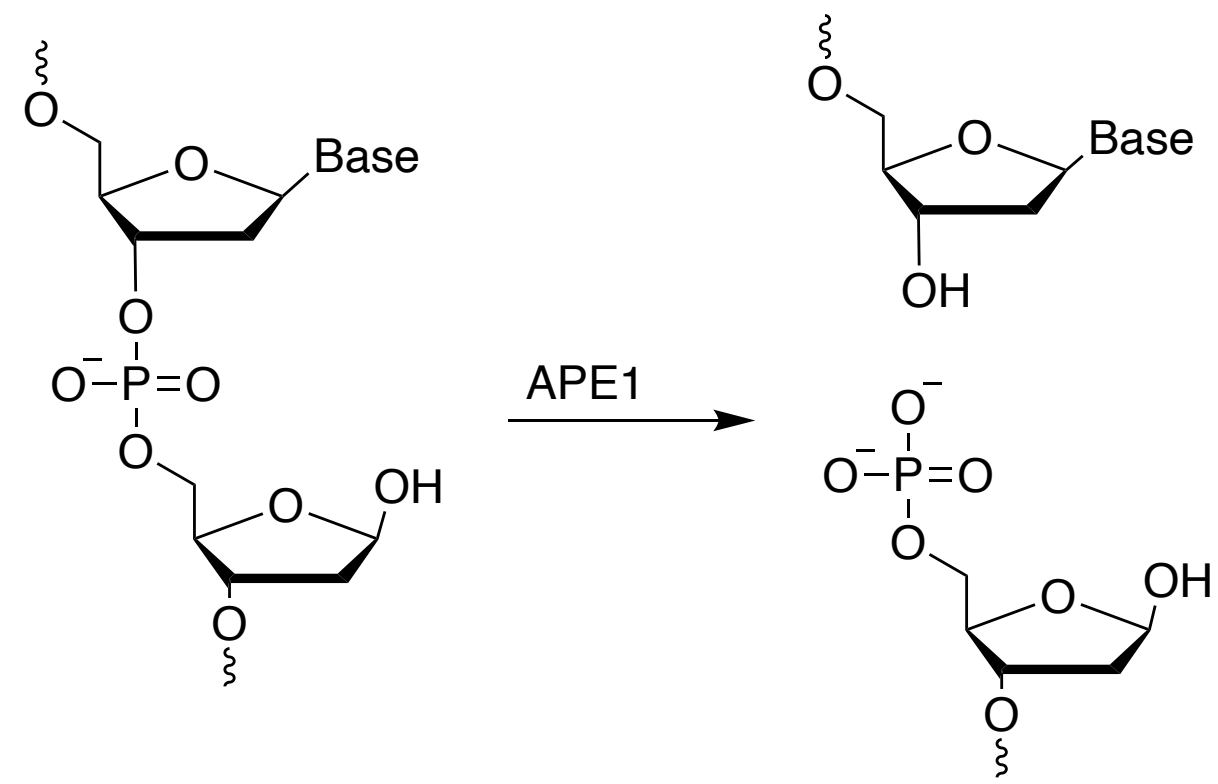

Scheme 2.1.1 Initiating the repair of an Ap site by the enzyme, APE1. 
$\mathrm{X}=\mathrm{AP}$

A 5'-TTATACAATGXTGTTCTAATT

3'-AАTATGTTACAACAAGATTAA

B 5'-ATAGAACXAAGAATA

3'-TATCTTGATTCTTAT

Figure 2.1.1 DNA duplex used in these studies.

\subsection{Formation of Ap adduct with glutathione}

Recent studies have shown that thiols, such as found in HMCES (a protein which is involved in DNA repair) can form adducts with Ap sites. ${ }^{26,27,28}$ Because of this adduct with HMCES, I hypothesized that glutathione, the most abundant thiol in the human body $^{29}$, can also form adducts with Ap sites (Scheme 2.2.1). 

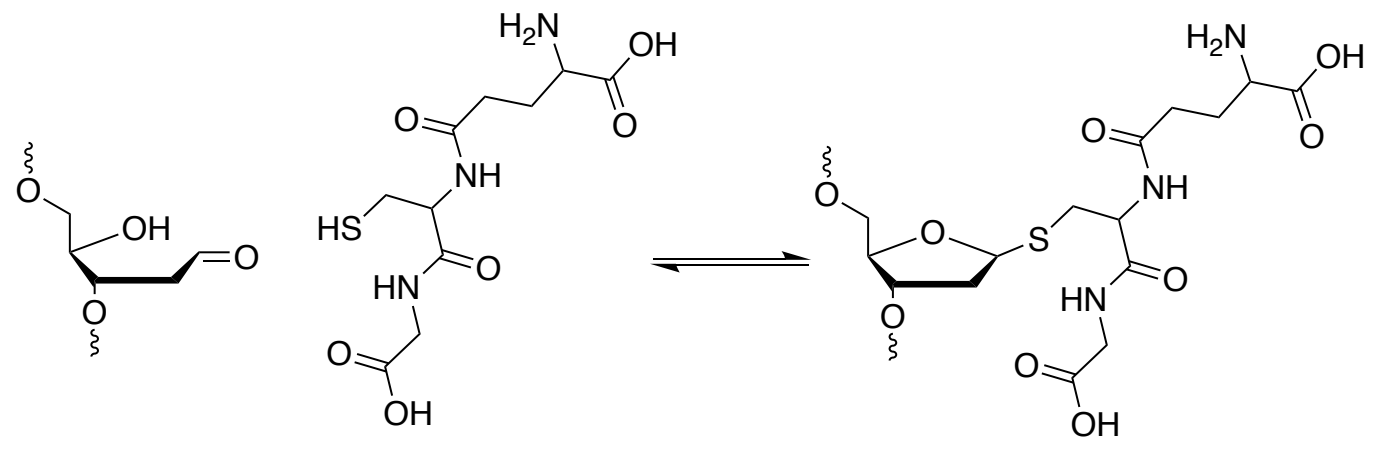

Scheme 2.2.1 Formation of GSH adduct with an Ap site.

Glutathione (GSH) is the most abundant thiol in the cell and is present at millimolar concentrations.$^{29}$ Here, the reactivity of GSH with Ap sites are studied in synthetic oligonucleotides (Scheme 2.2.1). The labeled products generated from the APcontaining duplex A under various conditions were resolved by electrophoresis on a $20 \%$ denaturing polyacrylamide gel and the radioactivity in each band quantitatively measured by storage phosphor autoradiography. The Ap containing DNA duplex B (Figure 2.1.1) was generated and efficient formation of the Ap site was confirmed by treatment of duplex B with $\mathrm{NaOH}\left(165 \mathrm{mM}\right.$ ) for 30 minutes at $37^{\circ} \mathrm{C}$ (Figure 2.2.1, lane 2). To investigate the reactivity of GSH with an Ap site, GSH was reacted with Ap containing duplex B with GSH (5 mM) in HEPES (50 mM, pH 7.4) and $\mathrm{NaCl}(100 \mathrm{mM})$ for $24 \mathrm{~h}$ at $37^{\circ} \mathrm{C}$ (Figure 2.2.1, lane 5). To confirm the stability and formation of the GSH-Ap adduct, the complex after formation was treated with $\mathrm{NaOH}(165 \mathrm{mM})$ for 30 minutes at $37^{\circ} \mathrm{C}$ (Figure 2.2.1, lane 6) and compared to the Ap containing duplex that was reacted 
with $\mathrm{NaOH}(165 \mathrm{mM}$ ) for 30 minutes (Figure 2.2.1, lane 2) and there was a $28+/-3 \% \%$ adduct observed. With evidence that the adduct was formed, the repair of the adduct was of interest. Under normal conditions, Ap sites can be cleaved by the addition of Ap Endonuclease 1 (APE1) (Scheme 2.1.1) (Figure 2.2.1, lane 3) to leave the 3'OH group on the base on the 5' side of the Ap site. To test the ability of APE1 to repair the GSH-Ap lesion, APE1 was added to the GSH-Ap lesion and reacted for 2 hours at $37^{\circ} \mathrm{C}$ (Figure 2.2.1, lane 7) and compared to the ability of APE1 to cleave the regular Ap site (Figure 2.2 .1 , lane 3$)$. It was shown that $33 \%+/-2 \%$ of the lesion remained; indicating that the GSH-Ap adduct is at least partially stable against APE1 repair.
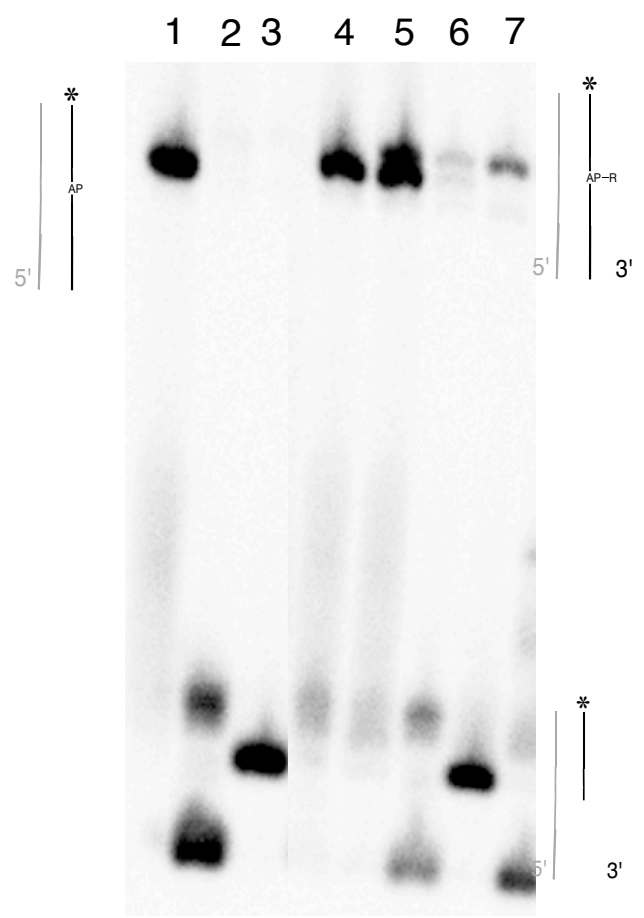
Figure 2.2.1 Formation of the capped Ap site with glutathione. By incubation of duplex $\mathrm{B}$ in HEPES buffer (50 mM, pH 7.4), $\mathrm{NaCl}(100 \mathrm{mM})$, and glutathione $(1 \mathrm{mM})$ at $37^{\circ} \mathrm{C}$. Lane 1 , freshly prepared Ap site size marker; Lane 2 , Ap containing duplex subjected to $\mathrm{NaOH}$ work-up $\left(165 \mathrm{mM}, 37^{\circ} \mathrm{C}, 30 \mathrm{~min}\right)$; Lane 3 , Ap containing duplex in APE1 buffer and APE1 at $37^{\circ} \mathrm{C}$ for $2 \mathrm{~h}$; Lane 4, Ap containing duplex in HEPES (50 $\mathrm{mM}, \mathrm{pH} 7.4)$ and $\mathrm{NaCl}(100 \mathrm{mM})$ at $37^{\circ} \mathrm{C}$ for $24 \mathrm{~h}$; Lane 5, Ap containing duplex in HEPES (50 mM, pH 7.4), $\mathrm{NaCl}(100 \mathrm{mM})$, and glutathione $(1 \mathrm{mM})$ at $37^{\circ} \mathrm{C}$ for $24 \mathrm{~h}$; Lane 6, Ap containing duplex in HEPES (50 mM, pH 7.4), $\mathrm{NaCl}(100 \mathrm{mM})$, and glutathione $(1 \mathrm{mM})$ at $37^{\circ} \mathrm{C}$ for $24 \mathrm{~h}$ followed by $\mathrm{NaOH}$ work-up $(165 \mathrm{mM}) 37^{\circ} \mathrm{C}$ for 30 minutes; Lane 7, Ap containing duplex in HEPES (50 mM, pH 7.4), $\mathrm{NaCl}(100 \mathrm{mM})$, and glutathione $(1 \mathrm{mM})$ at $37^{\circ} \mathrm{C}$ for $24 \mathrm{~h}$ followed by treatment with APE1 at $37^{\circ} \mathrm{C}$ for $2 \mathrm{~h}$. The 5' ${ }^{32} \mathrm{P}$-labeled oligonucleotides in these reactions were resolved by electrophoresis on a $20 \%$ denaturing polyacrylamide gel and the radioactivity in each band quantitatively measured by phosphorimager analysis.

\subsection{Formation of Ap adduct with 1-aminohydantoin}

A metabolite of nitrofurantoin (an antibacterial medication used to treat bladder infections), 1-aminohydantoin contains a hydrazine moiety. ${ }^{30}$ The nucleophilic hydrazine group suggests that it is a possible reactant that could form an adduct with the Ap site in DNA (Scheme 2.3.1). ${ }^{23}$ Here, the reactivity of 1-aminohydantoin with Ap sites is studied in synthetic oligonucleotides. The Ap containing DNA duplex A (Figure 2.1.1) was generated and efficient formation of the Ap site was confirmed by treatment of duplex A 
with $\mathrm{NaOH}(165 \mathrm{mM})$ for 30 minutes at $37^{\circ} \mathrm{C}$ (Figure 2.3.1, lane 3). To confirm the reactivity of 1-aminohydantoin with an Ap site, 1-aminohydantoin was reacted with Ap containing duplex A with 1-aminohydantoin (1 mM) in HEPES $(50 \mathrm{mM}, \mathrm{pH} 7.4)$ and $\mathrm{NaCl}(100 \mathrm{mM})$ for 24 hours at $37^{\circ} \mathrm{C}$ (Figure 2.3.1, lane 5). To confirm the stability and formation of the 1-aminohydantoin-Ap adduct, the complex after formation was treated with $\mathrm{NaOH}(165 \mathrm{mM})$ for 30 minutes at $37^{\circ} \mathrm{C}$ (Figure 2.3.1, lane 6) and compared to the Ap containing duplex that was reacted with $\mathrm{NaOH}(165 \mathrm{mM})$ for 30 minutes (Figure 2.3.1, lane 3 ) and where there was a $42+/-3 \%$ adduct shown. Now that the adduct was shown to have formed, the repair of the adduct was of interest. Under normal conditions, Ap sites can be cleaved by the addition of Ap Endonuclease 1 (APE1) (Scheme 2.1.1) (Figure 2.3.1, lane 4) to leave the 3'OH group on the base on the 5' side of the Ap site. To test the ability of APE1 to repair the 1-aminohydantoin-Ap lesion, APE1 was added to the 1-aminohydantoin-Ap lesion and reacted for 2 hours at $37^{\circ} \mathrm{C}$ (Figure 2.3.1, lane 7) and compared to the ability of APE1 to cleave the regular Ap site (Figure 2.3.1, lane 4). Analysis of the 1-aminohydantoin capped Ap site by Nanospray ESI(-)-MS revealed a major signal at 6389.11 amu (Figure 2.3.2) revealing the formation of the Ap-1aminohydantion product. 

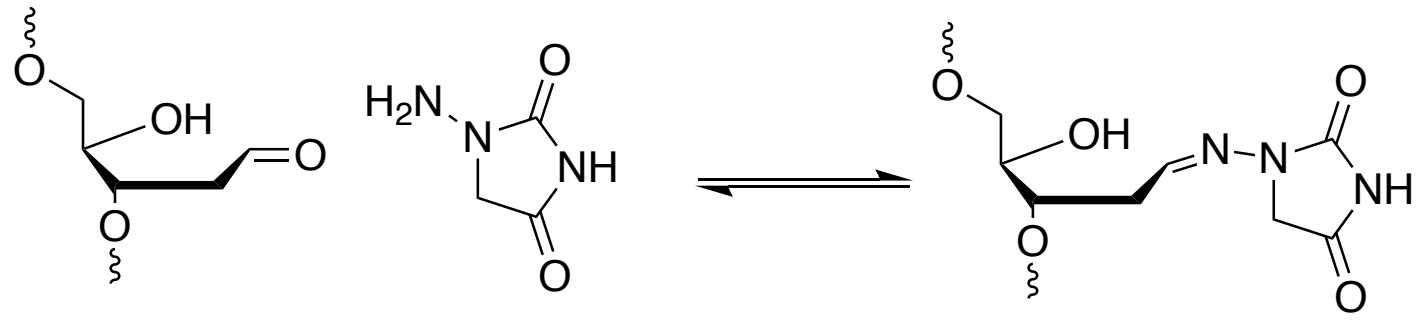

Scheme 2.3.1 Formation of 1-aminohydantoin adduct with an Ap site.
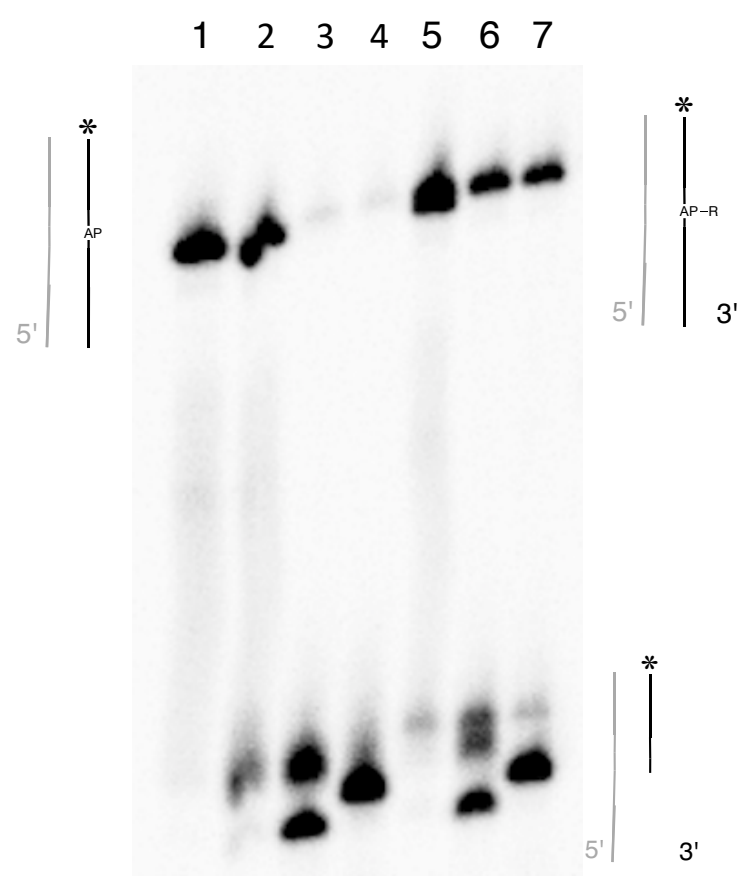
Figure 2.3.1 Formation of the capped Ap site with 1-aminohydantoin. By incubation of duplex A in HEPES buffer (50 mM, pH 7.4), $\mathrm{NaCl}(100 \mathrm{mM})$, and 1-aminohydantoin $(1 \mathrm{mM})$ at $37^{\circ} \mathrm{C}$. Lane 1 , freshly prepared Ap site size marker; Lane 2, Ap containing duplex in HEPES (50 mM, pH 7.4) and $\mathrm{NaCl}(100 \mathrm{mM})$ at $37^{\circ} \mathrm{C}$ for $24 \mathrm{~h}$; Lane 3 , Ap containing duplex subjected to $\mathrm{NaOH}$ work-up $\left(165 \mathrm{mM}, 37^{\circ} \mathrm{C}, 30 \mathrm{~min}\right)$; Lane 4 , Ap containing duplex in APE1 buffer and APE1 at $37^{\circ} \mathrm{C}$ for $2 \mathrm{~h}$; Lane 5, Ap containing duplex in HEPES (50 mM, pH 7.4), $\mathrm{NaCl}(100 \mathrm{mM})$, and 1-aminohydantoin $(1 \mathrm{mM})$ at $37^{\circ} \mathrm{C}$ for $24 \mathrm{~h}$; Lane 6, Ap containing duplex in HEPES (50 mM, pH 7.4), $\mathrm{NaCl}(100$ $\mathrm{mM})$, and 1 -aminohydantoin $(1 \mathrm{mM})$ at $37^{\circ} \mathrm{C}$ for $24 \mathrm{~h}$ followed by $\mathrm{NaOH}$ work-up (165 $\mathrm{mM}) 37^{\circ} \mathrm{C}$ for 30 minutes; Lane 7, Ap containing duplex in HEPES (50 mM, pH 7.4), $\mathrm{NaCl}(100 \mathrm{mM})$, and 1 -aminohydantoin $(1 \mathrm{mM})$ at $37^{\circ} \mathrm{C}$ for $24 \mathrm{~h}$ followed by treatment with APE1 at $37^{\circ} \mathrm{C}$ for $2 \mathrm{~h}$. The 5'-32 P-labeled oligonucleotides in these reactions were resolved by electrophoresis on a $20 \%$ denaturing polyacrylamide gel and the radioactivity in each band quantitatively measured by phosphorimager analysis. 


\section{Figure 2.3.2. ESI(-)-TOF-MS analysis of the 1-aminohydantoin adduct. Masses}

shown correspond to the most prominent peak in the isotope envelope for each species. Calculated molecular mass for the 1-aminohydantoin adduct is $6389.20 \mathrm{amu}$. Other masses include the Ap site at $6289.16 \mathrm{amu}$ and the complimentary strand at $6445.16 \mathrm{amu}$.

\subsection{Formation of Ap adduct with carbidopa}

Carbidopa is an FDA approved drug used to treat Parkinson's Disease. The hydrazine functional group suggests that it is a possible reactant that could form an adduct with the Ap site in DNA (Scheme 2.4.1). ${ }^{23}$ Here the reactivity of carbidopa with Ap sites are studied in synthetic oligonucleotides. The Ap containing DNA duplex A (Figure 2.1.1) was generated and efficient formation of the Ap site was confirmed by treatment of duplex A with $\mathrm{NaOH}(165 \mathrm{mM})$ for 30 minutes at $37^{\circ} \mathrm{C}$ (Figure 2.4.1, lane 3). To confirm the reactivity of carbidopa with an Ap site, carbidopa was reacted with Ap containing duplex A with carbidopa $(1 \mathrm{mM})$ in HEPES (50 mM, pH 7.4) and $\mathrm{NaCl}(100$ $\mathrm{mM}$ ) for 24 hours at $37^{\circ} \mathrm{C}$ (Figure 2.4.1, lane 5). To confirm the stability and formation of the carbidopa-Ap adduct, the complex after formation was treated with $\mathrm{NaOH}$ (165 
$\mathrm{mM}$ ) for 30 minutes at $37^{\circ} \mathrm{C}$ (Figure 2.4 .1 , lane 6) and compared to the Ap containing duplex that was reacted with $\mathrm{NaOH}(165 \mathrm{mM})$ for 30 minutes (Figure 2.4.1, lane 3) and where there was a $5+/-1 \%$ adduct shown. Now that the adduct was shown to have formed, the repair of the adduct was of interest. Ap sites can be cleaved by the addition of APE1 (Scheme 2.1.1) (Figure 2.4.1, lane 4). To test the ability of APE1 to repair the carbidopa-Ap lesion, APE1 was added to the carbidopa-Ap lesion and reacted for 2 hours at $37^{\circ} \mathrm{C}$ (Figure 2.4 .1 , lane 7 ) and compared to the ability of APE1 to cleave the regular Ap site (Figure 2.4.1, lane 4). Analysis of the carbidopa capped Ap site by Nanospray ESI(-)-MS revealed a major signal at 6497.07 amu (Figure 2.4.2) revealing the formation of the Ap-carbidopa adduct. 


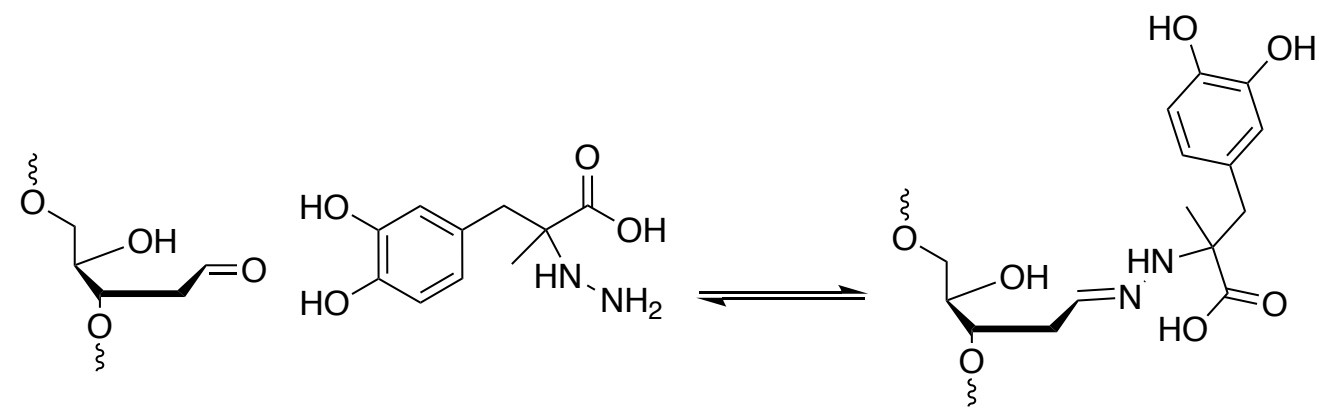

Scheme 2.4.1 Formation of carbidopa adduct with an Ap site.

$\begin{array}{lllllll}1 & 2 & 3 & 4 & 5 & 6 & 7\end{array}$
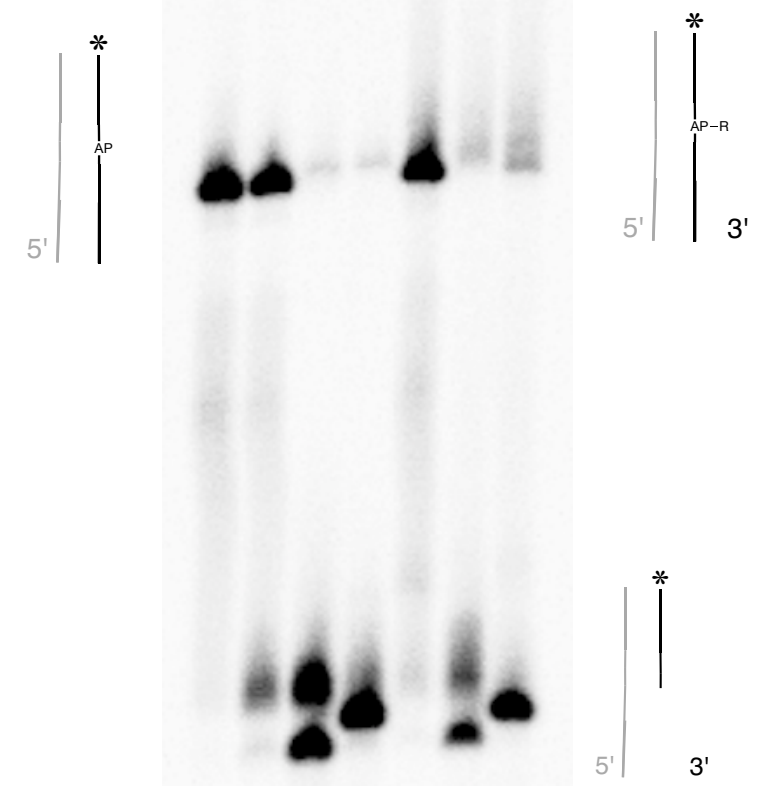
Figure 2.4.1 Formation of the capped Ap site with carbidopa. By incubation of duplex A in HEPES buffer (50 mM, pH 7.4), $\mathrm{NaCl}(100 \mathrm{mM})$, and carbidopa $(1 \mathrm{mM})$ at $37^{\circ} \mathrm{C}$. Lane 1, freshly prepared Ap site size marker; Lane 2, Ap containing duplex in HEPES (50 mM, pH 7.4) and $\mathrm{NaCl}(100 \mathrm{mM})$ at $37^{\circ} \mathrm{C}$ for $24 \mathrm{~h}$; Lane 3 , Ap containing duplex subjected to $\mathrm{NaOH}$ work-up $\left(165 \mathrm{mM}, 37^{\circ} \mathrm{C}, 30 \mathrm{~min}\right)$; Lane 4 , Ap containing duplex in APE1 buffer and APE1 at $37^{\circ} \mathrm{C}$ for $2 \mathrm{~h}$; Lane 5, Ap containing duplex in HEPES (50 $\mathrm{mM}, \mathrm{pH} 7.4), \mathrm{NaCl}(100 \mathrm{mM})$, and carbidopa $(1 \mathrm{mM})$ at $37^{\circ} \mathrm{C}$ for $24 \mathrm{~h}$; Lane $6, \mathrm{Ap}$ containing duplex in HEPES (50 mM, pH 7.4), $\mathrm{NaCl}(100 \mathrm{mM})$, and carbidopa (1 mM) at $37^{\circ} \mathrm{C}$ for $24 \mathrm{~h}$ followed by $\mathrm{NaOH}$ work-up $(165 \mathrm{mM}) 37^{\circ} \mathrm{C}$ for 30 minutes; Lane 7 , Ap containing duplex in HEPES (50 mM, pH 7.4), $\mathrm{NaCl}(100 \mathrm{mM})$, and carbidopa $(1 \mathrm{mM})$ at $37^{\circ} \mathrm{C}$ for $24 \mathrm{~h}$ followed by treatment with APE 1 at $37^{\circ} \mathrm{C}$ for $2 \mathrm{~h}$. The $5^{\prime}-{ }^{32} \mathrm{P}$-labeled oligonucleotides in these reactions were resolved by electrophoresis on a $20 \%$ denaturing polyacrylamide gel and the radioactivity in each band quantitatively measured by phosphorimager analysis. 

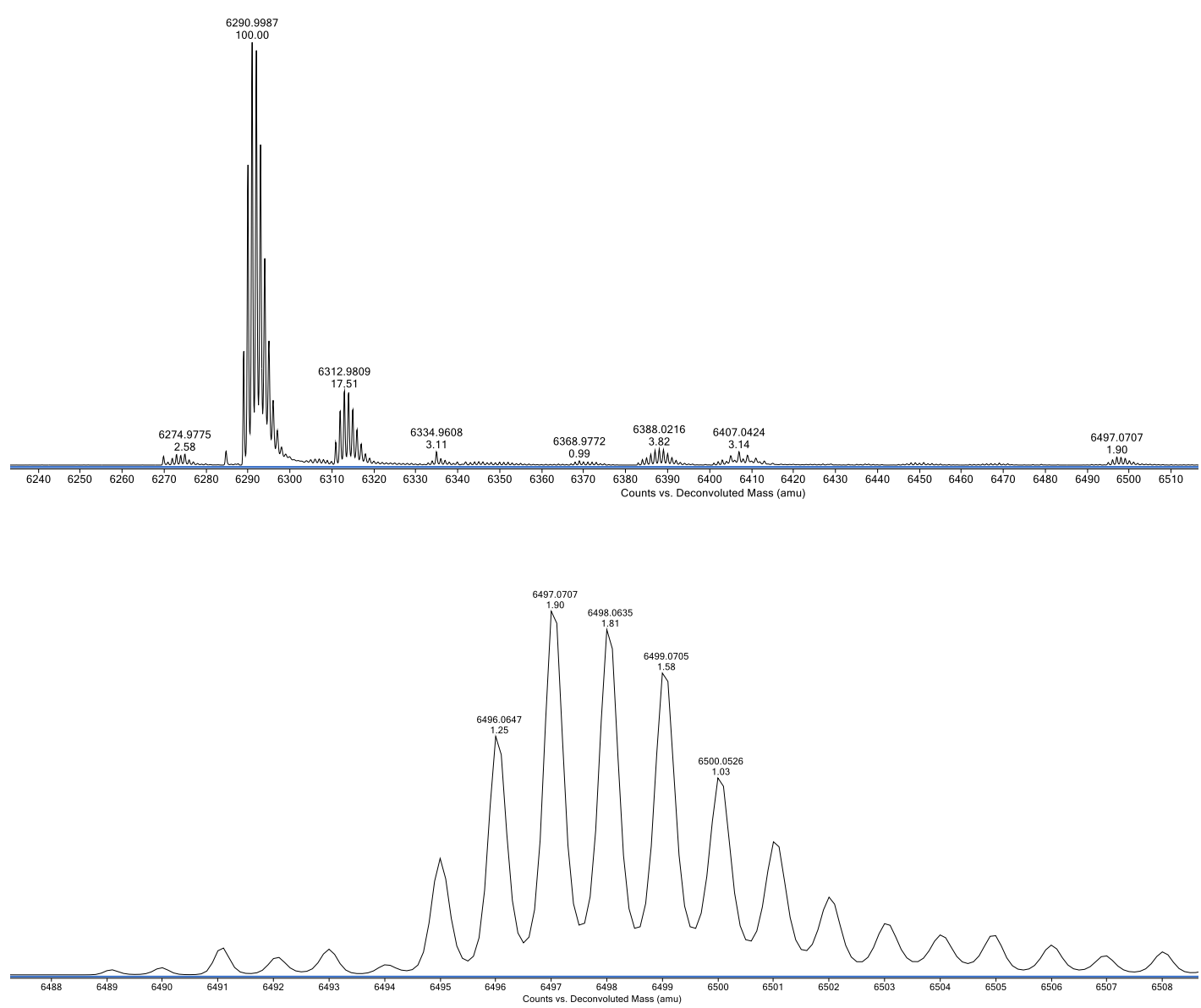

Figure 2.4.2. ESI(-)-TOF-MS analysis of the carbidopa adduct. Masses shown correspond to the most prominent peak in the isotope envelope for each species. Calculated molecular mass for the carbidopa adduct is $6500.34 \mathrm{amu}$. The Ap site is at $6291 \mathrm{amu}$ and the Ap site $+\mathrm{NA}^{+}$at $6312.98 \mathrm{amu}$. 


\subsection{Formation of the 3'dRP Adduct with dGTP}

A derivative of the Ap site, the 3'dRP is a reactive $\alpha, \beta$-unsaturated aldehyde that results from the $\alpha, \beta$-elimination of the 3'-phosphoryl group of the intact Ap site resulting in a single strand break in the DNA. ${ }^{14}$ The reactivity of this end group is yet to be fully studied. The 3'dRP group has been shown to react via 1,4-conjugate addition of nucleophiles. ${ }^{13}$ This leads to the question of whether nucleophiles present in the nucleus are capable of forming adducts with these lesions. Deoxyguanosine-5' -triphosphate (dGTP), present in the nucleus, ${ }^{31}$ could potentially be capable of forming an adduct with the 3'dRP site via a 1,4-conjugate addition (Scheme 2.5.1).

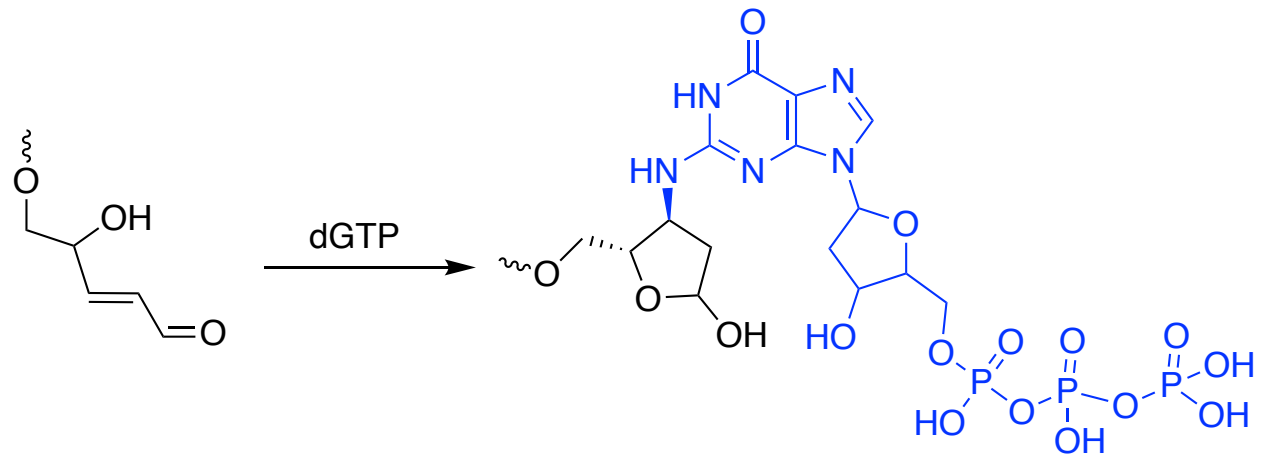

Scheme 2.5.1 Formation of dGTP adduct with the dRP site.

The Ap site was generated by acidic cleavage of the adenine residue in the sequence 5'-TTTTTATTTTTTTTTT (polyT) to give an Ap site after the acidic cleavage. The 3'dRP group was then generated by treatment of the polyamine, spermine, 
to give rise to a series of end groups, previously characterized by our group. 3 'dRP being one of the major products. dGTP was co-incubated during this process and the reaction mixture was analyzed using HPLC analysis (Figure 2.5.1). The polyT sequence with the Ap site embedded in it was treated with $1 \mathrm{mM}$ spermine, $50 \mathrm{mM}$ HEPES ( $\mathrm{pH}$ 7.4), 100 $\mathrm{mM} \mathrm{NaCl}$, and $1 \mathrm{mM} \mathrm{dGTP}$ at $37^{\circ} \mathrm{C}$ for $24 \mathrm{~h}$ showed the formation of a new peak at $\sim 12$ min (Figure 2.5.1, Panel B) compared to the same polyT sequence with the Ap site treated in the same conditions minus the addition of dGTP (Figure 2.5.1, Panel B). 
A
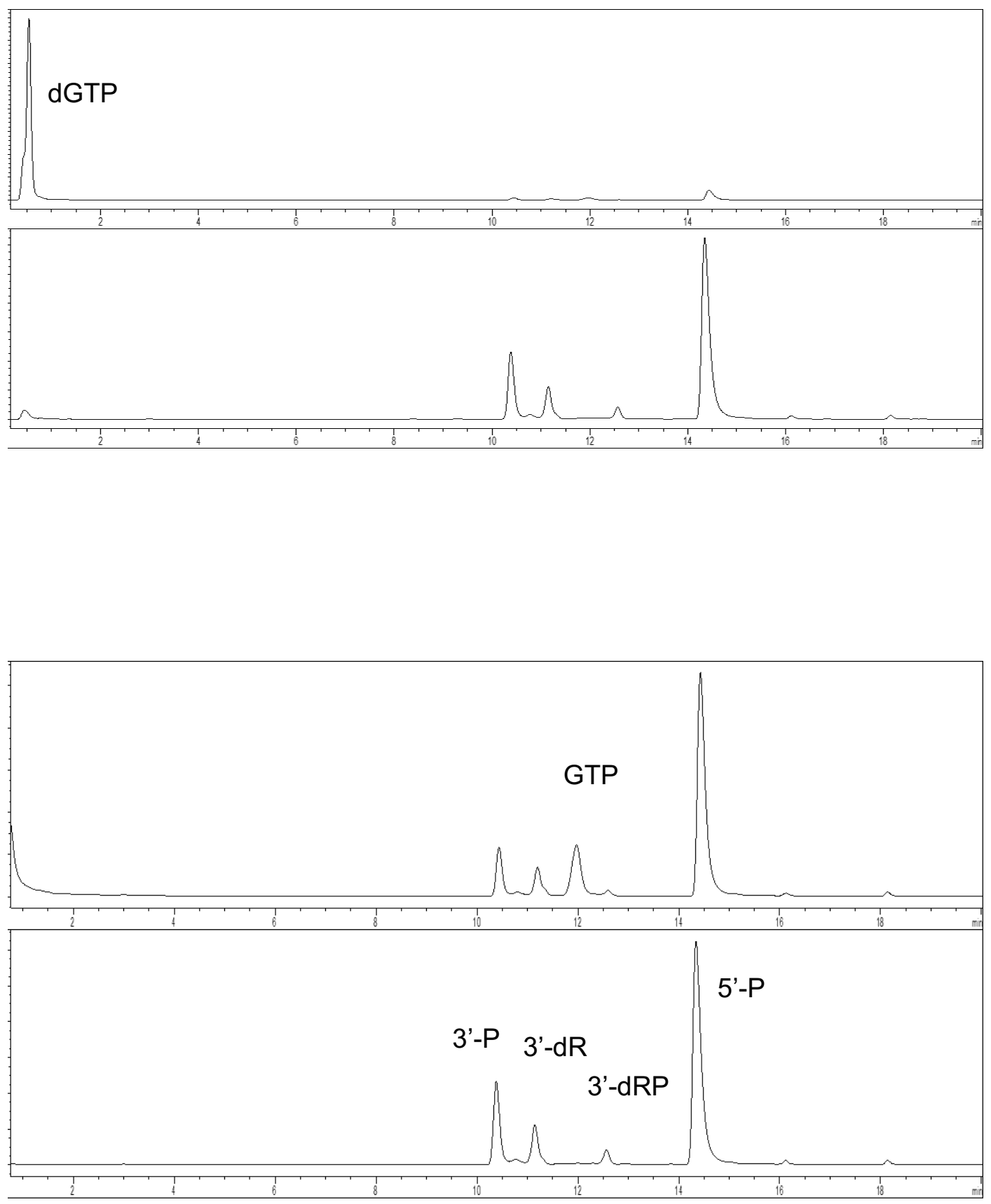
Figure 2.5.1. HPLC analysis of the dGTP adduct with the 3'dRP end group. Panel A shows the reaction of dGTP $(1 \mathrm{mM})$ with the PolyT oligo Ap site in HEPES $(50 \mathrm{mM}$, pH 7.4), $\mathrm{NaCl}(100 \mathrm{mM})$, and spermine (1 mM) for $24 \mathrm{~h}$ at $37^{\circ} \mathrm{C}$ (top) and PolyT oligo Ap site in HEPES (50 mM, pH 7.4), $\mathrm{NaCl}(100 \mathrm{mM})$, and spermine $(1 \mathrm{mM})$ for $24 \mathrm{~h}$ at $37^{\circ} \mathrm{C}$. Panel B, shows a zoomed in copy of panel A to show the incubation of dGTP in the presence of spermine $(1 \mathrm{mM})$ for $24 \mathrm{~h}$ shows a peak (panel B top) at $11.6 \mathrm{~min}$ that is absent when dGTP is not present (panel B bottom).

A

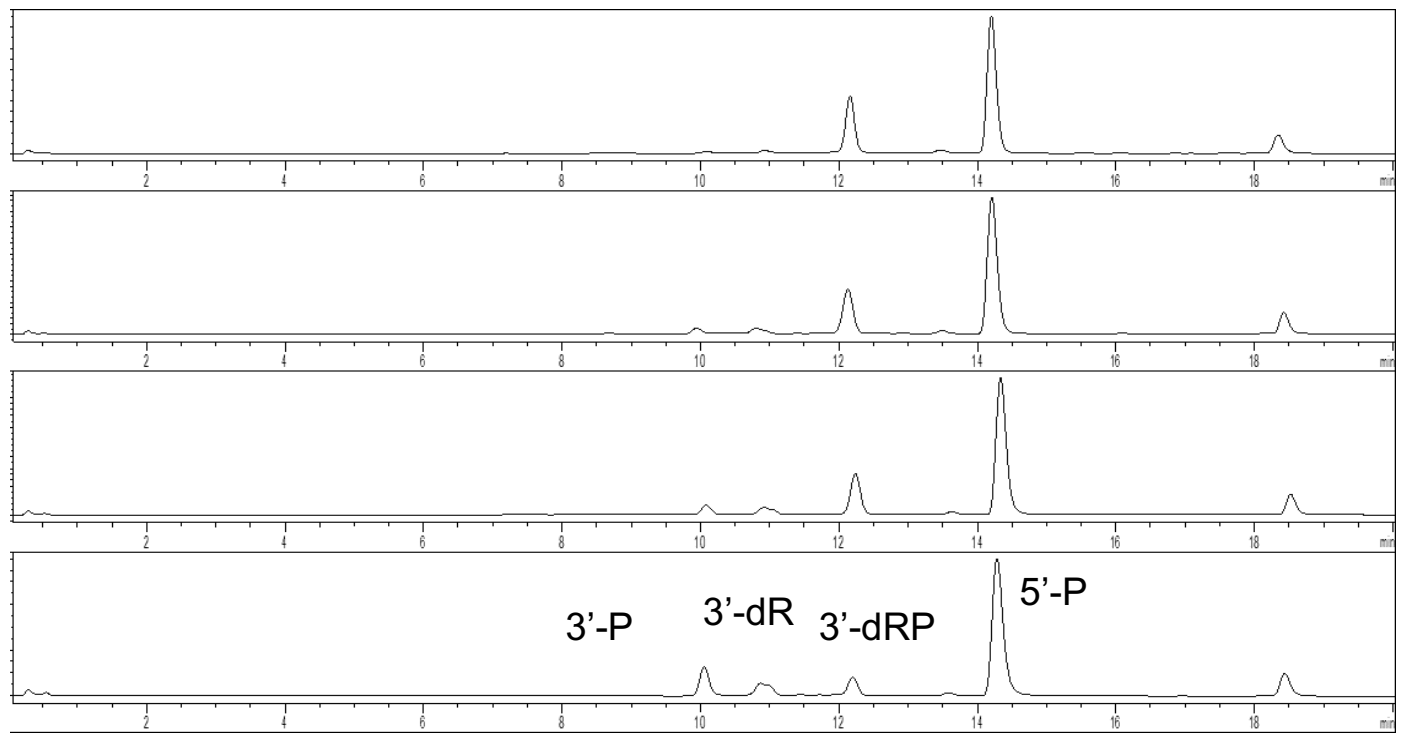


B
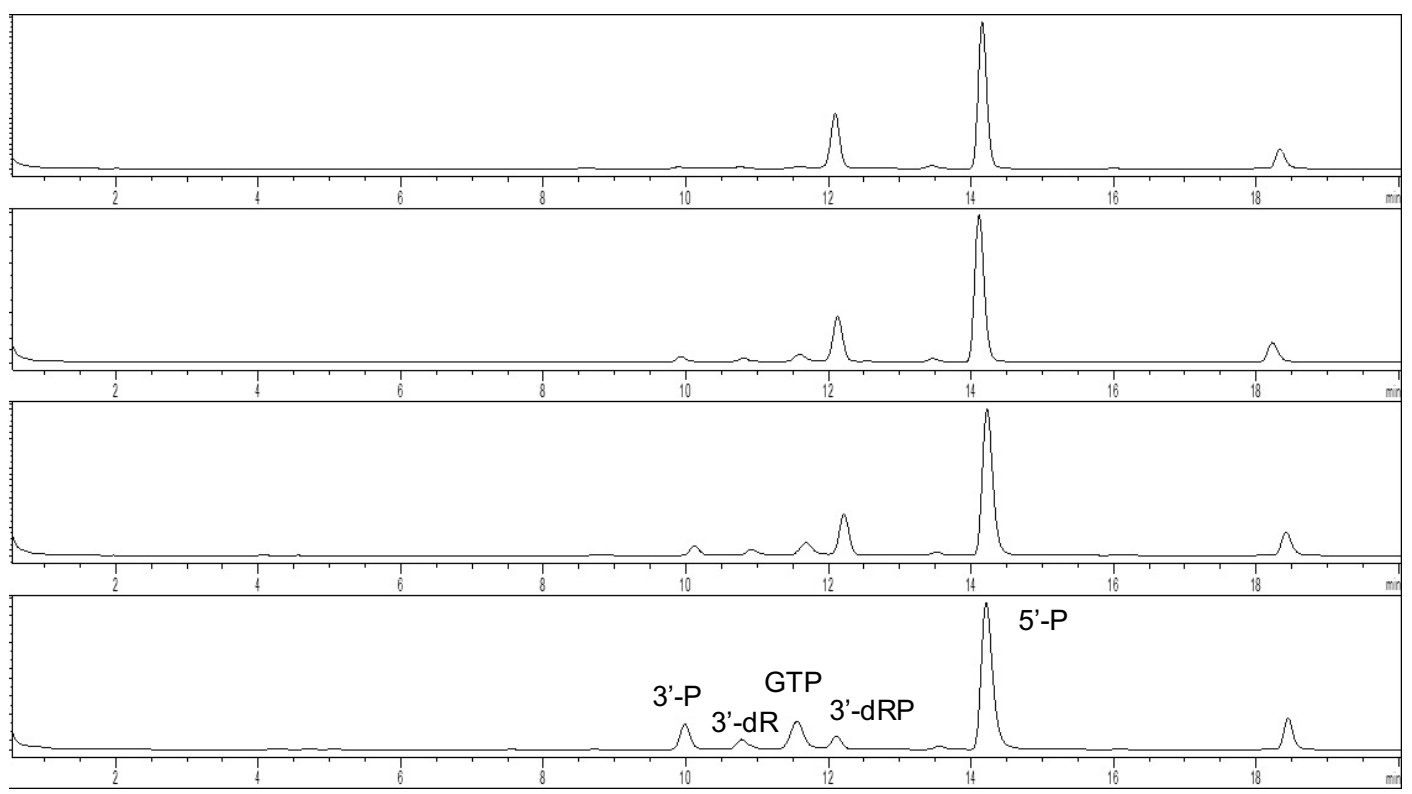

C
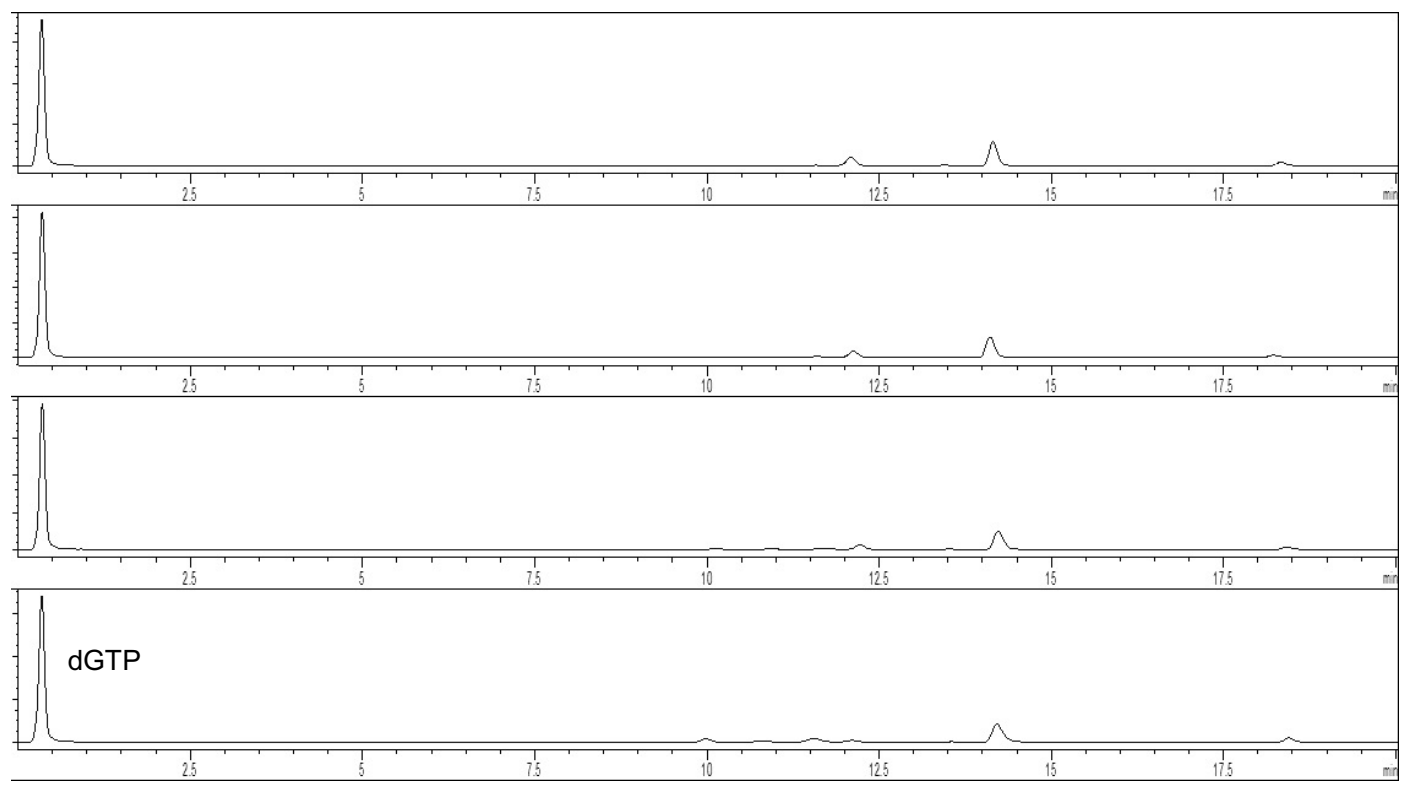
Figure 2.5.2 Time course for the formation of the dGTP adduct with the 3'dRP end group.

Panel A shows the reaction of the PolyT oligo Ap site with spermine $(1 \mathrm{mM})$ in HEPES (50 mM, pH 7.4) and $\mathrm{NaCl}(100 \mathrm{mM})$ at $37^{\circ} \mathrm{C}$ for $1,4,10,24 \mathrm{~h}$. Panel B shows the reaction of the PolyT oligo Ap site with spermine $(1 \mathrm{mM})$ and dGTP $(1 \mathrm{mM})$ in HEPES (50 mM, pH 7.4) and $\mathrm{NaCl}(100 \mathrm{mM})$ at $37^{\circ} \mathrm{C}$ for $1,4,10,24 \mathrm{~h}$. Panel $\mathrm{C}$ shows the zoomed out version of panel B of the reaction of the PolyT oligo Ap site with spermine $(1 \mathrm{mM})$ and dGTP $(1 \mathrm{mM})$ in HEPES $(50 \mathrm{mM}, \mathrm{pH} 7.4)$ and $\mathrm{NaCl}(100 \mathrm{mM})$ at $37^{\circ} \mathrm{C}$ for $1,4,10,24 \mathrm{~h}$.

Analysis of the dGTP-3'dRP adduct in the polyT sequence by Nanospray ESI(-)MS revealed a major signal at 2143.26 amu (Figure 2.5.2). This result combined with the HPLC data described above allowed us to suggest a reasonable mechanism for adduct formation (Scheme 2.5.1) involving 1,4-conjugate addition of the dGTP to the 3 '-dRP end group. 

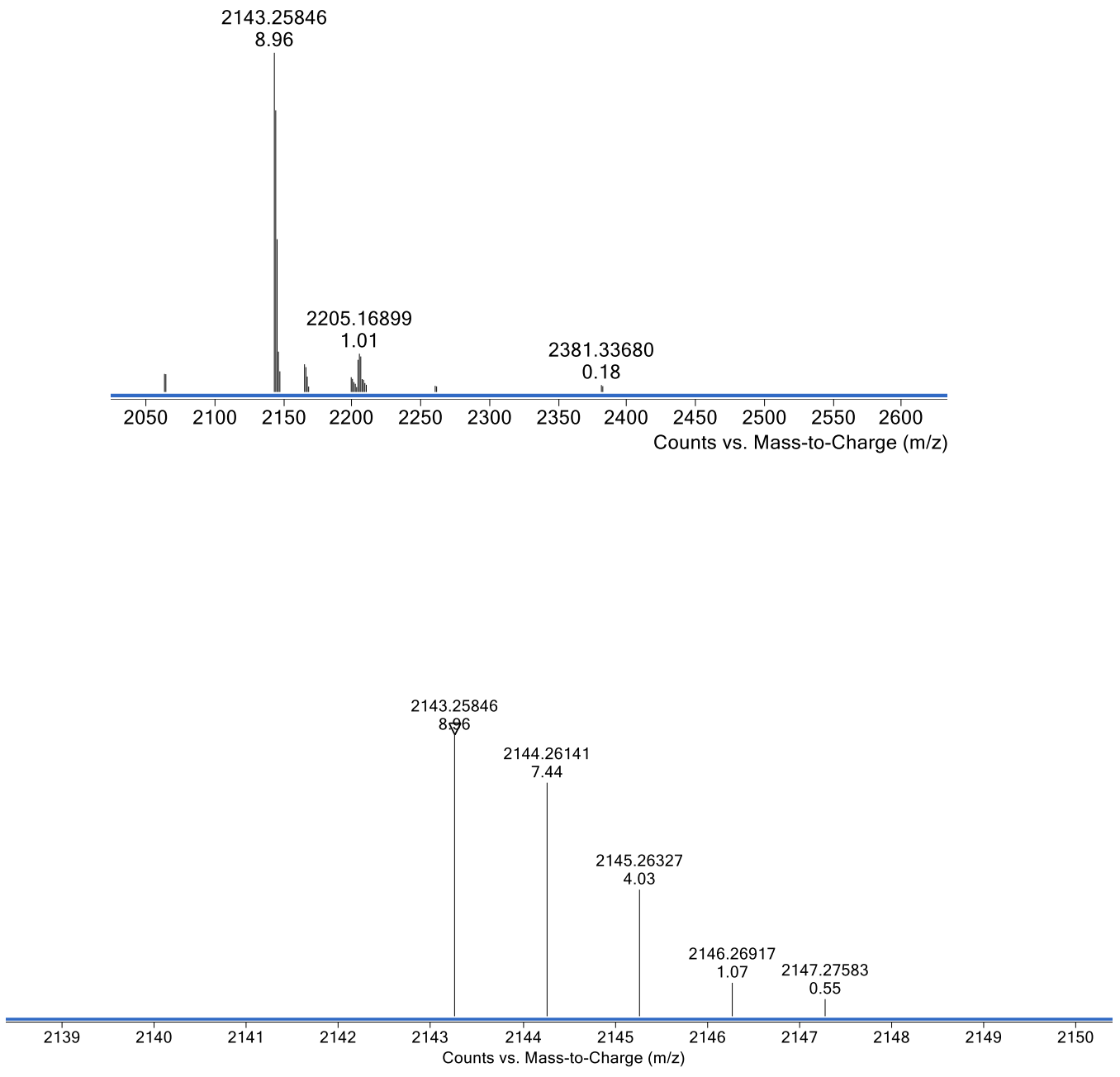

Figure 2.5.3. ESI(-)-TOF-MS analysis of the dGTP adduct. Masses shown correspond to the most prominent peak in the isotope envelope for each species. Calculated molecular mass for the dGTP adduct is $2144.27 \mathrm{amu}$. 


\subsection{Formation of the 3'dRP adduct with dGMP}

As a result of the addition of dGTP to the 3 'dRP end group, we were curious to see what other nucleophiles could form adducts with the reactive lesion. Another nucleophilic molecule found in the nucleus of the cell is deoxyguanosine-5'-

monophosphate (dGMP) ${ }^{31}$. dGMP, like dGTP, has nucleophilic amine groups present that are capable of undergoing a 1,4-conjugate addition with the 3 'dRP end group in DNA (Scheme 2.6.1).

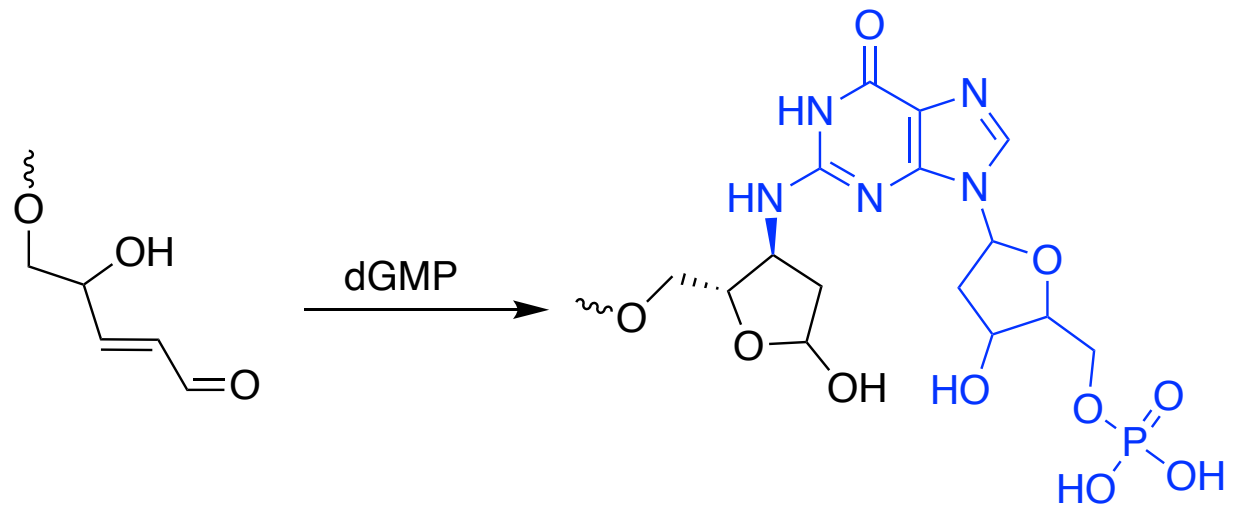

Scheme 2.6.1 Formation of dGMP adduct with the 3'dRP site. 
The Ap site was generated by acidic cleavage of the adenine residue in the sequence 5'-TTTTTATTTTTTTTTT (polyT) to give an Ap site after the acidic cleavage. The 3'dRP group was then generated by treatment of the polyamine, spermine, to give rise to a series of end groups, previously characterized by our group; 3 'dRP being one of the major products. dGMP was co-incubated during this process and the reaction mixture was analyzed using HPLC analysis (Figure 2.6.1). The polyT sequence with the Ap site embedded in it was treated with $1 \mathrm{mM}$ spermine, 50 mM HEPES (pH 7.4), 100 $\mathrm{mM} \mathrm{NaCl}$, and $1 \mathrm{mM} \mathrm{dGMP}$ at $37 \mathrm{C}$ for $24 \mathrm{~h}$ showed the formation of a new peak at $\sim 12$ min (Figure 2.6.1 A) compared to the same polyT sequence with the Ap site treated in the same conditions minus the addition of dGTP (Figure 2.6.1 B).

A

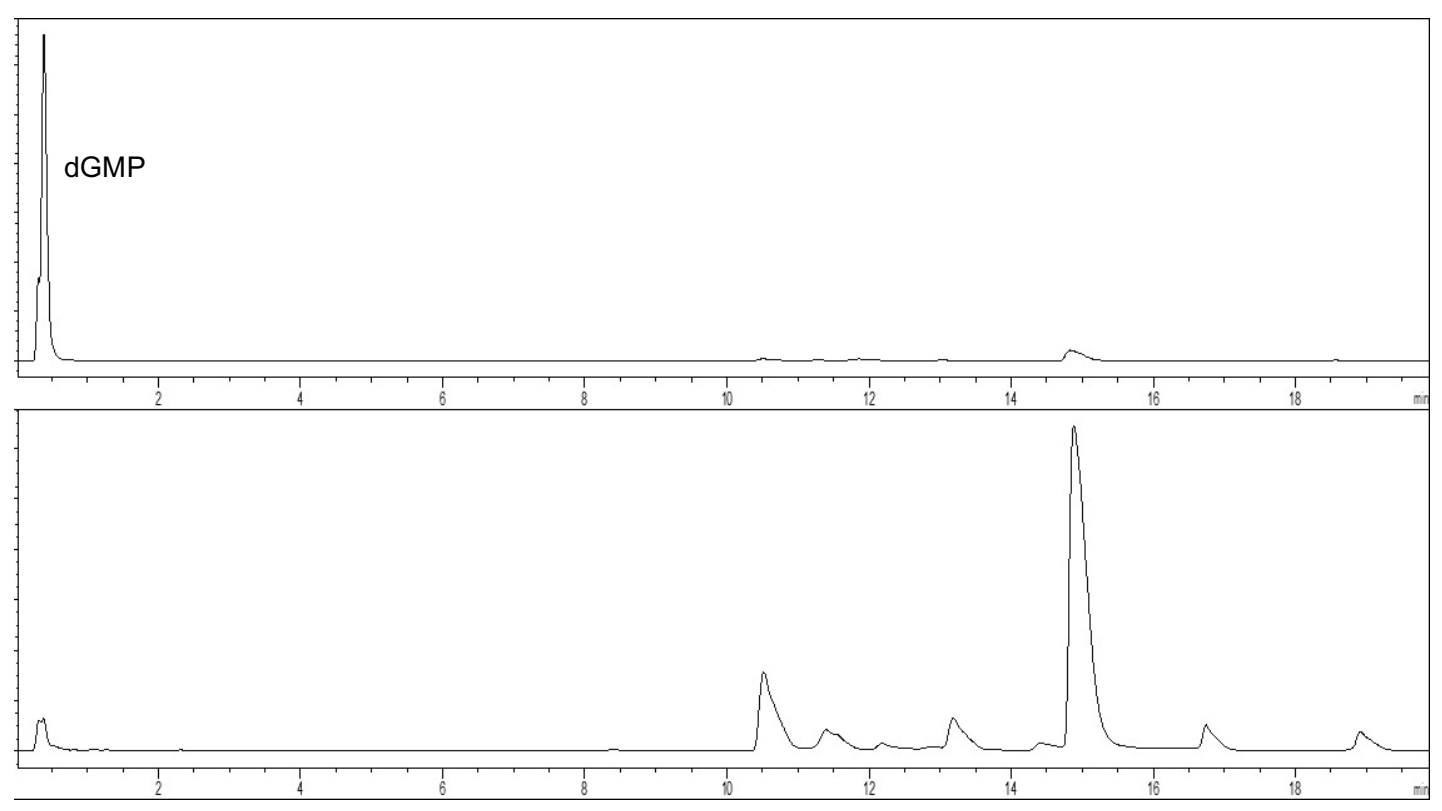


B

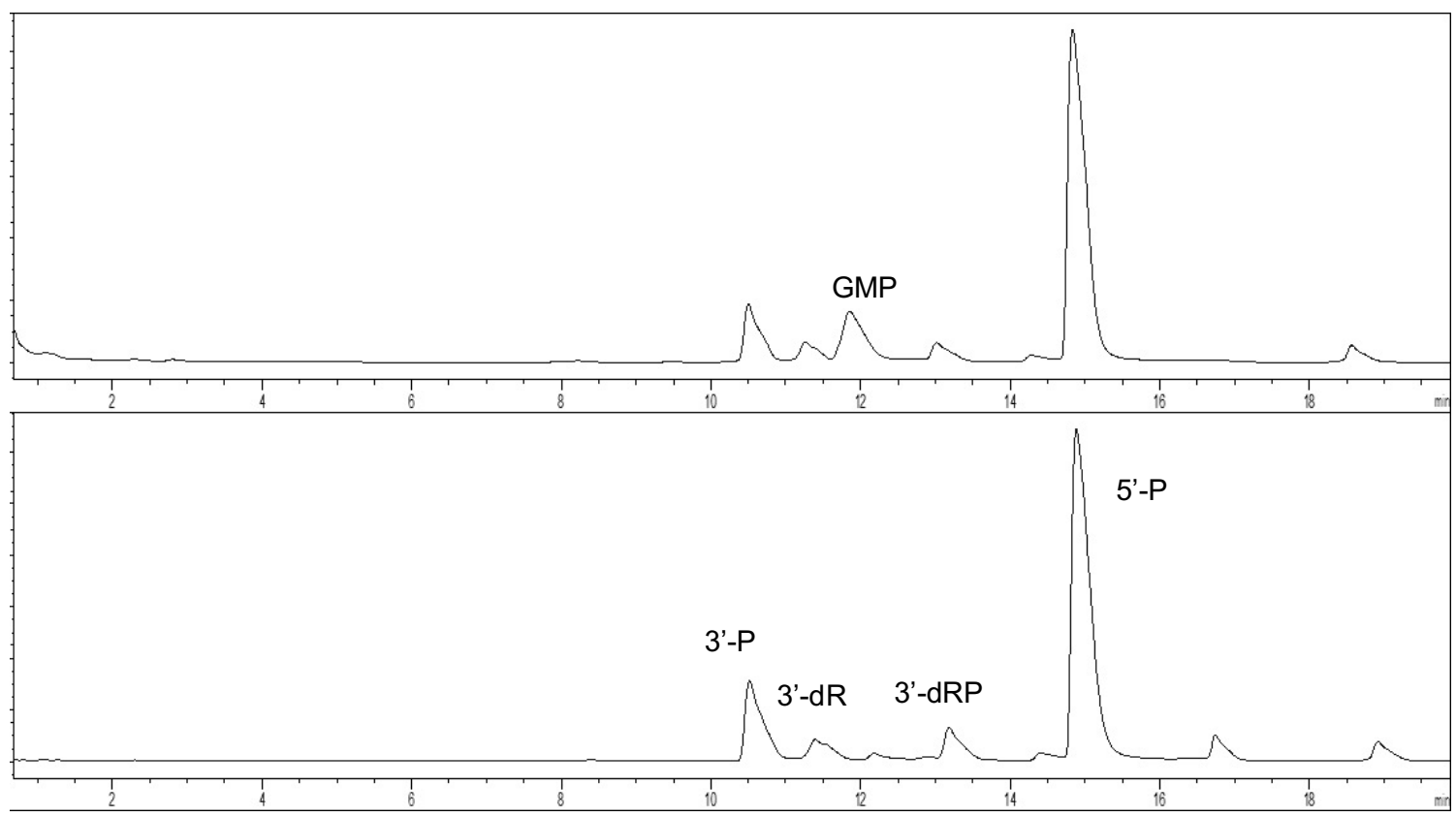

Figure 2.6.1. HPLC analysis of the dGMP adduct with the 3'dRP end group. Panel A shows the reaction of dGMP $(1 \mathrm{mM})$ with the PolyT oligo Ap site in HEPES (50 mM, $\mathrm{pH}$ 7.4), $\mathrm{NaCl}(100 \mathrm{mM})$, and spermine $(1 \mathrm{mM})$ for $24 \mathrm{~h}$ at $37^{\circ} \mathrm{C}$ (top) and PolyT oligo Ap site in HEPES (50 mM, pH 7.4), $\mathrm{NaCl}(100 \mathrm{mM})$, and spermine (1 mM) for $24 \mathrm{~h}$ at $37^{\circ} \mathrm{C}$. Panel B, shows a zoomed in copy of panel A to show the incubation of dGMP in the presence of spermine $(1 \mathrm{mM})$ for $24 \mathrm{~h}$ shows a peak (panel B top) at 11.9 min that is absent when dGMP is not present (panel B bottom). 
Analysis of the dGMP-3'dRP adduct in the polyT sequence by Nanospray ESI(-)MS revealed a major signal at 1983.24 amu (Figure 2.6.2). This result combined with the HPLC

data described above allowed us to suggest a reasonable mechanism for adduct formation (Scheme 2.6.1) involving 1,4-conjugate addition of the dGMP to the 3'-dRP end group.

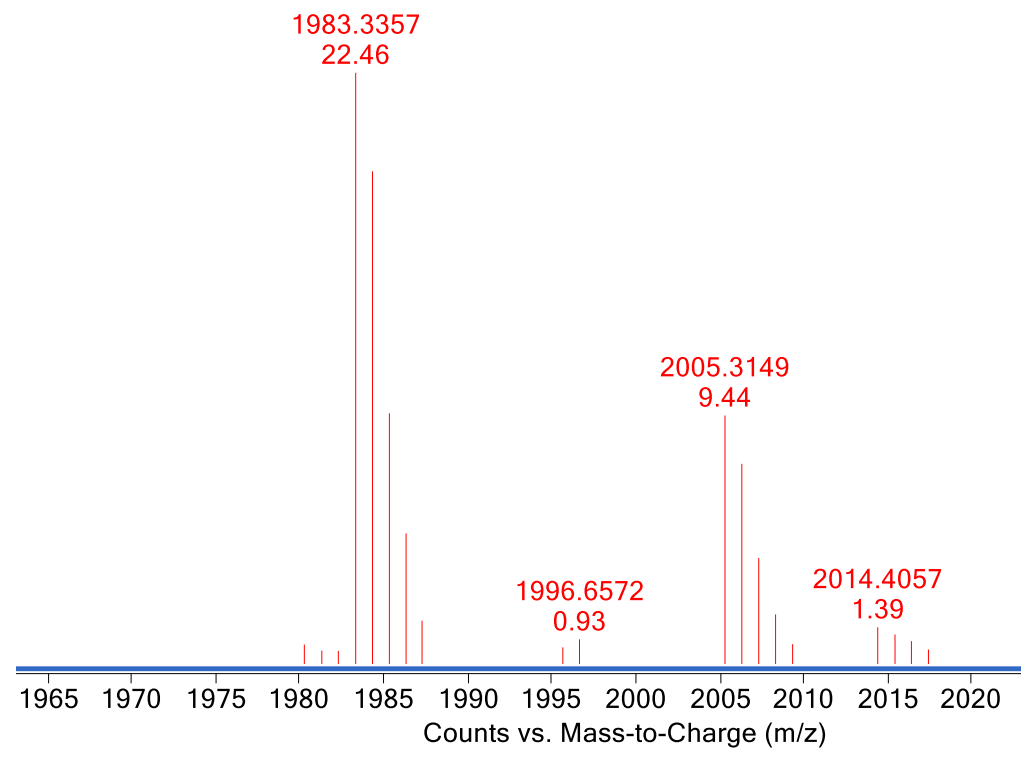

Figure 2.6.2. ESI(-)-TOF-MS analysis of the dGMP adduct. Masses shown

correspond to the most prominent peak in the isotope envelope for each species.

Calculated molecular mass for the dGMP adduct is $1984.31 \mathrm{amu}$. 


\subsection{Conclusion}

DNA is a highly complex and vital macromolecule. The Ap site is a ubiquitous and reactive lesion. The reactivity and repair of the Ap and 3'dRP sites are still not fully characterized.

Synthesizing the Ap site in oligonucleotides have allowed us to study the chemistry, reactivity, and repair of Ap and 3'dRP adducts. Glutathione, 1aminohydantoin, and carbidopa were all shown to form monoadducts with the Ap site and inhibit repair by the repair enzyme, APE1. dGTP and dGMP were both shown to form adducts with the 3 ' dRP group, a derivative of the Ap site.

The importance of studying and characterizing the lesions formed in DNA will help us better understand types of damage that can occur in cellular DNA and the role of repair enzymes against such lesions. 


\subsection{Experimental}

Oligonucleotides were purchased from Integrated DNA Technologies (Coralville, IA, USA $),\left[\gamma^{32} \mathrm{P}\right]-\mathrm{ATP}(6000 \mathrm{Ci} / \mathrm{mmol})$ was purchased from Perkin-Elmer, uracil DNA glycosylase (UDG) were from New England Biolabs (Ipswich, MA, USA), C-18 Sep-Pak cartridges were purchased from Waters (Milford, MA, USA), and BS Poly-prep columns were obtained from BioRad (Hercules, CA, USA), acrylamide/bis-acrlyamide 19:1 (40\% solution, electrophoresis grade) was purchased from Fisher Scientific (Waltham, MA, USA), all other chemical reagents were purchased from Sigma-Aldrich (St. Louis, MO, USA).

\section{Synthesis of Ap site by UDG}

In these experiments, 2'-deoxyuridine-containing oligonucleotides were used as precursors for the enzymatic generation of Ap-containing oligonucleotides. The singlestranded, uracil-containing 2'-deoxy-oligonucleotides were $\alpha-{ }^{32} \mathrm{P}$ 5'-end-labeled using standard procedures, and then annealed to the complimentary strand. The labeled duplex DNA was treated with the UDG (200 units/mL, final concentration) in Tris- $\mathrm{HCl}$ buffer (20 mM, pH 8) containing DTT (1 mM), EDTA (1 mM). After incubation at $37^{\circ} \mathrm{C}$ for 1 $\mathrm{hr}$, the UDG enzyme was removed by phenol-chloroform extraction and the DNA was ethanol precipitated to remove low molecular weight compounds. 


\section{Synthesis of Ap site by Acidic Cleavage}

In these experiments, the PolyT oligonucleotide (5'-TTTTTATTTTTTTTTT) was treated with $10 \mathrm{mM} \mathrm{HCl}$ at $65^{\circ} \mathrm{C}$ for $50 \mathrm{~min}$. The solution was then ran through a column containing G-25 sephadex to remove the $\mathrm{HCl}$.

\section{ESI-QTOF-LC-MS analysis of the Oligonucleotides.}

LC-MS data were acquired on an Agilent Technologies 6520A Accurate Mass

QTOF. Samples were analyzed according to the protocol of Studzinska and Buszewski, ${ }^{40}$ with slight modifications as outlined. The sample was injected onto a C8 trap column (Michrom Bioresources Captrap) at a flow rate of $5 \mu \mathrm{L} / \mathrm{min}$ of $10 \mathrm{mM}$ DMBAA, $\mathrm{pH} 7.1$ over $4 \mathrm{~min}$. and separated by isocratic elution (either $80 \%$ or $42.5 \%$ methanol, $15 \mathrm{mM}$ DMBAA, $\mathrm{pH} 7.1$ ) at a flow rate of $0.4 \mu \mathrm{L} / \mathrm{min}$ on a $10 \mathrm{~cm} \times 75 \mu \mathrm{m} \mathrm{C} 8$ analytical column (fused silica packed with Michrom Bioresources C8, $3.5 \mu \mathrm{m}$ particles). Following the 4 min trap load, separation on the trap/analytical columns continued for 16 min, under isocratic elution conditions. Total run time was $20 \mathrm{~min}$. Mass spectra were acquired using the following parameters: negative-ion mode; VCap $2500 \mathrm{~V}$; mass range 290-3200 $\mathrm{m} / \mathrm{z} ; 0.63$ spectra/second; fragmentor at $300 \mathrm{~V}$ (250 V for IDT oligo); internal MS recalibration was achieved using the K/Na adducted Hexakis 1221 Chip Cube High Mass Reference compound (m/z 1279.99). Samples were loaded in sequence as follows: blank (10 mM DMBAA), sample, and blank. Multiply-charged DNA peaks were deconvoluted using the maximum entropy algorithm in Qualitative Analysis software (version B.07.00 Agilent Technologies) with the following parameters: adduct $=$ proton-loss; $\mathrm{m} / \mathrm{z}$ range $=$ 
$600-1500 \mathrm{~m} / \mathrm{z}$; mass range $=$ expected mass $\pm 2 \mathrm{kDa}$; peak height to calculate mass $=$ $25 \%$. The $\mathrm{m} / \mathrm{z}$ values reported are neutral deconvoluted masses. The cross-linking reaction was carried out as described above. After a $72 \mathrm{~h}$ incubation 20 volumes of ammonium acetate $(2.5 \mathrm{M})$ was added and after $30 \mathrm{~min}$ at room temperature the mixture was and desalted using a C18 Sep-Pak column eluted with HPLC grade methanol and ultrapure, deionized water.

\section{HPLC Analysis of the Products Arising from Cleavage of the AP-Containing Oligonucleotide.}

HPLC analyses were conducted using a reverse phase column at $24{ }^{\circ} \mathrm{C}$ (Agilent AdvanceBio, C18, 4.6 x $50 \mathrm{~mm}, 2.7 \mu \mathrm{m}$ ) eluted with a linear gradient of $6-14 \%$ acetonitrile in aqueous $0.1 \mathrm{M}$ triethylammonium acetate $\mathrm{pH} 7.0$ over $20 \mathrm{~min}$ at a flow rate of $0.6 \mathrm{~mL} / \mathrm{min}$. The products were monitored by their absorbance at $260 \mathrm{~nm}$. 


\section{References}

(1) McKinnon, P. J. DNA Repair Deficiency and Neurological Disease. Nat. Rev. Neurosci. 2009, 10 (2), 100-112. https://doi.org/10.1038/nrn2559.

(2) Madabhushi, R.; Pan, L.; Tsai, L.-H. DNA Damage and Its Links to Neurodegeneration. Neuron 2014, 83 (2), 266-282. https://doi.org/10.1016/j.neuron.2014.06.034.

(3) Borgesius, N. Z.; de Waard, M. C.; van der Pluijm, I.; Omrani, A.; Zondag, G. C. M.; van der Horst, G. T. J.; Melton, D. W.; Hoeijmakers, J. H. J.; Jaarsma, D.; Elgersma, Y. Accelerated Age-Related Cognitive Decline and Neurodegeneration, Caused by Deficient DNA Repair. J. Neurosci. Off. J. Soc. Neurosci. 2011, 31 (35), 12543-12553. https://doi.org/10.1523/JNEUROSCI.1589-11.2011.

(4) Schumacher, B.; Garinis, G. A.; Hoeijmakers, J. H. J. Age to Survive: DNA Damage and Aging. Trends Genet. TIG 2008, 24 (2), 77-85. https://doi.org/10.1016/j.tig.2007.11.004.

(5) Menck, C. F.; Munford, V. DNA Repair Diseases: What Do They Tell Us about Cancer and Aging? Genet. Mol. Biol. 2014, 37 (1 Suppl), 220-233.

(6) Hoeijmakers, J. H. J. DNA Damage, Aging, and Cancer. N. Engl. J. Med. 2009, 361 (15), 1475-1485. https://doi.org/10.1056/NEJMra0804615.

(7) Lindahl, T.; Nyberg, B. Rate of Depurination of Native Deoxyribonucleic Acid. Biochemistry 1972, 11 (19), 3610-3618. https://doi.org/10.1021/bi00769a018.

(8) Zhou, B.-B. S.; Elledge, S. J. The DNA Damage Response: Putting Checkpoints in Perspective. Nature 2000, 408 (6811), 433-439. https://doi.org/10.1038/35044005. 
(9) Norbury, C. J.; Hickson, I. D. Cellular Responses to DNA Damage. Annu. Rev.

Pharmacol. Toxicol. 2001, 41, 367-401.

https://doi.org/10.1146/annurev.pharmtox.41.1.367.

(10) Fritz, K. S.; Petersen, D. R. An Overview of the Chemistry and Biology of Reactive Aldehydes. Free Radic. Biol. Med. 2013, 59, 85-91.

https://doi.org/10.1016/j.freeradbiomed.2012.06.025.

(11) O’Brien, P. J.; Siraki, A. G.; Shangari, N. Aldehyde Sources, Metabolism, Molecular Toxicity Mechanisms, and Possible Effects on Human Health. Crit. Rev. Toxicol. 2005, 35 (7), 609-662. https://doi.org/10.1080/10408440591002183.

(12) LoPachin, R. M.; Gavin, T. Molecular Mechanisms of Aldehyde Toxicity: A Chemical Perspective. Chem. Res. Toxicol. 2014, 27 (7), 1081-1091. https://doi.org/10.1021/tx5001046.

(13) Yang, Z.; Price, N. E.; Johnson, K. M.; Wang, Y.; Gates, K. S. Interstrand CrossLinks Arising from Strand Breaks at True Abasic Sites in Duplex DNA. Nucleic Acids Res. 2017, 45 (11), 6275-6283. https://doi.org/10.1093/nar/gkx394.

(14) Bailly, V.; Verly, W. G. Possible Roles of Beta-Elimination and Delta-Elimination Reactions in the Repair of DNA Containing AP (Apurinic/Apyrimidinic) Sites in Mammalian Cells. Biochem. J. 1988, 253 (2), 553-559.

(15) Tubbs, A.; Nussenzweig, A. Endogenous DNA Damage as a Source of Genomic Instability in Cancer. Cell 2017, 168 (4), 644-656. https://doi.org/10.1016/j.cell.2017.01.002.

(16) Lindahl, T.; Barnes, D. E. Repair of Endogenous DNA Damage. Cold Spring Harb. Symp. Quant. Biol. 2000, 65, 127-133. https://doi.org/10.1101/sqb.2000.65.127. 
(17) Lindahl, T. The Croonian Lecture, 1996: Endogenous Damage to DNA. Philos. Trans. R. Soc. Lond. B. Biol. Sci. 1996, 351 (1347), 1529-1538. https://doi.org/10.1098/rstb.1996.0139.

(18) Barnes, D. E.; Lindahl, T. Repair and Genetic Consequences of Endogenous DNA Base Damage in Mammalian Cells. Annu. Rev. Genet. 2004, 38, 445-476. https://doi.org/10.1146/annurev.genet.38.072902.092448.

(19) Lindahl, T. The Intrinsic Fragility of DNA (Nobel Lecture). Angew. Chem. Int. Ed Engl. 2016, 55 (30), 8528-8534. https://doi.org/10.1002/anie.201602159.

(20) Wilson, D. M.; Takeshita, M.; Grollman, A. P.; Demple, B. Incision Activity of Human Apurinic Endonuclease (Ape) at Abasic Site Analogs in DNA. J. Biol. Chem. 1995, 270 (27), 16002-16007. https://doi.org/10.1074/jbc.270.27.16002.

(21) Lindahl, T. Suppression of Spontaneous Mutagenesis in Human Cells by DNA Base Excision-Repair. Mutat. Res. 2000, 462 (2-3), 129-135. https://doi.org/10.1016/s1383-5742(00)00024-7.

(22) Loeb, L. A.; Preston, B. D. Mutagenesis by Apurinic/Apyrimidinic Sites. Annu. Rev. Genet. 1986, 20, 201-230. https://doi.org/10.1146/annurev.ge.20.120186.001221.

(23) Melton, D.; Lewis, C. D.; Price, N. E.; Gates, K. S. Covalent Adduct Formation between the Antihypertensive Drug Hydralazine and Abasic Sites in Double- and Single-Stranded DNA. Chem. Res. Toxicol. 2014, 27 (12), 2113-2118. https://doi.org/10.1021/tx5003657.

(24) Price, N. E.; Johnson, K. M.; Wang, J.; Fekry, M. I.; Wang, Y.; Gates, K. S. Interstrand DNA-DNA Cross-Link Formation Between Adenine Residues and 
Abasic Sites in Duplex DNA. J. Am. Chem. Soc. 2014, 136 (9), 3483-3490. https://doi.org/10.1021/ja410969x.

(25) Dutta, S.; Chowdhury, G.; Gates, K. S. Interstrand Cross-Links Generated by Abasic Sites in Duplex DNA. J. Am. Chem. Soc. 2007, 129 (7), 1852-1853. https://doi.org/10.1021/ja067294u.

(26) Mohni, K. N.; Wessel, S. R.; Zhao, R.; Wojciechowski, A. C.; Luzwick, J. W.; Layden, H.; Eichman, B. F.; Thompson, P. S.; Mehta, K. P. M.; Cortez, D. HMCES Maintains Genome Integrity by Shielding Abasic Sites in Single-Strand DNA. Cell 2019, 176 (1-2), 144-153.e13. https://doi.org/10.1016/j.cell.2018.10.055.

(27) Shukla, V.; Halabelian, L.; Balagere, S.; Samaniego-Castruita, D.; Feldman, D. E.; Arrowsmith, C. H.; Rao, A.; Aravind, L. HMCES Functions in the Alternative EndJoining Pathway of the DNA DSB Repair during Class Switch Recombination in B Cells. Mol. Cell 2020, 77 (2), 384-394.e4. https://doi.org/10.1016/j.molcel.2019.10.031.

(28) Halabelian, L.; Ravichandran, M.; Li, Y.; Zeng, H.; Rao, A.; Aravind, L.; Arrowsmith, C. H. Structural Basis of HMCES Interactions with Abasic DNA and Multivalent Substrate Recognition. Nat. Struct. Mol. Biol. 2019, 26 (7), 607-612. https://doi.org/10.1038/s41594-019-0246-6.

(29) Meister, A. Selective Modification of Glutathione Metabolism. Science 1983, 220 (4596), 472-477. https://doi.org/10.1126/science.6836290.

(30) Wei Liu; Chengbiao Zhao; Yulan Zhang; Shengxin Lu; Jinting Liu, and; Xi*, R. Preparation of Polyclonal Antibodies to a Derivative of 1-Aminohydantoin (AHD) and Development of an Indirect Competitive ELISA for the Detection of 
Nitrofurantoin Residue in Water https://pubs.acs.org/doi/pdf/10.1021/jf070620k (accessed Mar 4, 2021). https://doi.org/10.1021/jf070620k.

(31) Traut, T. W. Physiological Concentrations of Purines and Pyrimidines. Mol. Cell. Biochem. 1994, 140 (1), 1-22. https://doi.org/10.1007/BF00928361. 


\section{Chapter 3}

\section{A complex interstrand DNA cross-link arising from a common endogenous lesion}

\subsection{Introduction}

DNA carries the genetic code that is critical for all living organisms. ${ }^{1}$ Under biological conditions, DNA displays impressive chemical stability. Nonetheless, in the context of a human genome containing 12.6 billion nucleotides in a diploid cell, even inefficient reactions can produce a significant number of DNA lesions. ${ }^{2,3,4}$ For example, the spontaneous loss of purine residues generates 10,000 abasic (AP) sites per cell each day. ${ }^{5}$ Enzymatic reactions further increase the load of AP sites and other DNA lesions. ${ }^{6}$

Unavoidable DNA damage has important biological consequences. ${ }^{7,8,9}$ Replication of a damaged DNA template can lead to mutations and other types of genetic instability. Such genetic changes drive the evolution of species but, in the context of individual organisms, are generally detrimental. DNA damage also has the potential to cause cell death or senescence. In humans, endogenous DNA damage may contribute to cancer, neurodegeneration, and aging. ${ }^{10,11,12,13,14,15,16}$

Deeper understanding of the formation, biological consequences, and repair of endogenous DNA damage may provide insights regarding the processes that drive disease and determine health span in humans. Along these lines, a wide variety of unavoidable, endogenous DNA lesions have been identified. Most of the abundant endogenous lesions arise from "single-hits" on the DNA structure. These include AP sites, oxidized nucleobases (e.g. 8-oxoguanine), strand breaks, and base modifications by lipid peroxidation products. . $^{3,2,17,4,18,19,20}$ These lesions can be repaired via pathways in which 
the sequence of undamaged nucleobases on the opposing strand provides an information failsafe to guide reconstitution of the genetic code..$^{21,22,23,24}$

There is a distinct category of DNA damage known as clustered or complex lesions, defined by two (or more) modifications located within a 20 base pair (bp) stretch of duplex DNA. ${ }^{25,26}$ Relatively little is known about the endogenous generation of complex lesions in cellular DNA. Double strand breaks and interstrand cross-links (ICLs) are two wellknown examples of clustered lesions that are highly cytotoxic. ${ }^{27}$ Complex lesions are generated in small amounts, but can have profound biological consequences because they block critical DNA transactions and are difficult to repair. ${ }^{25,26}$

Here we describe a structurally novel complex/clustered lesion arising from a common type of endogenous DNA damage (Scheme 3.1.2). The lesion consists of an interstrand cross-link adjacent to a DNA strand break and is produced from decomposition of a single AP site in duplex DNA (Scheme 3.1.1). As noted above, AP sites are among the most abundant endogenous lesions in cellular DNA. ${ }^{28}$ Our results define a crosslinking mechanism involving conjugate addition of the $N^{2}$-amino group of a guanine residue to the $\alpha, \beta$-unsaturated iminium ion intermediate generated during amine-catalyzed strand cleavage at an AP site in duplex DNA. LC-MS experiments were employed to elucidate the chemical structure of the ICL and provide a method for detection of this novel clustered lesion in DNA. The cross-link is chemically stable. Finally, we provide biochemical evidence that human apurininc endonuclease (hAPE1) can unhook this ICL (Scheme 3.1.3), offering the possibility that this enzyme initiates repair through-via a variant of the canonical single-strand break repair (SSBR) pathway. 


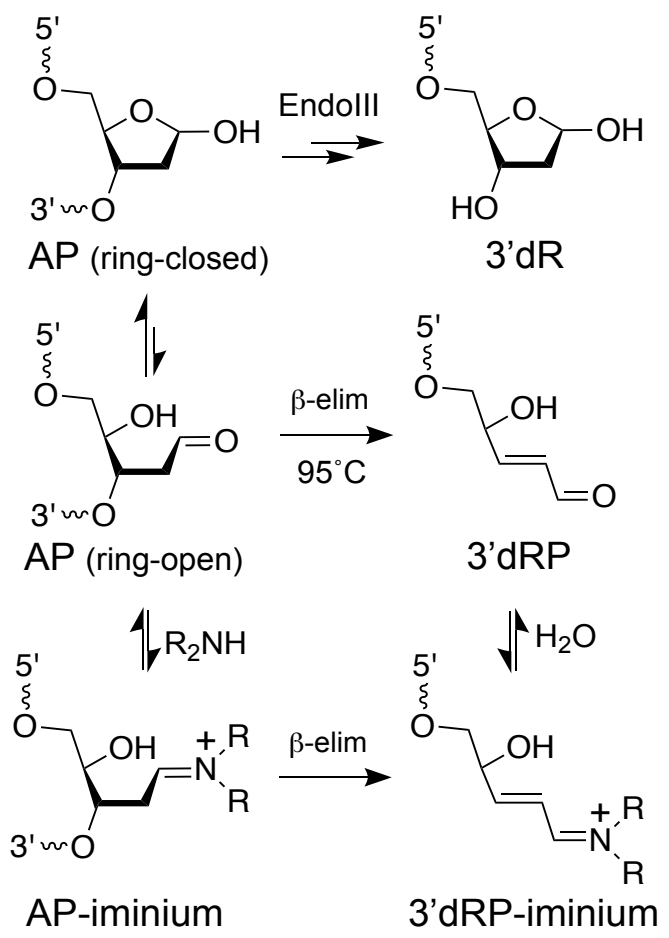

Scheme 3.1.1. $\beta$-Elimination at an AP site in DNA generates a strand break with electrophilic $\alpha, \beta$-unsaturated sugar remnants on the 3 '-terminus. The $\mathrm{R}$ groups on the amine catalyst represent either hydrogens or alkyl groups, depending on the identity of the amine. 

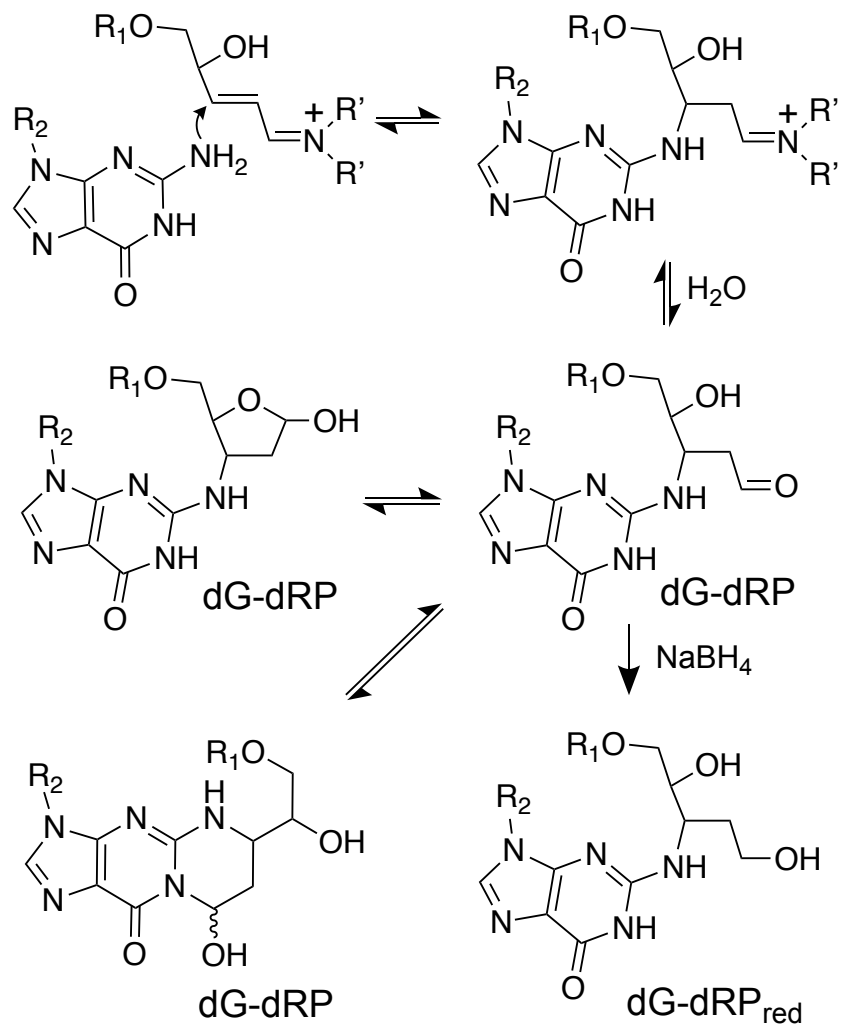

Scheme 3.1.2. Amine-catalyzed strand cleavage at an AP site in duplex DNA gives rise to a complex ICL via reaction of the $\alpha, \beta$-unsaturated iminium ion intermediate with a guanine residue on the opposing strand. $R^{\prime}$ represents spermine and $R_{1}$ and $R_{2}=$ DNA. 


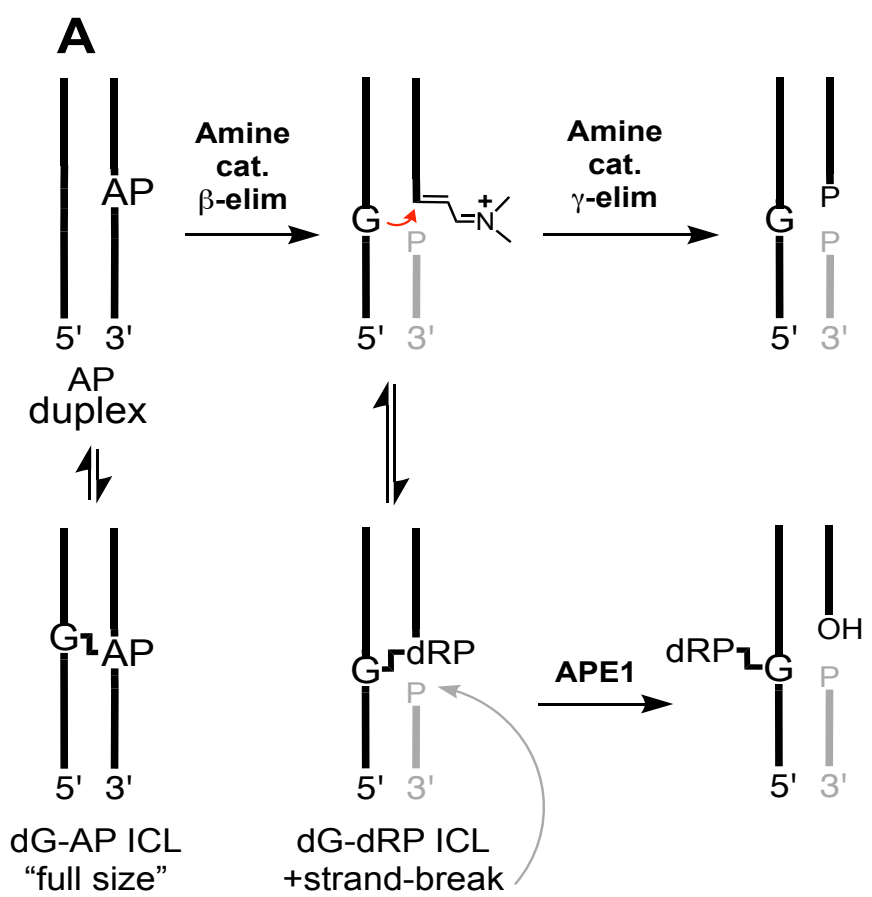

B

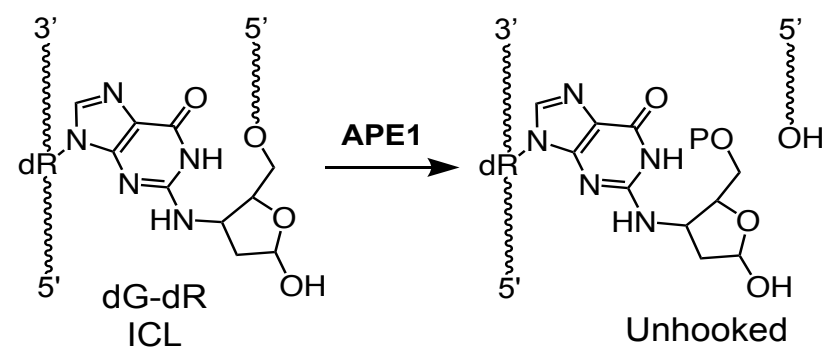

Scheme 3.1.3. Panel A: Architecture of nicked duplex and ICLs generated at an AP site in duplex DNA. The presence of a gray fragment indicates duplexes containing a strand break at the AP site. Panel B: Unhooking of the dG-dRP ICL by APE1 has the potential to initiate repair of this ICL by a variant of the single-strand break repair pathway. 


$$
X=A p
$$

A 5 '-ATACCACATAGATGAACXCAGATATATATAGAGAT

3' -TATGGTGTATCTACTTGGGTCTATATATATCTCTA

B 5'-ATACCACATAGATGAACXCAGATATATATAGAGAT

3' -TATGGTGTATCTACTTGGGTCTATATATATCTCTA

C 5'-ATACCACATAGATGAACZCAGATATATATAGAGAT

3'-TATGGTGTATCTACTTGGGTCTATATATATCTCTA

5' -ATACCACATAGATGAACXCAGACATATACACAGAT

D $3^{\prime}$-TATGGTGTATCTACTTGGGTCTGTATATGTGTCTA

E 5' -ATACCACATAGATGAACXCAGACATATACACAGAT

3' -TATGGTGTATCTACTTGGGTCTGTATATGTGTCTA

F 5'-ATACCACATAGATGAACYCAGACATATACACAGAT

3' -TATGGTGTATCTACTTGGETCTGTATATGTGTCTA

G 5'-ATACATCGTATTATATTGGATCXCAGATAT

3 '-TACGTAGCATAATATAACCTAGGGTCTATA

H 5'-ATACATCGTATTATATTGGATCXCAGATAT

H 3'-TACGTAGCATAATATAACCTAGGGTCTATA

I 5'-ATACATCGTATTATATTGGATCYCAGATAT

3' -TACGTAGCATAATATAACCTAGGGTCTATA

J 5' -ATACATCGTATTATATTGGATCXCAGACAC

J 3 '-TACGTAGCATAATATAACCTAGGGTCTGTG

K 5'-ATACATCGTATTATATTGGATCXCAGACAC

3' -TACGTAGCATAATATAACCTAGGGTCTGTG

5' -ATACATCGTATTATATTGGATCYCAGACAC

L 3 '-TACGTAGCATAATATAACCTAGGGTCTGTG

M 5'-ATATGACCACATAGAACXCGAAAGATATAGATATAGTGAATATTA

3' -TATACTGGTGTATCTTGGGCTTTCTATATCTATATCACTTATAAT

N 5'-ATATGACCACATAGAACXCGAAAGATATAGATATAGTGAATATTA

N 3'-TATACTGGTGTATCTTGGGCTTTCTATATCTATATCACTTATAAT

- 5'-ATATGACCACATAGAACłCGAAAGATATAGATATAGTGAATATTA

3' -TATACTGGTGTATCTTGGGCTTTCTATATCTATATCACTTATAAT

P 5'-ATATGACCACATAGAACXCGAAAGATATACATATACTCAATATTA

3' -TATACTGGTGTATCTTGGGCTTTCTATATGTATATGAGTTATAAT

Q 5'-ATATGACCACATAGAACXCGAAAGATATACATATACTCAATATTA 3' -TATACTGGTGTATCTTGGGCTTTCTATATGTATATGAGTTATAAT

R 5'-ATATGACCACATAGAACҰCGAAAGATATACATATACTCAATATTA 3' -TATACTGGTGTATCTTGGECTTTCTATATGTATATGAGTTATAAT<smiles>OCC1OC(O)CC1O[Hg]</smiles>

$\mathrm{X}=\mathrm{AP}$<smiles>[X]CCC(O)C(CCNc1nc2c(ncn2[Tl])c(=O)[nH]1)OC</smiles>

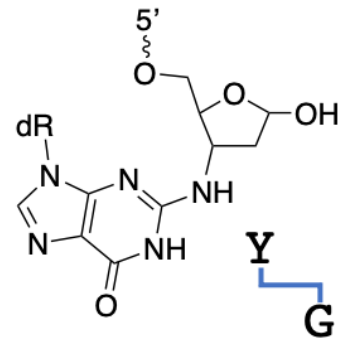


Figure 3.1.1 Sequences used in these studies. $Y$ denotes a strand break and the gray coloring indicates separate DNA fragments eliminated from the AP sites. The identity of $\mathrm{X}, \mathrm{G}-\mathrm{X}$, and G-Y are shown in the lower portion of the Figure.

\subsection{Evidence that amine-catalyzed strand cleavage gives rise to a complex ICL} in duplex DNA.

The labeled products generated from the AP-containing duplex $\mathbf{A}$ under various conditions were resolved by electrophoresis on a $20 \%$ denaturing polyacrylamide gel and the radioactivity in each band quantitatively measured by storage phosphor autoradiography. Treatment of the duplex with $\mathrm{NaOH}$ induced complete cleavage of the AP-containing strand, as indicated by its conversion to fast-migrating cleavage products in the gel (near the bottom of the gel image in Figure 3.2.1, lane 2). This result confirmed successful generation of the AP site in duplex $\mathbf{A}$.

In denaturing gel electrophoretic analyses, ICLs typically appear as slow-migrating bands, located above the uncross-linked DNA in the gel images shown here. Incubation of the AP-containing duplex $\mathbf{A}$ in $\mathrm{pH} 7.4$ buffer led to a low yield ( $<1 \%)$ of a slow-migrating product consistent with formation of the "full-size" dG-AP ICL described previously (Figure 3.2.1, lane 5 ). Incubation in sodium acetate buffer $(750 \mathrm{mM}, \mathrm{pH}$ 5) containing $\mathrm{NaBH}_{3} \mathrm{CN}(200 \mathrm{mM})$ produced larger yield of slow-migrating product $(7 \pm 1 \%$, Figure 3.2.1, lane 6) consistent with generation of the full-size dG-AP red ICL (duplex B). The 
full-sized cross-linked duplex $\mathbf{B}$ serves as a useful size-marker in the characterization of the novel ICL described here.

Incubation of duplex A with spermine (1 mM) in HEPES buffer $(50 \mathrm{mM}, \mathrm{pH} 7.4)$ containing $\mathrm{NaCl}(100 \mathrm{mM})$ for $72 \mathrm{~h}$ at $37^{\circ} \mathrm{C}$ led to complete disappearance of the labeled, AP-containing strand in duplex A. The expected fast-migrating cleavage fragments were observed (near the bottom of the gel, lane 7 of Figure 3.2.1). Importantly, treatment of duplex $\mathbf{A}$ with spermine also generated a $31 \pm 3 \%$ yield of a slow-migrating band on the gel (Figure 3.2.1, lane 7). The gel mobility of this product was between that of the uncrosslinked AP-containing duplex $\mathbf{A}$ and the "full-size" dG-APred ICL, duplex $\mathbf{B}$. The intermediate gel mobility of the slow-migrating product generated by treatment of duplex A with spermine was consistent with that expected for a "low molecular weight" ICL arising from a strand cleavage product that has eliminated the DNA fragment on the 3'side of the AP site (the general architecture of this type of ICL is illustrated as duplex $\mathbf{C}$ on the right side of Figure 3.2.1).

Importantly, no slow-migrating ICL band was observed when cleavage of the AP site in duplex A was induced by the enzyme Endo III. The failure of the 3'dR cleavage product generated by Endo III (Scheme 3.1.1) to generate ICL provided evidence that an $\alpha, \beta$-unsaturated elimination product (Scheme 3.1.1) was central to formation of the ICL induced by amine-catalyzed cleavage at an AP site in duplex DNA. 

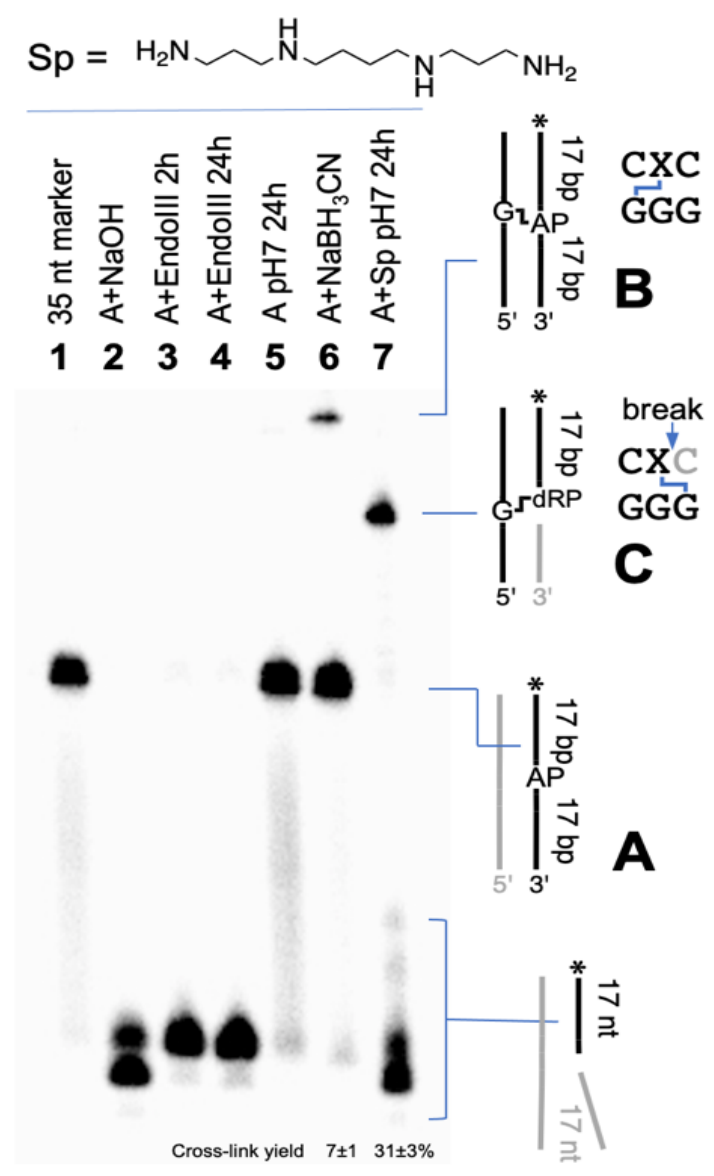

$5^{\prime}-{ }^{32} \mathrm{P}$-ATACCACATAGATGAaCXCAGATATATATAGAGAT 3'-TATGGTGTATCTACTTGGGTCTATATATATCTCTA Duplex A (X=AP) 


\section{Figure 3.2.1. Gel electrophoretic evidence for an interstrand cross-link generated}

by spermine-catalyzed strand cleavage at the AP site in duplex A. Lane 1: A singlestranded, $35 \mathrm{nt}$ size marker consisting of the ${ }^{32} \mathrm{P}$-labeled, AP-containing oligodeoxynucleotide (the top strand of duplex A). Lane 2: The AP-containing duplex A treated with $\mathrm{NaOH}\left(165 \mathrm{mM}, 37^{\circ} \mathrm{C}, 30 \mathrm{~min}\right)$ to induce strand cleavage at the AP site, generating 3'P and 3'dRP cleavage products. Lane 3: AP-containing duplex A treated with Endo III $\left(2 \mathrm{~h}, 10 \mathrm{U}, 37^{\circ} \mathrm{C}\right)$ to induce strand cleavage at the AP site, with generation of the 3 'dR product. Lane 4: Duplex A treated with Endo III (24 h, X U/ $\left.\mu \mathrm{L}, 37^{\circ} \mathrm{C}\right)$. Lane 5: Duplex A incubated in pH 5 sodium acetate buffer $(750 \mathrm{mM})$ for $24 \mathrm{~h}$ at $37{ }^{\circ} \mathrm{C}$. Lane 6: Duplex A incubated in sodium acetate buffer (pH 5, $750 \mathrm{mM})$ containing $\mathrm{NaBH}_{3} \mathrm{CN}(250 \mathrm{mM})$ at $37^{\circ} \mathrm{C}$ for $24 \mathrm{~h}$. Lane 7: Duplex $\mathrm{A}+$ spermine $(\mathrm{Sp}, 1 \mathrm{mM})$ in HEPES buffer $(50 \mathrm{mM}, \mathrm{pH} 7)$ containing $\mathrm{NaCl}(100 \mathrm{mM})$ at $37{ }^{\circ} \mathrm{C}$ for $24 \mathrm{~h}$. The ${ }^{32} \mathrm{P}$ labeled oligodeoxynucleotides in the reactions were resolved by electrophoresis on a 0.4 $\mathrm{mm}$ thick $20 \%$ denaturing polyacrylamide gel and the radioactivity in each band quantitatively measured by storage-phosphor autoradiography.

Formation of the cross-link generated by spermine-mediated strand cleavage of the AP site in duplex $\mathbf{A}$ in $\mathrm{pH} 7.4$ buffer at $37^{\circ} \mathrm{C}$ can be detected within minutes, reaches its half-maximal yield by about $8 \mathrm{~h}$, and begins to plateau after $20 \mathrm{~h}$ (Figure 3.2.2). At longer incubation times ( $70 \mathrm{~h}$ in the presence of spermine) there is some evidence for decomposition of the ICL, with a corresponding increase in the 3'-phosphate cleavage product. 


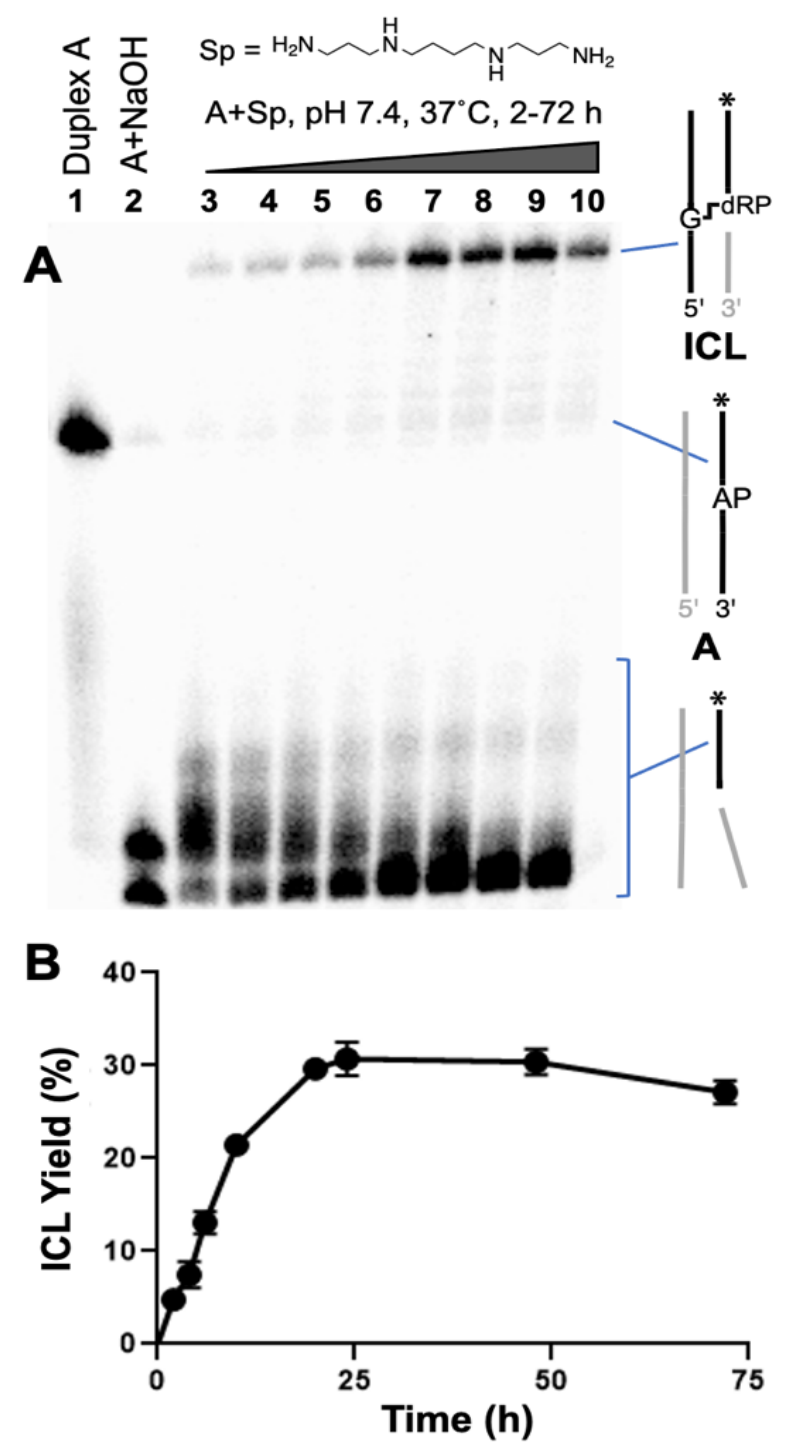


Figure 3.2.2. Time course for the formation of cross-linked DNA generated by amine-catalyzed cleavage of the AP site in duplex A. Panel A: Gel electrophoretic analysis of amine-catalyzed cross-link formation in duplex A. Lane 1: AP-containing duplex A. Lane 2: The AP-containing duplex A treated with $\mathrm{NaOH}\left(165 \mathrm{mM}, 37^{\circ} \mathrm{C}, 30\right.$ min) to induce strand cleavage at the AP site, with generation of 3'P and 3'dRP cleavage products. Lanes 3-12: AP-containing duplex A + spermine (1 mM) in HEPES buffer (50 $\mathrm{mM}, \mathrm{pH} 7)$ containing $\mathrm{NaCl}(100 \mathrm{mM})$ at $37^{\circ} \mathrm{C}$. At prescribed times aliquots were removed and frozen for subsequent gel electrophoretic analysis. The ${ }^{32} \mathrm{P}$-labeled oligodeoxynucleotides in the reactions were resolved by electrophoresis on a $0.4 \mathrm{~mm}$ thick $20 \%$ denaturing polyacrylamide gel and the radioactivity in each band quantitatively measured by storage-phosphor autoradiography. Panel B: A plot of ICL yield versus time. The error bars reflect the standard deviation from three separate measurements.

\section{Evidence that the 3'dRP-iminium ion is the key intermediate involved in ICL formation.}

Amines catalyze strand cleavage at AP sites via a covalent mechanism involving iminium ion intermediates (Scheme 3.1.1). The increased acidity of the $\alpha$-protons in the AP-iminium ion facilitates $\beta$-elimination of the 3'-phosphoryl group (Scheme 3.1.1). The $3^{\prime} \alpha, \beta$-unsaturated iminium ion is an intermediate in the amine-catalyzed strand cleavage at AP sites in DNA. Importantly, the electrophilicity of $\alpha, \beta$-unsaturated iminium ions is substantially greater than the parent $\alpha, \beta$-unsaturated aldehydes. 
With this in mind, we examined whether ICL formation induced by sperminecatalyzed cleavage of the AP site in duplex A was driven by the 3'dRP-iminium ion, the 3'dRP group, or both. To address this question, we first generated the authentic 3'dRP cleavage product by heat treatment of the AP-containing duplex A (Scheme 3.1.1). Heating duplex $\mathbf{A}$ at $95{ }^{\circ} \mathrm{C}$ for 30 min generated the desired 3'dRP cleavage product (21\%), alongside a mixture of the 3'-phosphate (24\%) cleavage product and the intact APcontaining DNA (45\%) (Figure 3.2.3, lane 3). Incubation of the 3'dRP cleavage product for $24 \mathrm{~h}$ in $\mathrm{pH} 7.4$ buffer produced a barely-detectable trace of the slow-migrating ICL band in the gel (Figure 3.2.3, lane 4). On the other hand, when cleavage of the AP site was induced by spermine $(1 \mathrm{mM})$, a significant yield of the slow-migrating ICL band was observed $(27 \% \pm 3 \%$, Figure 3.2 .2 , lane 6$)$. These results provided evidence that the 3 'dRP group is relatively ineffective as a cross-linking agent and thereby implicates the 3 'dRPiminium ion as the key intermediate involved in the spermine-catalyzed generation of an ICL from duplex $\mathbf{A}$. 


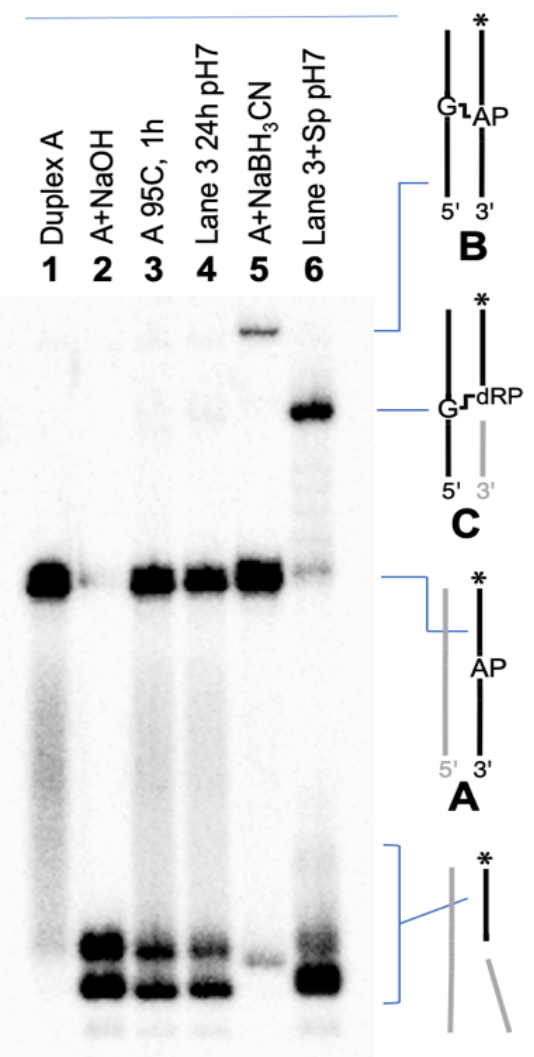

Figure 3.2.3. Evidence that the cross-link generated by spermine-catalyzed strand cleavage in duplex A arises from the 3'dRP iminium ion and not the 3'dRP cleavage product. For structures of the 3 'dRP iminium ion and 3 'dRP cleavage products, see Scheme 3.1.1. Lane 1: A single-stranded, $35 \mathrm{nt}$ size marker consisting of the ${ }^{32} \mathrm{P}-$-labeled, AP-containing oligodeoxynucleotide (the top strand of duplex A). Lane 2: The APcontaining duplex A treated with $\mathrm{NaOH}\left(165 \mathrm{mM}, 37^{\circ} \mathrm{C}, 30 \mathrm{~min}\right)$ to generate the $3^{\prime} \mathrm{P}$ and 3'dRP cleavage products. Lane 3: AP-containing duplex A heated at $95{ }^{\circ} \mathrm{C}$ for $30 \mathrm{~min}$ in HEPES buffer $(50 \mathrm{mM}, \mathrm{pH} 7.4)$ containing $\mathrm{NaCl}(100 \mathrm{mM})$ to generate a mixture of intact AP site (45\%) alongside the 3'dRP (21\%) and 3'phosphate (24\%) cleavage 
products and then incubated for $1 \mathrm{~h}$ at $37{ }^{\circ} \mathrm{C}$. Lane 4: Duplex A heated at $95{ }^{\circ} \mathrm{C}$ and then incubated at $37{ }^{\circ} \mathrm{C}$ for $24 \mathrm{~h}$. Lane 5: size marker showing the "full-size" dG-APred $\mathrm{ICL}$ generated by incubation of duplex A in $\mathrm{pH} 5$ sodium acetate buffer $(750 \mathrm{mM})$ containing $\mathrm{NaBH}_{3} \mathrm{CN}(250 \mathrm{mM})$ for $24 \mathrm{~h}$ at $37{ }^{\circ} \mathrm{C}$. Lane 6: Duplex A heated at $95{ }^{\circ} \mathrm{C}$ for $30 \mathrm{~min}$ and then incubated with spermine $(1 \mathrm{mM})$ in HEPES buffer $(50 \mathrm{mM}, \mathrm{pH} 7.4)$ containing $\mathrm{NaCl}(100 \mathrm{mM})$ at $37{ }^{\circ} \mathrm{C}$ for $24 \mathrm{~h}$. The ${ }^{32} \mathrm{P}$-labeled oligodeoxynucleotides in the reactions were resolved by electrophoresis on a $0.4 \mathrm{~mm}$ thick $20 \%$ denaturing polyacrylamide gel and the radioactivity in each band quantitatively measured by storage-phosphor autoradiography.

\section{Iron-EDTA- $\mathrm{H}_{2} \mathrm{O}_{2}$ footprinting pinpoints the location of ICL to opposing guanine residues.}

We employed iron-EDTA footprinting to pinpoint the site(s) of cross-link attachment in the slow-migrating band generated by spermine-mediated strand cleavage of the AP-containing duplex A. The cross-linked DNA was isolated from a denaturing polyacrylamide gel and subjected to cleavage by an iron-EDTA- $\mathrm{H}_{2} \mathrm{O}_{2}$ system (Figure 3.2.4). In this type of experiment, the location where the "ladder" of labeled cleavage fragments is interrupted reveals the site of cross-link attachment. The results indicated that the cross-link is predominantly (60\%) attached to the guanine residue offset one nucleotide to the 3 '-side of the AP site on the opposing strand, as shown in the diagram labeled $\mathbf{C}$ on

the right side of Figure 3.2.1. A smaller-but-significant amount of cross-link (approximately 40\%) was attached to the guanine residue directly opposing the AP site. 
The footprinting data indicate that the slow-migrating band seen in Figure 3.2.1 is actually a mixture of two different cross-link attachments. The evidence presented thus far depicts a novel cross-linking process involving spermine-catalyzed strand cleavage of the AP site in duplex $\mathbf{A}$, followed by ICL formation via reaction of a guanine residue on the opposing strand with the 3 ' $\alpha, \beta$-unsaturated iminium ion intermediate (3'dRP-iminium, Scheme 3.1.1). 


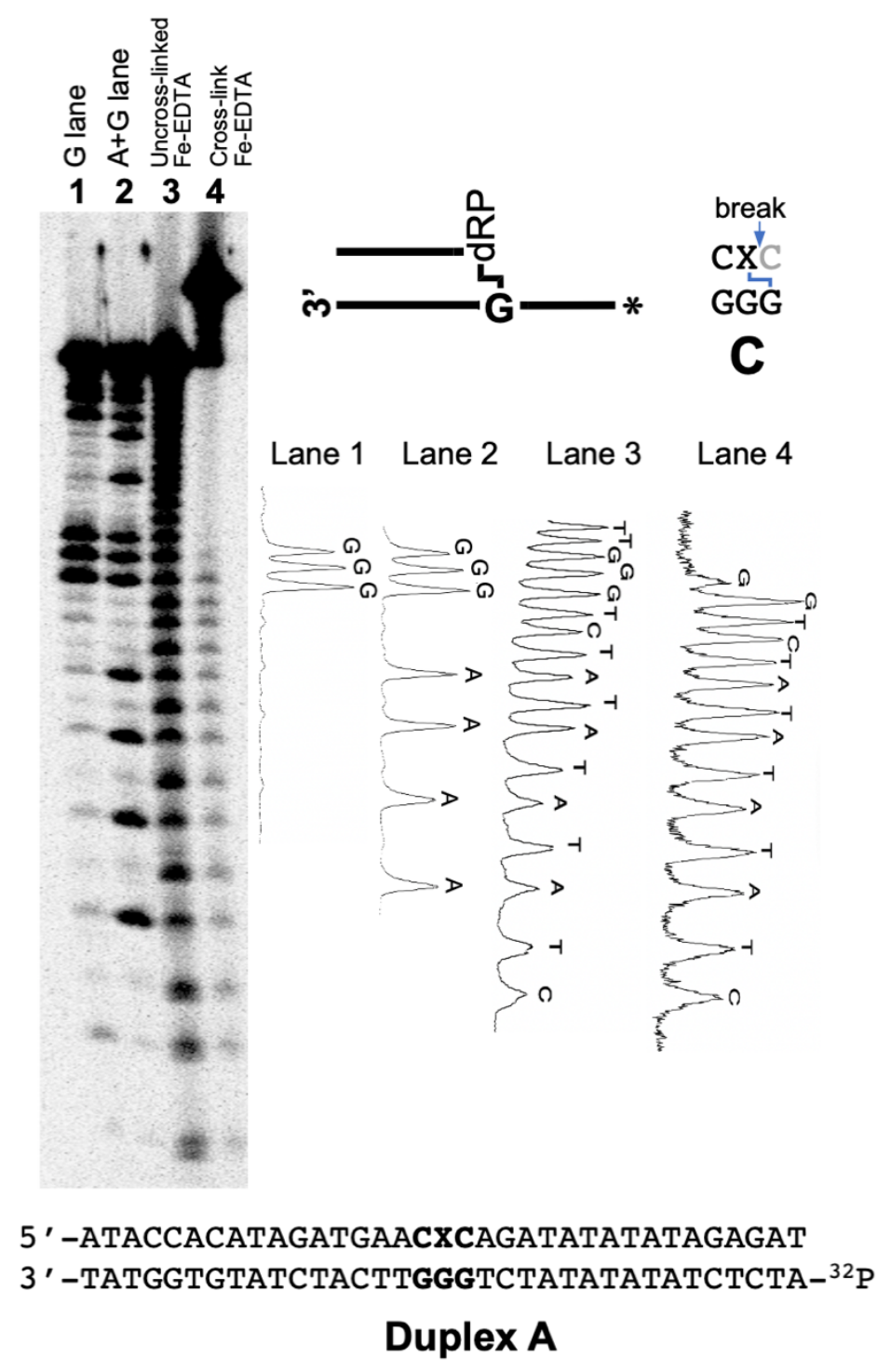


Figure 3.2.4. Iron-EDTA-H $\mathrm{H}_{2} \mathrm{O}_{2}$ footprinting of the cross-linked DNA generated by spermine-catalyzed strand cleavage of the AP site in duplex A. In this type of experiment, the site of cross-link attachment appears as the last band before an interruption in the "ladder" of strand cleavage products generated by the iron-EDTA$\mathrm{H}_{2} \mathrm{O}_{2}$, "hydroxyl radical" DNA-cleaving reagent, because cleavages beyond the crosslink yield large, slowly-migrating DNA fragments that are connected to the opposing strand (Luce, R. A.; Hopkins, P. B. Methods Enzymol. 2001, 340, 396-412). These large fragments can be seen at the top of lane 4. Lane 1: Maxam-Gilbert G-specific cleavage (sequencing) reaction on the 5'-32 P-labeled strand of duplex A. Lane 2: A+G MaxamGilbert sequencing reaction on the $5{ }^{\prime}{ }^{32} \mathrm{P}-$ labeled strand of duplex A. Lane 3: Fe-EDTA$\mathrm{H}_{2} \mathrm{O}_{2}$, hydroxyl radical cleavage of the uncross-linked, 5'-32 $\mathrm{P}$-labeled duplex shown above. Lane 4: is the hydroxyl radical footprinting reaction on the cross-linked duplex $\mathrm{C}$ generated by incubation of duplex A with spermine $(1 \mathrm{mM})$ in $\mathrm{pH} 7.4$ buffer (HEPES 50 $\mathrm{mM}$ containing $100 \mathrm{mM} \mathrm{NaCl}$ ) at for $24 \mathrm{~h}$ at $37{ }^{\circ} \mathrm{C}$. The ${ }^{32} \mathrm{P}$-labeled oligodeoxynucleotides were resolved on a $20 \%$ denaturing polyacrylamide gel and visualized by phosphorimager analysis. The densitometry trace on the right shows the cleavage products resolved in lane 4 of the gel. 


\section{ESI-QTOF-LC-MS analysis is consistent with cross-link formation via conjugate}

addition of a guanine residue to the 3 'dRP-iminium cleavage product.

We isolated the cross-linked DNA generated by spermine-catalyzed strand cleavage of the AP site in duplex $\mathbf{A}$ by gel electrophoresis and characterized this material using ESI-QTOF-LC-MS mass spectrometry (ESI-MS). The major signal in the deconvoluted mass spectrum corresponded to an $\mathrm{m} / \mathrm{z}$ value of 16081.28 (Figure 3.2.5). This result, alongside the other data presented here, was consistent with a dG-dRP crosslink structure arising from conjugate addition of a guanine residue to the $\alpha, \beta$-unsaturated 3'dRP-iminium ion intermediate (Scheme 3.1.3, calcd $m / z$ 16,081.53). 


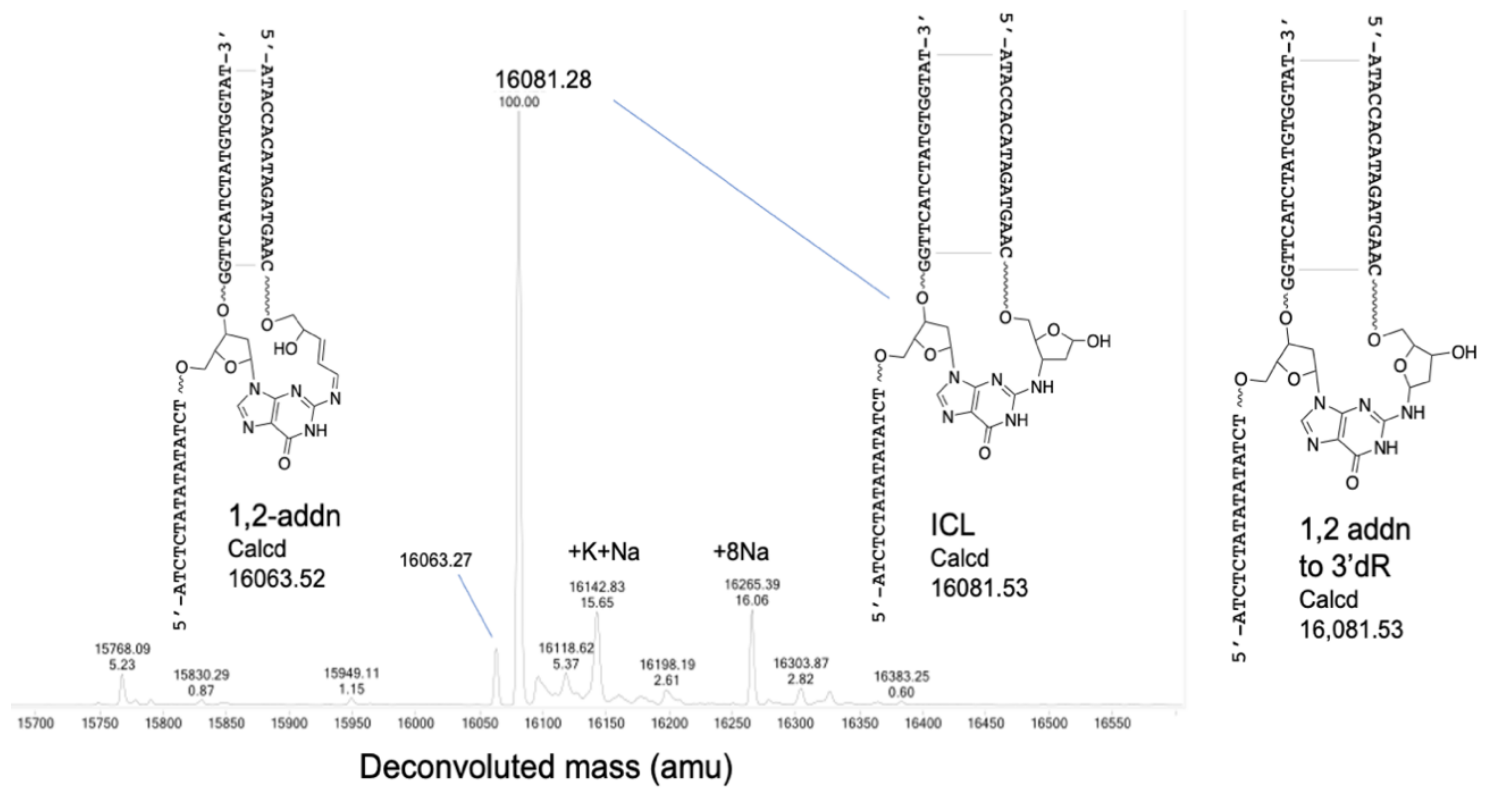

Figure 3.2.5. ESI(-)-QTOF-LC-MS analysis of the cross-linked DNA generated by spermine-mediated cleavage of the AP-containing duplex A. Masses shown correspond to the most prominent peak in the isotope envelope. The deconvoluted mass for the most intense signal was $16081.28 \mathrm{amu}$. This result was consistent with a cross-link arising from conjugate addition of a guanine residue to the $\alpha, \beta$-unsaturated strand cleavage product (calcd 16081.53 amu). The major signal (16081.28 amu) was not consistent with an alternate cross-linking product arising from 1,2-addition of a guanine residue to the $\alpha, \beta$ unsaturated cleavage product (calcd 16,063.52 amu for structure shown on the left side above). A relatively weak signal at $16,063.27$ amu that may correspond to this product 
was observed. A third structural possibility (shown on the right above) involving a crosslink arising from 1,2-addition of a guanine residue to a 3 'deoxyribose cleavage product ( 3 'dR) was ruled out by our observation that the 3 'dR end product generated by Endo IIImediated cleavage of duplex A does not generate cross-linked DNA (see Figure 3.2.1, lanes 3 and 4).

\section{The dG-dRP ICL is chemically stable under physiological conditions.}

Formation of the cross-link generated by spermine-mediated strand cleavage of the AP site in duplex $\mathbf{A}$ in $\mathrm{pH} 7.4$ buffer at $37^{\circ} \mathrm{C}$ can be detected within minutes, reaches its half-maximal yield by about $8 \mathrm{~h}$, and begins to plateau after $20 \mathrm{~h}$ (Figure 3.2.2). At longer incubation times ( $70 \mathrm{~h}$ in the presence of spermine) there is some evidence for decomposition of the ICL, with a corresponding increase in the 3'-phosphate cleavage product. In a separate experiment, the cross-linked DNA was isolated by gel electrophoresis and its stability examined in $\mathrm{pH} 7.4$ buffer at $37{ }^{\circ} \mathrm{C}$, in the absence of spermine. Under this condition, the cross-link was very stable, undergoing decomposition over the course of $168 \mathrm{~h}$ (Figure 3.2.6). 


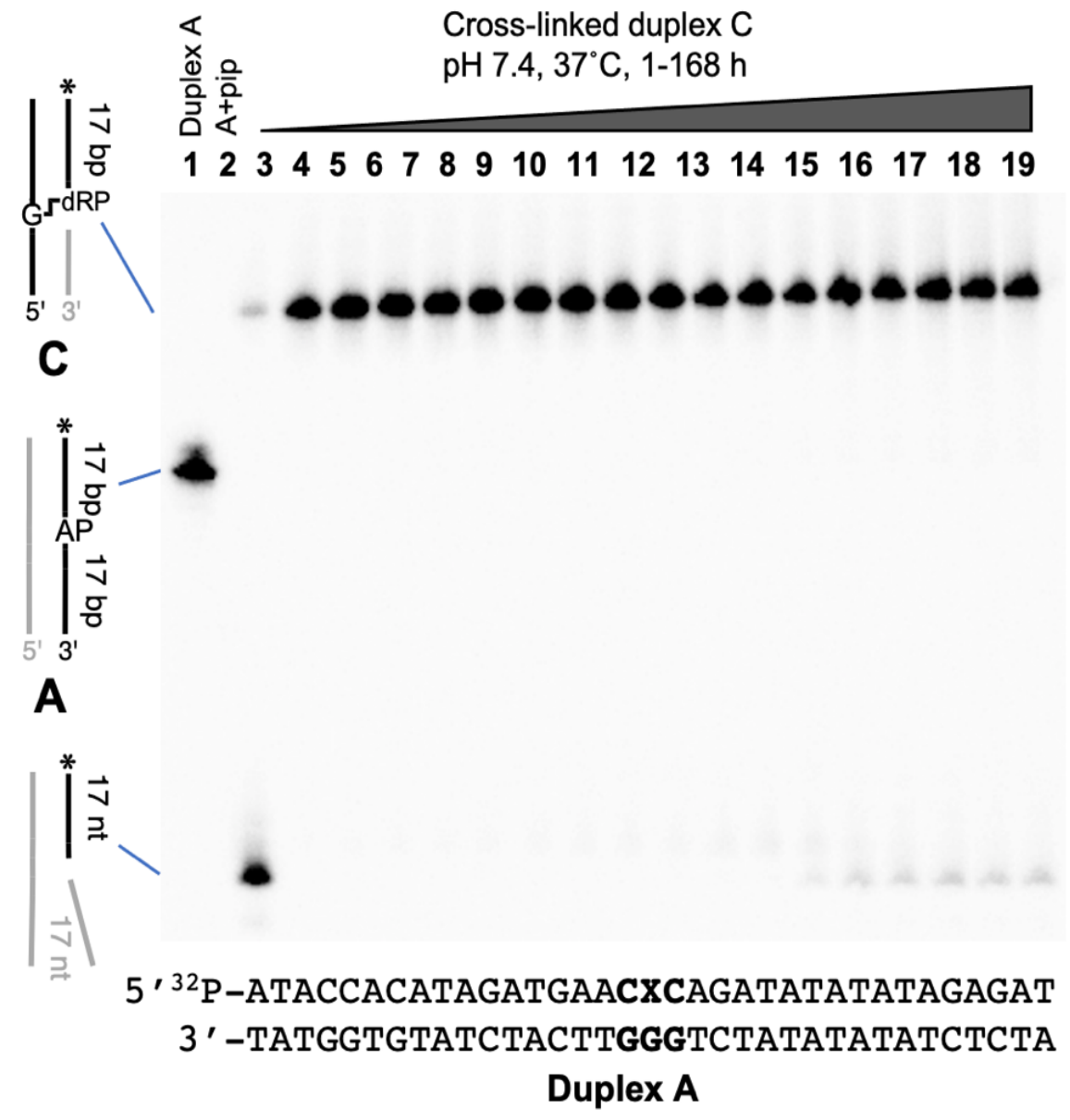


Figure 3.2.6. Stability of the cross-linked DNA arising from spermine-mediated strand cleavage of the AP site in duplex A. The cross-linked duplex C was isolated from a denaturing polyacrylamide gel and redissolved in HEPES buffer (50 mM, pH 7.4) containing $\mathrm{NaCl}(100 \mathrm{mM})$ and incubated at $37^{\circ} \mathrm{C}$ for $1,2,4,6,10,20,24,30,36,42$, $48,72,96,120,144$, and $168 \mathrm{~h}$. Aliquots were removed at the prescribed time points and frozen at $-20{ }^{\circ} \mathrm{C}$ prior to gel electrophoresis. The 5'-32 $\mathrm{P}$ labeled oligodeoxynucleotides were resolved by electrophoresis on a $20 \%$ denaturing polyacrylamide gel and the radioactivity in each band quantitatively measured by storage-phosphor autoradiography.

Heating at $95{ }^{\circ} \mathrm{C}$ caused degradation of the cross-linked duplex over the course of approximately $8 \mathrm{~h}$ (Figure 3.2.7). On the other hand, treatment of the cross-linked DNA with $\mathrm{NaBH}_{4}$ prior to heating at $95{ }^{\circ} \mathrm{C}$ dramatically stabilized the DNA against degradation (Figure 3.2.7). Similarly, treatment with piperidine $\left(1 \mathrm{M}, 95^{\circ} \mathrm{C}, 25 \mathrm{~min}\right)$ resulted in disappearance of the cross-link with simultaneous appearance of the 3'phosphate cleavage product, while the $\mathrm{NaBH}_{4}$-treated cross-link was somewhat resistant to piperidine-induced degradation (Figure 3.2.7). These results were consistent with the structure of the dG-dRP cross-link shown in Scheme 3.1.2 due to the increased stability in the reduced form. Specifically, thermal and base-mediated decomposition of the ICL may involve $\beta$ elimination of the nucleobase from the ring-opened, aldehyde form of the cross-linkage and reduction of the aldehyde residue to the corresponding alcohol by $\mathrm{NaBH}_{4}(\mathrm{Scheme}$ 3.1.2) is expected to suppress this reaction. 


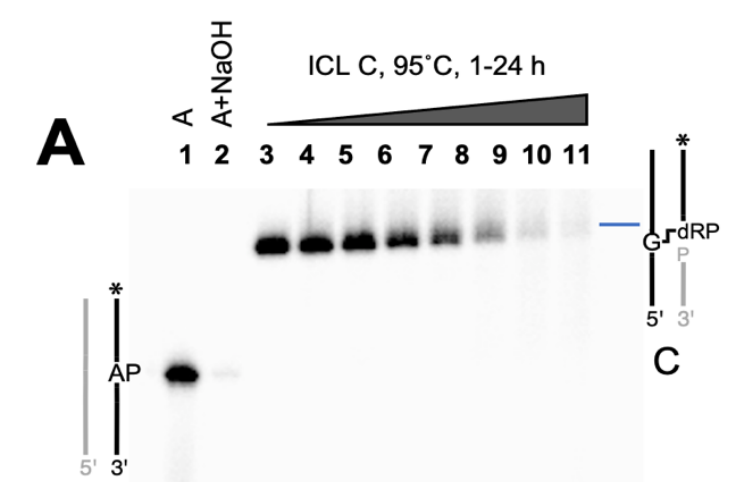

A

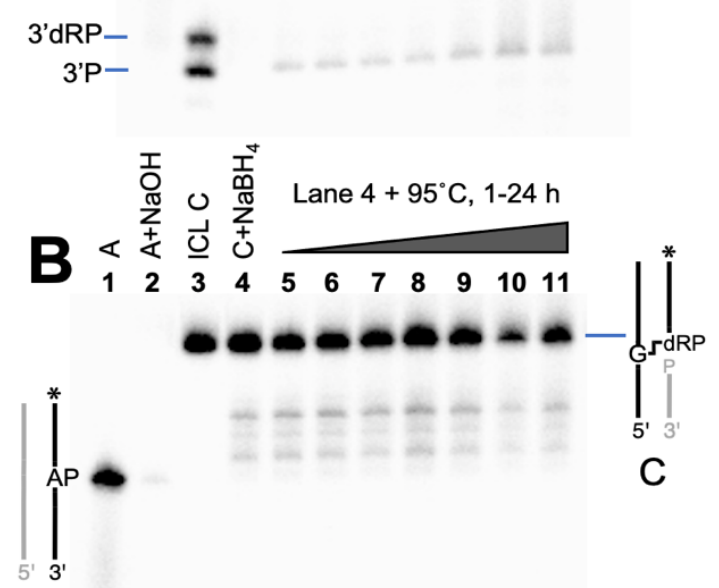

A

$\frac{\text { 3'dRP- }}{3{ }^{\prime} \mathrm{P}-}=$

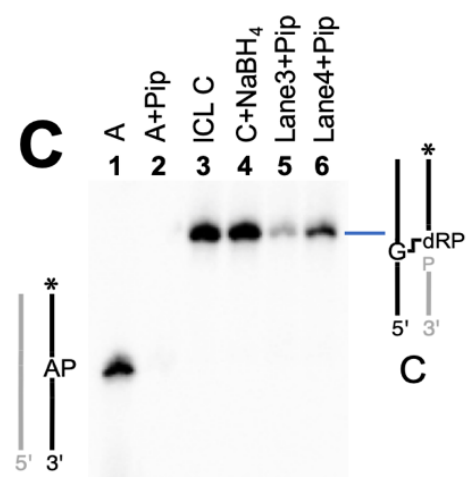

A

3'P-

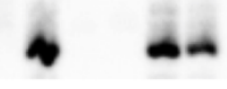


Figure 3.2.7. This Figure provides gel electrophoretic evidence for the stability of interstrand cross-link duplex $\mathrm{C}$ for both reduced and unreduced cross-link. Panel A:

The cross-linked duplex $\mathrm{C}$ was isolated from a denaturing polyacrylamide gel and redissolved in HEPES buffer $(50 \mathrm{mM}, \mathrm{pH} 7.4)$ containing $\mathrm{NaCl}(100 \mathrm{mM})$ and incubated at $95{ }^{\circ} \mathrm{C}$ for $1-24 \mathrm{~h}$. Aliquots were removed at the prescribed time points and frozen at $20{ }^{\circ} \mathrm{C}$ prior to gel electrophoresis. Panel B: The cross-linked duplex C was isolated from a denaturing polyacrylamide gel and treated with $\mathrm{NaBH}_{4}(100 \mathrm{mM})$ in HEPES $(50 \mathrm{mM}$, $\mathrm{pH} 7.4)$ and $\mathrm{NaCl}(100 \mathrm{mM})$ at $37{ }^{\circ} \mathrm{C}$ for $4 \mathrm{~h}$. The reduced cross-link mixture was then EtOH precipitated and redissolved in HEPES buffer $(50 \mathrm{mM}, \mathrm{pH} 7.4)$ containing $\mathrm{NaCl}$ $(100 \mathrm{mM})$ and incubated at $95{ }^{\circ} \mathrm{C}$ for $1-24 \mathrm{~h}$. Aliquots were removed at the prescribed time points and frozen at $-20{ }^{\circ} \mathrm{C}$ prior to gel electrophoresis. Panel C: The cross-linked duplex C was treated with $\mathrm{NaBH}_{4}(100 \mathrm{mM})$ in HEPES $(50 \mathrm{mM}, \mathrm{pH} 7.4)$ and $\mathrm{NaCl}(100 \mathrm{mM})$ at $37{ }^{\circ} \mathrm{C}$ for $4 \mathrm{~h}$ and was isolated from a denaturing polyacrylamide gel (Lane 4). The crosslinked duplex $\mathrm{C}$ was treated with piperidine $(1 \mathrm{M})$ at $95{ }^{\circ} \mathrm{C}$ for $25 \mathrm{~min}$ (Lane 5). The reduced cross-linked duplex $\mathrm{C}$ was treated with piperidine $(1 \mathrm{M})$ at $95{ }^{\circ} \mathrm{C}$ for $25 \mathrm{~min}$ (Lane 6). The $5^{\prime}-{ }^{32} \mathrm{P}$ labeled oligodeoxynucleotides were resolved by electrophoresis on a $20 \%$ denaturing polyacrylamide gel and the radioactivity in each band quantitatively measured by storage-phosphor autoradiography. 


\section{LC-MS analyses define the structure of the dG-dRP ICL in duplex DNA.}

For LC-MS analyses the cross-linked DNA generated by spermine-mediated cleavage of the AP-containing duplex A was isolated from a denaturing polyacrylamide gel and digested using a four-enzyme cocktail consisting of nuclease P1, alkaline phosphatase, and phosphodiesterases I and II. We prepared the samples and sent them to a collaborator (Yinsheng Wang) who analyzed cross-linked DNA with and without treatment with $\mathrm{NaBH}_{4}$.

Analysis of the $\mathrm{NaBH}_{4}$-treated cross-link revealed two peaks eluting at 16.9 and 18.2 min displaying the $\mathrm{m} / \mathrm{z} 386 \rightarrow 270$ transition anticipated for the neutral loss of 2 deoxyribose from the $d G-d R P_{\text {red }}$ cross-link remnant (Figure 3.2.8). Further cleavage of the $m / z 270$ ion produced a fragment ion at $m / z 152$ in MS/MS/MS, corresponding to the $[\mathrm{M}+\mathrm{H}]^{+}$ion of the guanine free base (Figure 3.2.8).

The multiple peaks displaying the $m / z 386 \rightarrow 270$ transition in the LC-MS/MS ion chromatogram presumably reflect a diastereoisomeric mixture generated in the conjugate addition reaction. Additional LC-MS/MS/MS analysis of the unreduced cross-link was consistent with the dG-dRP cross-link structure depicted in Scheme 3.1.2.

Overall, the LC-MS analyses of cross-linked DNA allowed us to elucidate the chemical structure of the dG-dRP ICL formed in duplex DNA (Scheme 3.1.2). In addition, the LC-MS work-flow described here provides for the detection of this novel ICL in cellular DNA. 

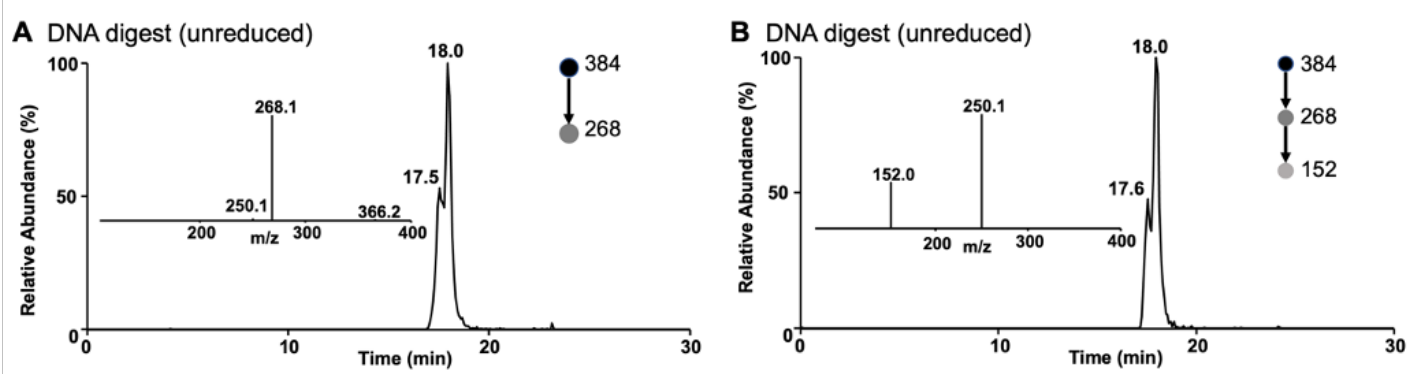

C DNA digest, reduced

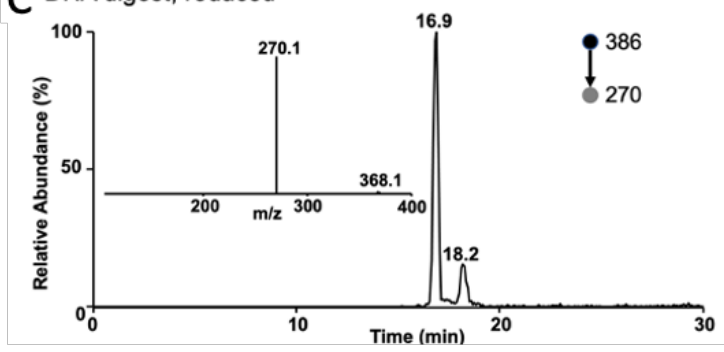

D DNA digest, reduced
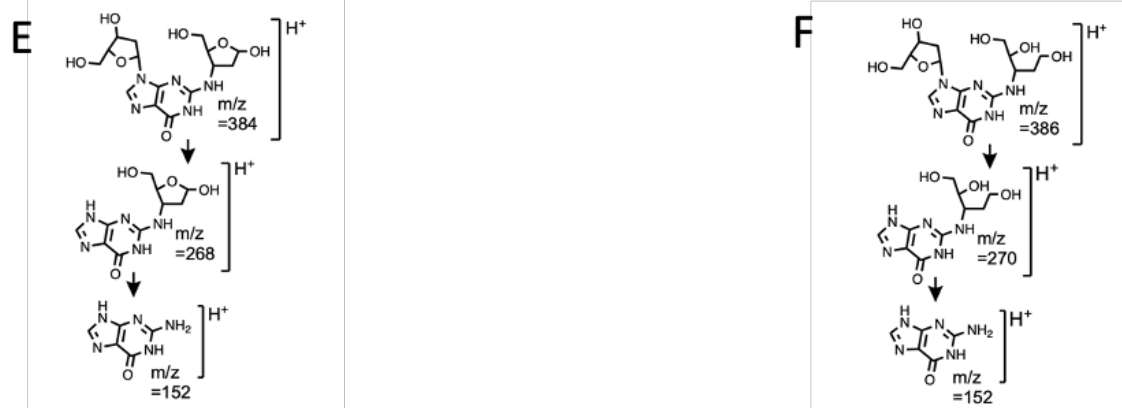

Unreduced dG-dRP

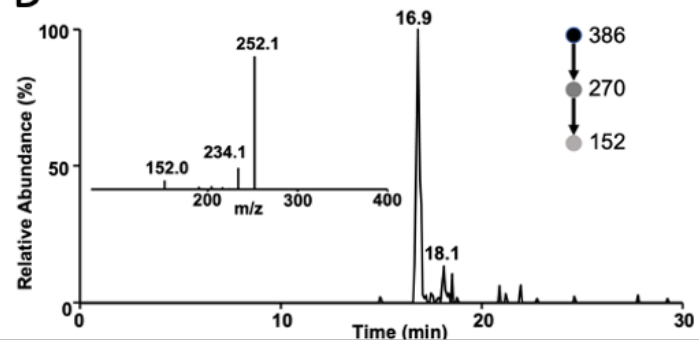

Reduced dG-dRP 
Figure 3.2.8. LC-MS/MS and LC-MS/MS/MS analyses of the cross-linked DNA generated by spermine-mediated strand cleavage of the AP site in duplex A. Panel A, the selected-ion chromatogram for the purified, digested, cross-link from duplex A for the $\mathrm{m} / \mathrm{z}$ 384-268 transition. Panel B, the selected-ion chromatogram for the $\mathrm{m} / \mathrm{z}$ 384-268-152 transition of the purified, digested, cross-link from duplex A. The multiple peaks displaying the $m / z 384 \rightarrow 268 \rightarrow 152$ transitions in the LC-MS/MS and LC-MS/MS/MS ion chromatograms reflect the fact that the $\mathrm{dG}-\mathrm{dRP}$ cross-link exists as an equilibrating mixture of isomers. Panel C, the selected-ion chromatogram for the purified, reduced, digested, cross-link from duplex A for the m/z 386-270 transition. Panel D, the selectedion chromatogram for the $\mathrm{m} / \mathrm{z} 386-270-152$ transition of the purified, reduced, digested, cross-link from duplex A. Shown in the insets are the MS/MS (A, C) and MS/MS/MS (B,D) averaged from the $18.0 \& 16.9$ min fractions. Panel E, possible structures for the ions observed at the 384,268 , and 152. Panel F, possible structures for the ions observed at the 386,270 , and 152 .

\subsection{Unhooking of the dG-dRP cross-link by human apurinic endonuclease 1} (hAPE1) has the potential to initiate repair of the dG-dRP ICL.

The primary function of the enzyme apurinic endonuclease 1 (hAPE1) is to initiate repair of AP sites via incision of the phosphodiester linkage on the 5' -side of the lesion. ${ }^{29,30}$ In addition, hAPE1 has the capacity to remove mismatched nucleotides or sugar remnants located on the 3 '-end of a strand break in duplex DNA. ${ }^{31}$ Recent structural studies revealed that the 3'-exonuclease activity of hAPE1 does not require extrusion scissile 
phosphodiester linkage from the duplex. ${ }^{31}$ These facts suggested to us that the dG-dRP ICL might be a substrate for the 3'-exonuclease activity of hAPE1.

We found that the dG-dRP ICL in DNA is indeed a substrate for 3'-exonuclease activity of APE1 (Figure 3.3.1). A time course showed that the unhooking reaction occurs with a half-time in the range of $10-15 \mathrm{~min}$. The gel mobility of the initial unhooking product is consistent the $3{ }^{\prime} \mathrm{OH}$ product expected from the 3 '-exonuclease action of the enzyme. At longer incubation times, smaller products arising from further 3'-exonuclease activity of the enzyme on the initial product were observed (Figure 3.3.1). 


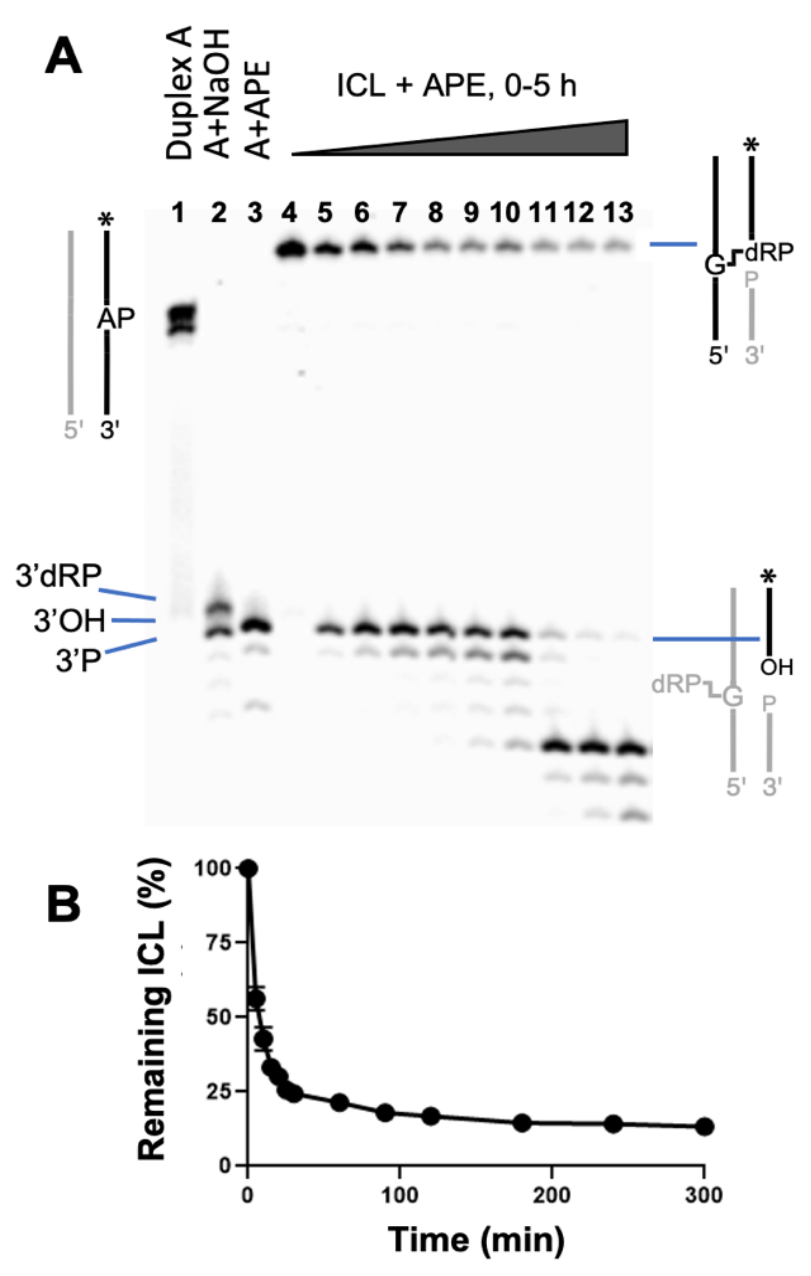

Figure 3.3.1. Unhooking of the dG-dRP ICL by the DNA repair enzyme apurinic endonuclease (APE1). The cross-linked DNA generated by amine-catalyzed cleavage of the AP site in duplex $\mathbf{G}$ was isolated by gel electrophoresis and annealed with a complementary 5'-phosphorylated oligonucleotide to generate the gapped substrate $\mathbf{O}$ (the complete sequences for duplexes are provided in Figure 3.1.1). The gapped ICL was incubated with APE1 (30 units) in Tris buffer ( $\mathrm{pH} 7.4)$ containing $\mathrm{MgCl}_{2}(0.1 \mathrm{mM})$ and 
$\mathrm{NaCl}(20 \mathrm{mM})$ at $37{ }^{\circ} \mathrm{C}$. At prescribed times aliquots were removed and frozen for subsequent gel electrophoretic analysis. The 5'-32 P-labeled oligodeoxynucleotides in the reactions were resolved by electrophoresis on a $0.4 \mathrm{~mm}$ thick $20 \%$ denaturing polyacrylamide gel and the radioactivity in each band quantitatively measured by storagephosphor autoradiography. The initial unhooking product has gel mobility consistent with the $3^{\prime} \mathrm{OH}$ product. The smaller, faster-migrating products that increase over time are ascribed to continued 3'-exonuclease activity of APE1 on the initial 3'OH product. Panel A shows the gel electrophoretic analysis of the enzymatic unhooking reaction and panel B shows a plot of the decrease in cross-linked DNA as a function of time. The error bars reflect the standard deviation from three separate experiments.

The action of APE1 on the dG-dRP ICL is more effective on a "gapped" substrate (Figure 3.3.1) than it is on a "resected" substrate lacking the oligonucleotide fragment on the 3 '-side of the strand break (Figure 3.3.2). In addition, unhooking the dG-dRP ICL is more effective when conducted in a buffer optimized for the 3'-exonuclease activity of APE1 rather than the standard endonuclease buffer for this enzyme (Figure 3.3.3). 


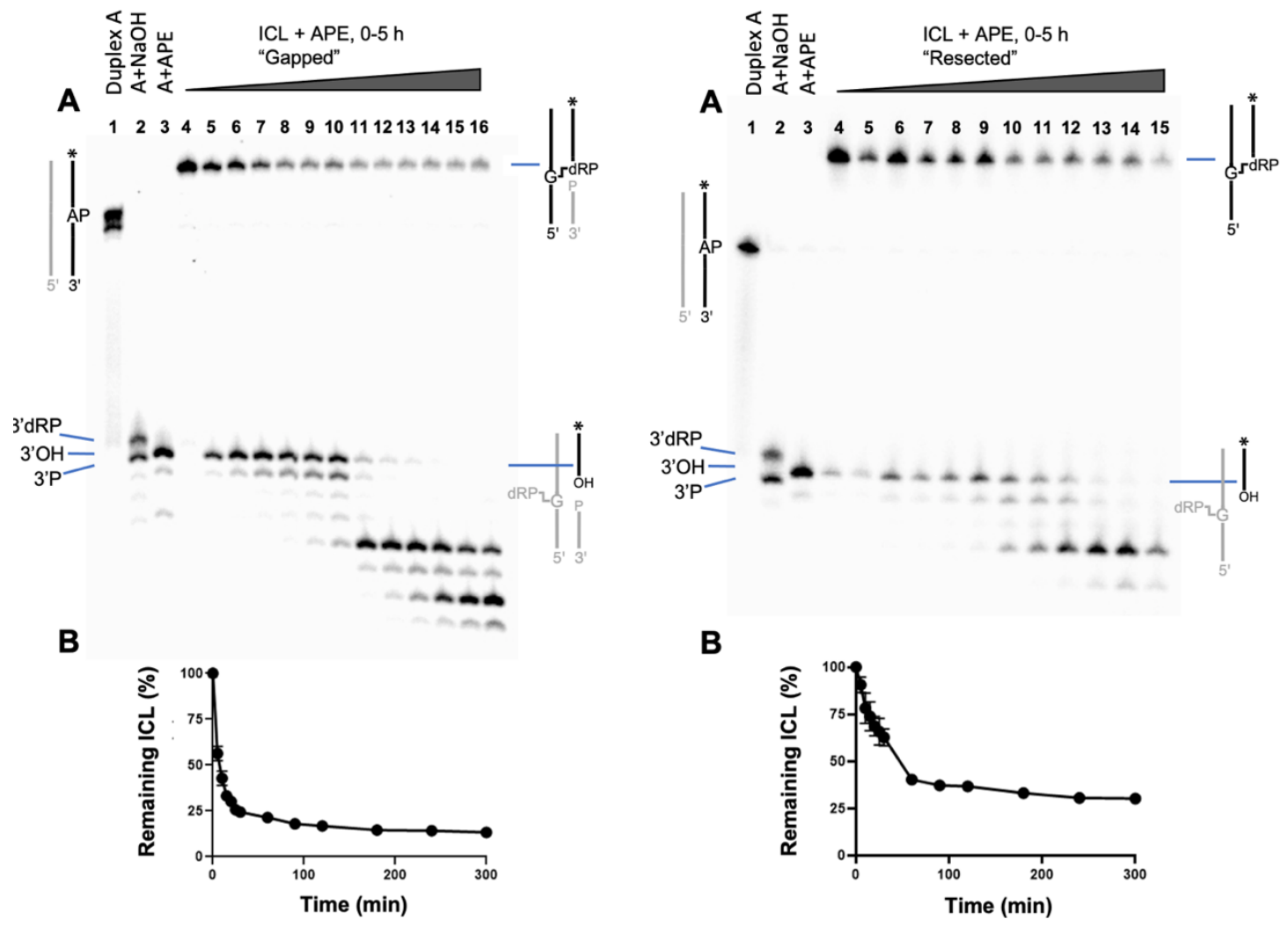

Figures 3.3.2. Unhooking of the dG-dRP ICL by APE1 in a gapped substrate is more effective than in a resected substrate (lacking the duplex region on the 3'-side of the strand break). Lanes 1-3 are marker lanes for the uncross-linked DNA and possible strand cleavage products generated from it. The cross-linked DNA generated by sperminecatalyzed strand cleavage of duplex A. In the experiment shown on the left side a complementary oligonucleotide with a 5'-phosphoryl group was annealed to the gapped ICL. In the experiment shown on the right, there is no complementary oligonucleotide annealed on the 3'-side of the cleavage site. The ICL-containing DNA was incubated with APE1 (30 units) in Tris- $\mathrm{HCl}(\mathrm{pH} 7.4)$ containing $\mathrm{MgCl}_{2}(0.1 \mathrm{mM})$ and $\mathrm{NaCl}(20 \mathrm{mM})$ at $37{ }^{\circ} \mathrm{C}$. At prescribed times aliquots were removed and frozen for subsequent gel 
electrophoretic analysis. The ${ }^{32} \mathrm{P}$-labeled oligodeoxynucleotides in the reactions were resolved by electrophoresis on a $0.4 \mathrm{~mm}$ thick $20 \%$ denaturing polyacrylamide gel and the radioactivity in each band quantitatively measured by storage-phosphor autoradiography. The initial unhooking product has gel mobility consistent with the $3^{\prime} \mathrm{OH}$ product. The faster-migrating (smaller) products that grow in at longer times presumably result from continued 3'-exonuclease activity of APE1 on the initial 3'OH product. In each case, Panel A shows the gel electrophoretic analysis of the enzymatic unhooking reaction and panel B shows a plot of the decrease in remaining cross-linked DNA as a function of time. 

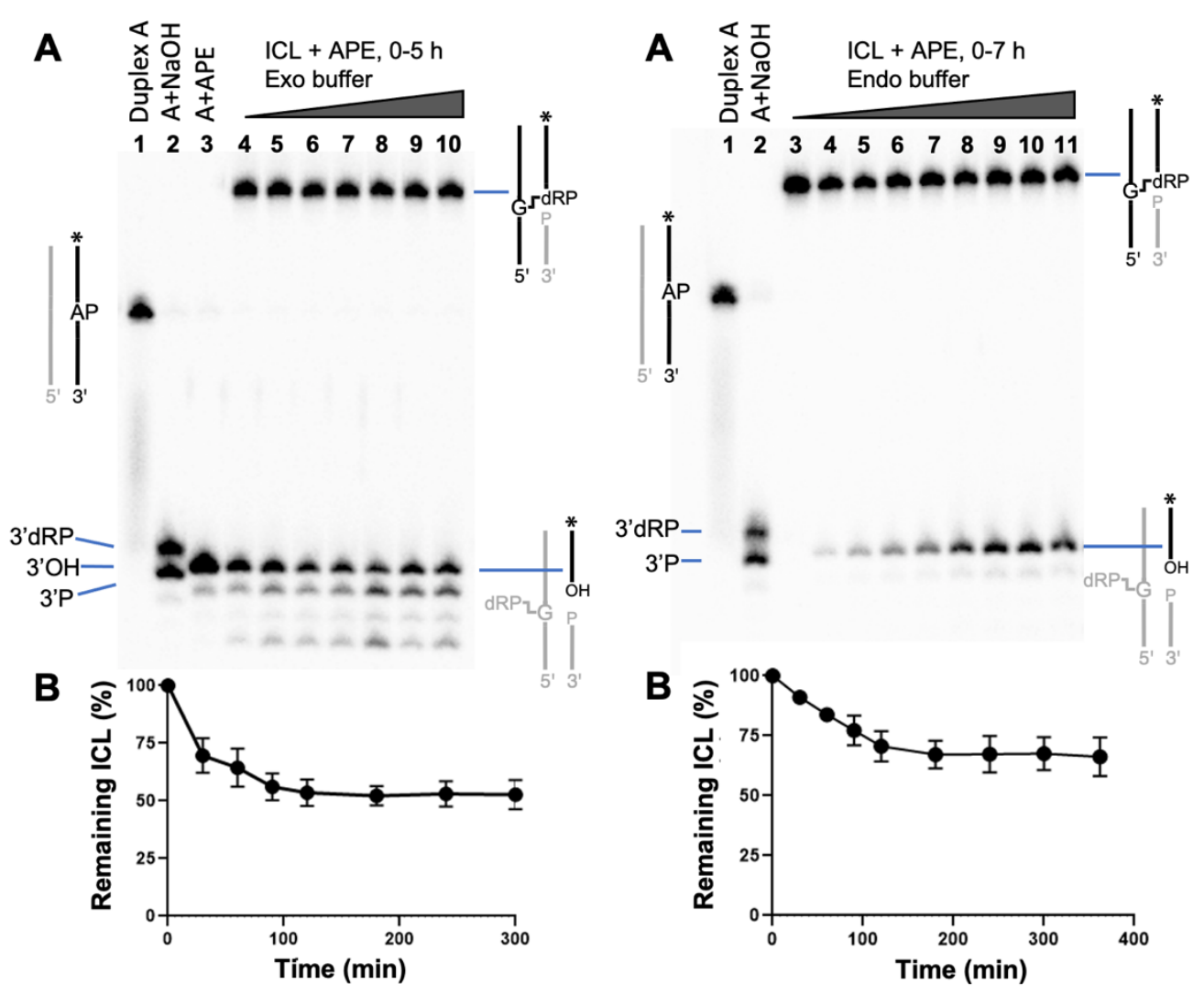

Figure 3.3.3. Two left-hand panels: Unhooking of the (resected) dG-dRP ICL by APE1 is more effective in exonuclease-specific buffer than in the traditional AP endonuclease buffer. The cross-linked DNA generated by spermine-catalyzed strand cleavage of duplex A was isolated by from a denaturing gel. The resected ICL-containing DNA was incubated with APE1 (10 units) in either Tris-HCl ( $\mathrm{pH} 7.4)$ containing $\mathrm{MgCl}_{2}$ $(0.1 \mathrm{mM})$ and $\mathrm{NaCl}(20 \mathrm{mM})$ (exo buffer) or a buffer composed of $50 \mathrm{mM}$ potassium acetate. $20 \mathrm{mM}$ Tris acetate. $10 \mathrm{mM}$ Magnesium acetate. $1 \mathrm{mM}$ DTT at $\mathrm{pH} 7.9$ (endo buffer) at $37^{\circ} \mathrm{C}$. At prescribed times aliquots were removed and frozen for subsequent gel electrophoretic analysis. The ${ }^{32} \mathrm{P}$-labeled oligodeoxynucleotides in the reactions were resolved by electrophoresis on a $0.4 \mathrm{~mm}$ thick $20 \%$ denaturing polyacrylamide gel and the 
radioactivity in each band quantitatively measured by storage-phosphor autoradiography. The initial unhooking product has gel mobility consistent with the 3'OH product. The faster-migrating (smaller) products that grow in at longer times presumably result from continued 3'-exonuclease activity of APE1 on the initial 3'OH product. In each case, Panel A shows the gel electrophoretic analysis of the enzymatic unhooking reaction and panel B shows a plot of the decrease in remaining cross-linked DNA as a function of time.

For comparison, we characterized the ability of hAPE1 to "trim" the 3 ' $\mathrm{dR}$ end group generated by the action of Endo III on the AP site in duplex DNA. The sugar remnant generated by the glycosylase-lyase action of Endo III is a known substrate for the 3'-exonuclease activity of APE1. Removal of the 3' $\mathrm{dR}$ end group from a gapped substrate by APE1 (10 units) took place with a half-time of approximately 5-10 min (Figure 3.3.4). The unhooking of the dG-dRP ICL by APE1 described above was somewhat less effective than trimming of the 3 ' $\mathrm{dR}$, requiring 3 -fold greater enzyme concentrations to proceed at a similar rate. 


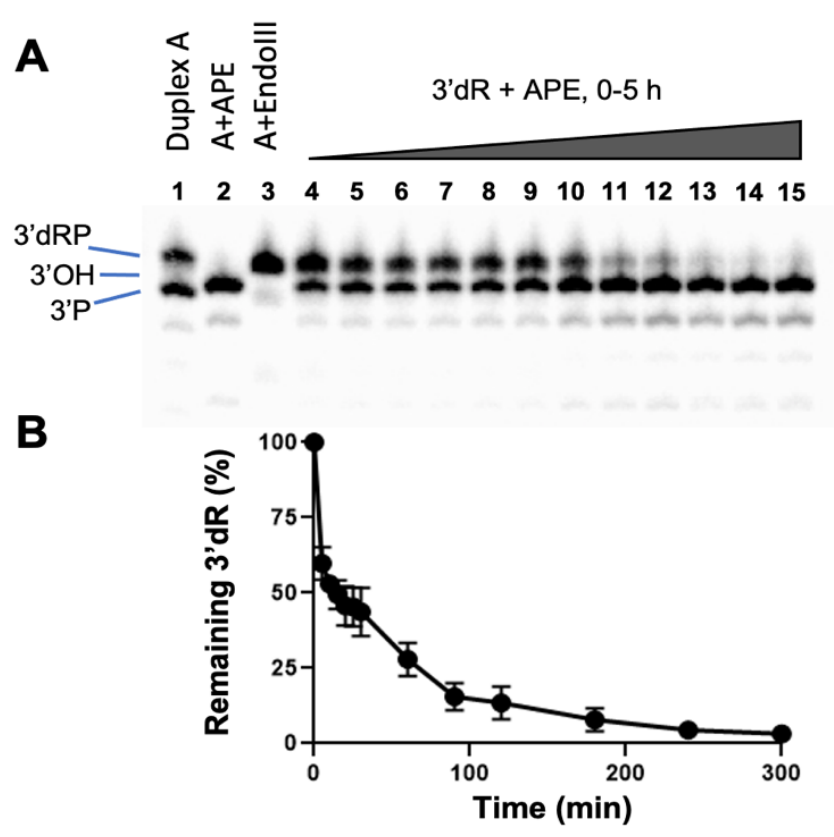

Figure 3.3.4. Trimming of the 3'dR end group from a gapped substrate by APE1. Duplex A was treated with Endo III to form the 3'dR product and EtOH precipitated. Lane 1, cleavage markers from the $\mathrm{NaOH}$ treatment (165 mM, $30 \mathrm{~min})$ with duplex A. Lane 2, duplex A treated with APE1. Lane 3, duplex A treated with Endo III for $2 \mathrm{~h}$ at $37^{\circ} \mathrm{C}$. Lanes 4-15, 3'dR treated with 10 unites APE1 in Tris- $\mathrm{HCl}(\mathrm{pH} 7.4)$ containing $\mathrm{MgCl}_{2}(0.1 \mathrm{mM})$ and $\mathrm{NaCl}(20 \mathrm{mM})$ for $0-5 \mathrm{~h}$. At prescribed times aliquots were removed and frozen for subsequent gel electrophoretic analysis. The ${ }^{32} \mathrm{P}$-labeled oligodeoxynucleotides in the reactions were resolved by electrophoresis on a $0.4 \mathrm{~mm}$ thick $20 \%$ denaturing polyacrylamide gel and the radioactivity in each band quantitatively measured by storagephosphor autoradiography. The initial unhooking product has gel mobility consistent with the 3 'OH product. The faster-migrating (smaller) products that grow in at longer times presumably result from continued 3'-exonuclease activity of APE1 on the initial 3'OH 
product. In each case, Panel A shows the gel electrophoretic analysis of the enzymatic unhooking reaction and panel B shows a plot of the decrease in remaining cross-linked DNA as a function of time.

In principle, unhooking of the dG-dRP ICL could be catalyzed by enzymes with amine-dependent AP lyase activity. However, we found that the base excision repair glycosylase FPG, an enzyme with efficient lyase activity, was not capable of unhooking the dG-dRP ICL (Figure 3.3.5).

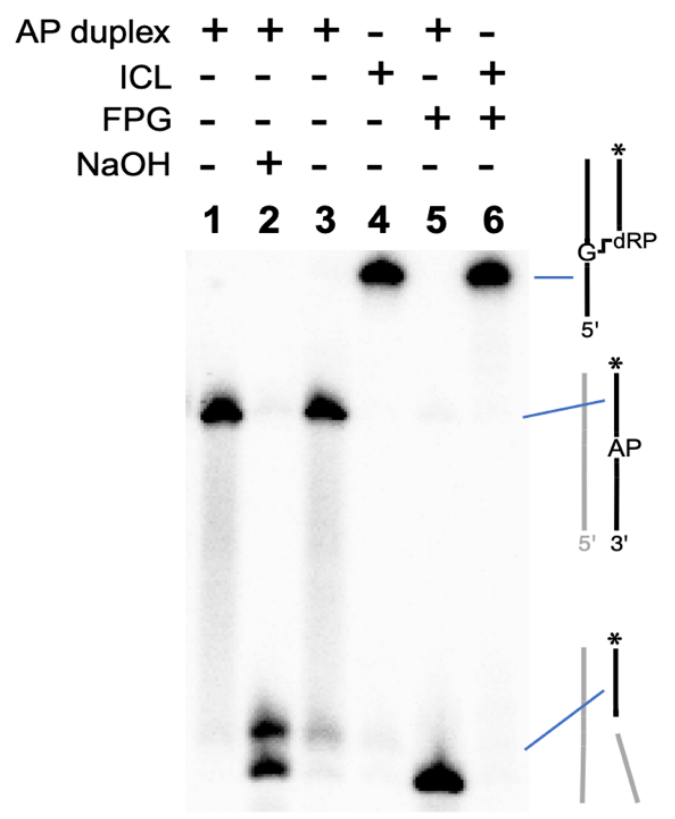

Figure 3.3.5. The BER glycosylase FPG does not unhook the dG-dRP ICL. The crosslinked DNA generated by spermine-catalyzed strand cleavage of duplex A was isolated by from a denaturing gel. Ap size marker from duplex A in lane 1. Lane 2, $\mathrm{NaOH}$ treatment of the Ap containing strand to show cleavage markers. Lane 3, Ap containing duplex in 
FPG reaction buffer, $40 \mathrm{mM}$ HEPES, $0.1 \mathrm{M} \mathrm{KCl}, 0.5 \mathrm{mM}$ EDTA, $0.2 \mathrm{mg} / \mathrm{ml} \mathrm{BSA}, \mathrm{pH} 8.0$ with $\mathrm{KOH}$ for $24 \mathrm{~h}$ at $37^{\circ} \mathrm{C}$. Lane 4, purified cross-linked duplex A. Lane 5, Ap containing duplex in $40 \mathrm{mM}$ HEPES, $0.1 \mathrm{M} \mathrm{KCl}, 0.5 \mathrm{mM}$ EDTA, $0.2 \mathrm{mg} / \mathrm{ml} \mathrm{BSA}$, pH 8.0 with $\mathrm{KOH}$ and 10 units Fpg for $24 \mathrm{~h}$ at $37^{\circ} \mathrm{C}$. Lane 6, purified cross-linked duplex A in $40 \mathrm{mM}$ HEPES, $0.1 \mathrm{M} \mathrm{KCl}, 0.5 \mathrm{mM}$ EDTA, $0.2 \mathrm{mg} / \mathrm{ml} \mathrm{BSA}$, pH 8.0 with $\mathrm{KOH}$ and 10 units Fpg for $24 \mathrm{~h}$ at $37^{\circ} \mathrm{C}$. The ${ }^{32} \mathrm{P}$-labeled oligodeoxynucleotides in the reactions were resolved by electrophoresis on a $0.4 \mathrm{~mm}$ thick $20 \%$ denaturing polyacrylamide gel and the radioactivity in each band quantitatively measured by storage-phosphor autoradiography.

\subsection{Scope and generality of the cross-linking reaction: formation of the dG-dRP ICL in various sequences and conditions.}

To examine the scope and generality of this novel cross-linking process we examined spermine-mediated ICL formation in a series of AP-containing duplexes with single guanine residues on the opposing strand near the strand cleavage site (Figure 3.4.1). We found that spermine-induced strand cleavage in all of these duplexes led to the generation of slow-migrating ICL bands. Among the three single-G duplexes, the highest ICL yield was obtained in the duplex containing a guanine residue offset one nucleotide to the 3'-side of the AP site on the opposing strand. Mass spectrometric analysis of the mixture generated in this cross-linking reaction was consistent with formation of the expected dG-dRP ICL (Figure 3.4.9). The preferred sites of ICL formation in the single$\mathrm{G}$ duplexes mirrored the preferred cross-link location in the triple-G sequence of duplex A. 


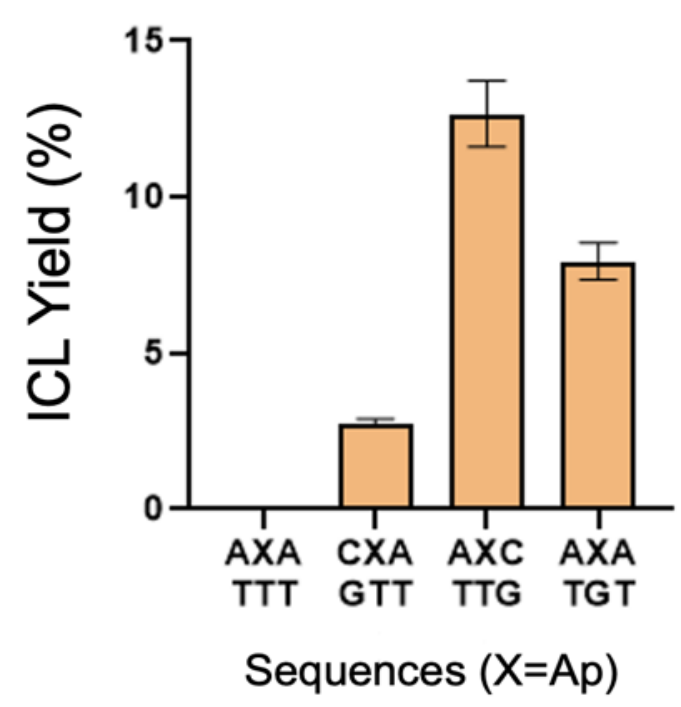

Figure 3.4.1. Yield of ICLs resulting from amine-catalyzed strand cleavage of an AP site in various sequence contexts.

The size of the 'tail' that is cleaved off in duplex A after the treatment with spermine is 17 oligonucleotides in length- giving it a predicted melting temperature of $39{ }^{\circ} \mathrm{C}$ which could mean a partial hybridization when the reaction is run at $37^{\circ} \mathrm{C}$. To check the ability of the dG-dRP interstrand cross-link to form under different conditions, we designed two other oligonucleotides that have 'tails' with a melting point of $0{ }^{\circ} \mathrm{C}$ and $52^{\circ} \mathrm{C}$ after cleavage with spermine (duplexes G \& M respectively). The standard reaction conditions were runHEPES (50 mM, pH 7.4), $\mathrm{NaCl}(100 \mathrm{mM})$, spermine (1 mM), $24 \mathrm{~h}$ at $37^{\circ} \mathrm{C}$ (Figure 3.4.2). It was found that when the 'tail' of the oligonucleotide is present during the cross-link reaction to form cross-linked duplex $\mathrm{O}$, the yield is $28 \%$ (Figure 3.4.2, Panel C, Lane 5), 
but when the 'tail' is not hybridized to the oligonucleotide during cross-link formation the percent yield jumps to 58\% yield to form cross-linked duplex I (Figure 3.4.2, Panel B, Lane 5). This results allowed us to hypothesize that the tail being unhybridized allows for greater flexibility in the oligonucleotide putting the $\mathrm{G}$ residue in a prime position for nucleophilic attack- resulting in a higher percent yield of the cross-link. 


\section{A}

5 ' - ${ }^{32} \mathrm{P}-\mathrm{ATACCACATAGATGAACXCAGATATATATAGAGAT}$

3 '-TATGGTGTATCTACTTGGGTCTATATATATCTCTA

Duplex $\mathbf{A}(X=A P)$ see Figure 1 of the main manuscript $T_{m}$ of blue $3^{\prime}$-fragment after strand cleavage is $39^{\circ} \mathrm{C}$ Cross-link yield $31 \pm 3 \%$

B
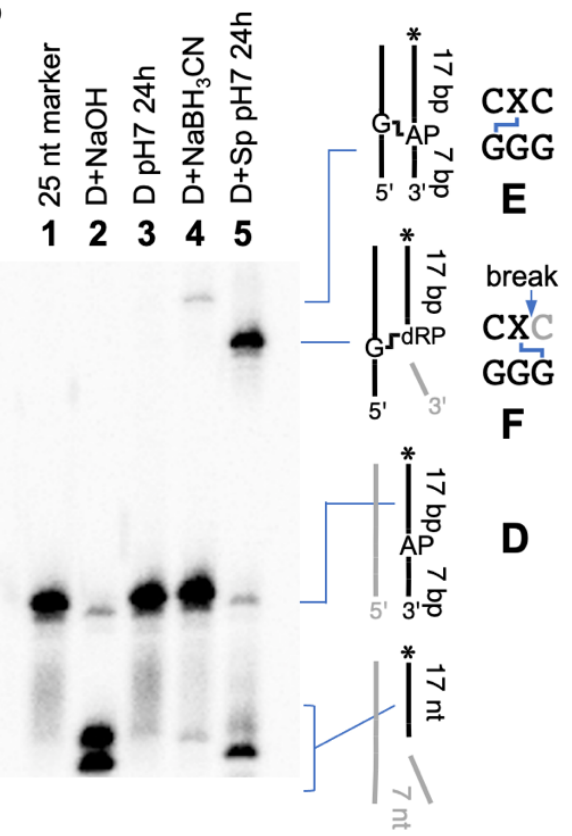

$5^{\prime}-{ }^{32} \mathrm{P}-\mathrm{ATACCACATAGATGAACXCAGATAT}$ 3'-TATGGTGTATCTACTTGGGTCTATA

Duplex D (X=AP)

$\mathrm{T}_{\mathrm{m}}$ of blue $3^{\prime}$-fragment after cleavage $0^{\circ} \mathrm{C}$ Cross-link yield $58 \pm 1 \%$ (lane 5 )
C
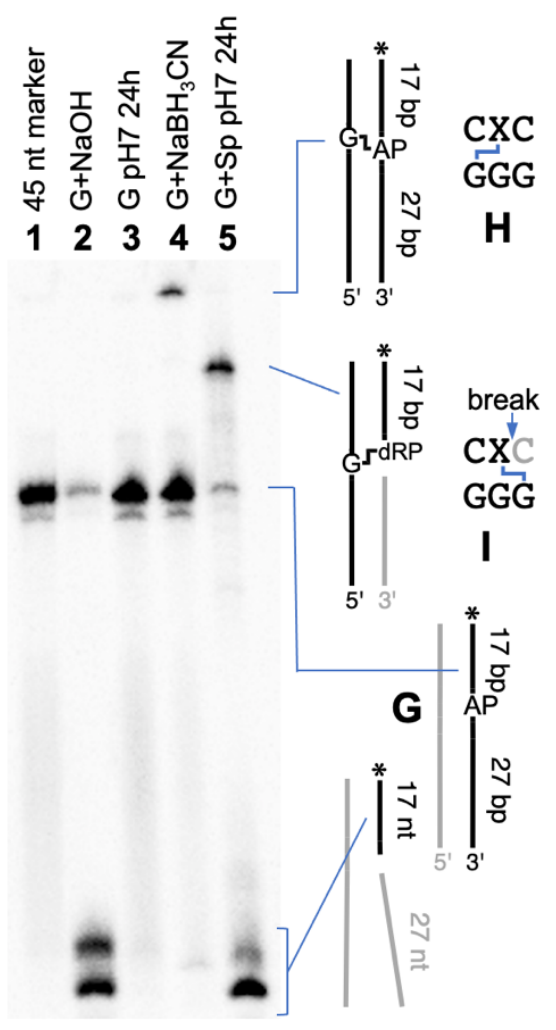

5' - ${ }^{32} \mathrm{P}-\mathrm{ATACCACATAGATGAACXCGAAAGATATAGATATAGTGAATATTA}$ 3'-TATGGTGTATCTACTTGGGCTTTCTATATCTATATCACTTATAAT

Duplex $\mathbf{G}(\mathrm{X}=\mathrm{AP})$

$\mathrm{T}_{\mathrm{m}}$ of blue $3^{\prime}$-fragment after strand cleavage is $52^{\circ} \mathrm{C}$ Cross-link yield $28 \pm 2$ (lane 5) 
Figure 3.4.2. Amine-catalyzed cross-link generation in AP-containing duplexes with differing numbers of base pairs on the 3'-side of the AP site. This Figure provides gel electrophoretic evidence for interstrand cross-link generation by spermine-catalyzed strand cleavage at the AP site in duplexes D and G. Panel A: Duplex A shown in Figure 1 of the main manuscript gives a $31 \pm 3 \%$ yield of the cross-linked duplex $\mathrm{C}$ generated following spermine-catalyzed strand cleavage of the AP-containing duplex A. Panel B: Interstrand cross-link formation arising from spermine-catalyzed strand cleavage of the AP-containing duplex D Lane 1: A single-stranded, 25 nt size marker consisting of the ${ }^{32} \mathrm{P}-$ labeled, APcontaining oligodeoxynucleotide (the top strand of duplex D). Lane 2: The AP-containing duplex $\mathbf{D}$ treated with $\mathrm{NaOH}\left(165 \mathrm{mM}, 37^{\circ} \mathrm{C}, 30 \mathrm{~min}\right)$ to induce strand cleavage at the AP site, with 3'P and 3'dRP cleavage products. Lane 3: AP-containing duplex D incubated in HEPES buffer $\left(50 \mathrm{mM}\right.$, pH 7) containing $\mathrm{NaCl}(100 \mathrm{mM})$ at $37^{\circ} \mathrm{C}$ for $24 \mathrm{~h}$. Lane 4 : Duplex D incubated in sodium acetate buffer $(\mathrm{pH} 5,750 \mathrm{mM})$ containing $\mathrm{NaBH}_{3} \mathrm{CN}$ (250 $\mathrm{mM})$ at $37{ }^{\circ} \mathrm{C}$ for $24 \mathrm{~h}$ to generate the full-size cross-linked duplex. Lane 5: Duplex $\mathbf{D}+$ spermine $(\mathrm{Sp}, 1 \mathrm{mM})$ in HEPES buffer $(50 \mathrm{mM}, \mathrm{pH}$ 7) containing $\mathrm{NaCl}(100 \mathrm{mM})$ at 37 ${ }^{\circ} \mathrm{C}$ for $24 \mathrm{~h}$ (cross-link yield $58 \pm 1 \%$ ). Panel C: Interstrand cross-link formation arising from spermine-catalyzed cleavage of the AP site in duplex G. Lane 1: A single-stranded, $45 \mathrm{nt}$ size marker consisting of the ${ }^{32} \mathrm{P}$-labeled, AP-containing oligodeoxynucleotide (the top strand of duplex $\mathbf{G})$. Lane 2: The AP-containing duplex $\mathbf{G}$ treated with $\mathrm{NaOH}$ (165 $\mathrm{mM}, 37^{\circ} \mathrm{C}, 30 \mathrm{~min}$ ) to induce strand cleavage at the AP site, with 3'P and 3'dRP cleavage products. Lane 3: AP-containing duplex $\mathbf{G}$ incubated in HEPES buffer (50 mM, pH 7) containing $\mathrm{NaCl}(100 \mathrm{mM})$ at $37{ }^{\circ} \mathrm{C}$ for $24 \mathrm{~h}$. Lane 4: Duplex $\mathbf{G}$ incubated in sodium 
acetate buffer $(\mathrm{pH} 5,750 \mathrm{mM})$ containing $\mathrm{NaBH}_{3} \mathrm{CN}(250 \mathrm{mM})$ at $37{ }^{\circ} \mathrm{C}$ for $24 \mathrm{~h}$ to generate the full-size cross-linked duplex. Lane 5: Duplex $\mathbf{G}+$ spermine $(1 \mathrm{mM})$ in HEPES buffer $(50 \mathrm{mM}, \mathrm{pH} 7)$ containing $\mathrm{NaCl}(100 \mathrm{mM})$ at $37{ }^{\circ} \mathrm{C}$ for $24 \mathrm{~h}$ (cross-link yield $28 \pm 2 \%)$.

Given the results from the tail hybridization during cross-link formation described above, the question arose if guanine residues on the opposing strand on the downstream of the dRP group could also undergo nucleophilic addition to the dRP site to form additional cross-links. In previously described duplexes, no downstream guanine residues were present. So, we designed a duplex (duplex D) that contained guanine residues downstream of the strand break and subjected it to the standard cross-linking reaction conditions of HEPES (50 mM, pH 7.4), $\mathrm{NaCl}(100 \mathrm{mM})$, spermine $(1 \mathrm{mM}), 37^{\circ} \mathrm{C}$ for $24 \mathrm{~h}$ (Figure 3.4.3). This resulted in multiple slow migrating bands appearing that are consistent with the location of the dG-dRP cross-link described above (Figure 3.4.3, Lane 5). 

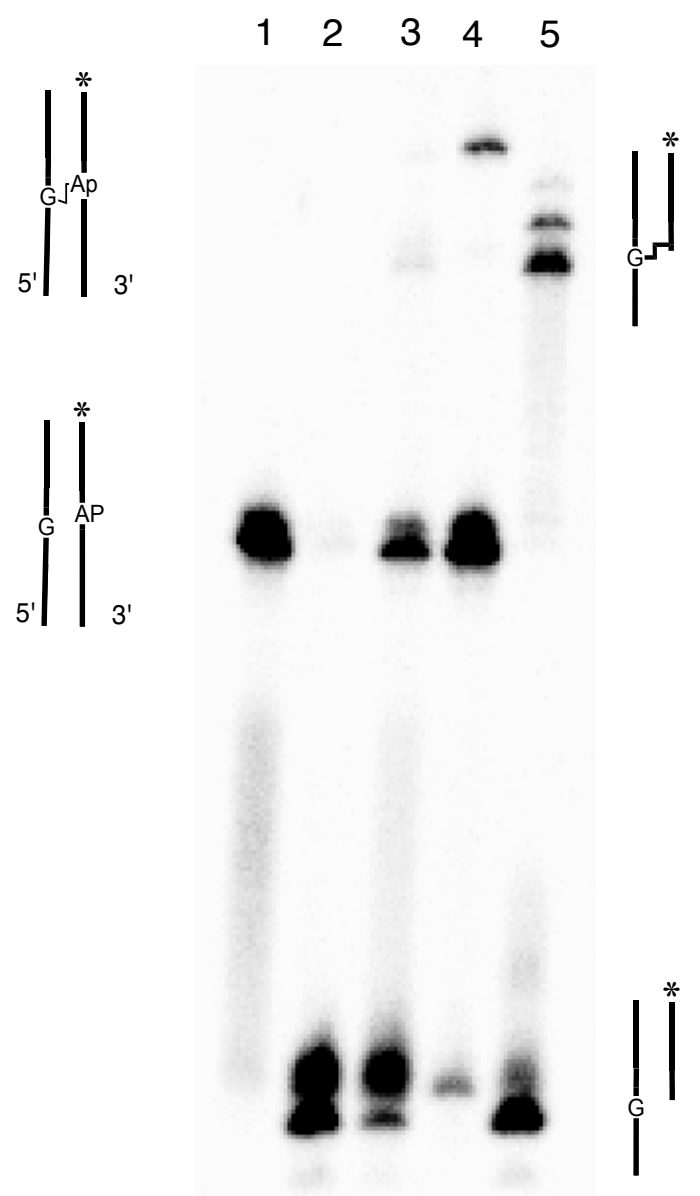

Figure 3.4.3. Formation of the nicked cross-linked duplex F. By incubation of nicked duplex D in HEPES buffer (50 mM, pH 7.4), $\mathrm{NaCl}(100 \mathrm{mM})$, and spermine $(1 \mathrm{mM})$ at $37^{\circ} \mathrm{C}$. Lane 1 , freshly prepared Ap site size marker; Lane 2, Ap containing duplex subjected to $\mathrm{NaOH}$ work-up $\left(165 \mathrm{mM}, 37^{\circ} \mathrm{C}, 30 \mathrm{~min}\right)$; Lane 3 , Ap containing duplex in HEPES (50 $\mathrm{mM}, \mathrm{pH} 7.4)$ and $\mathrm{NaCl}(100 \mathrm{mM})$ at $37^{\circ} \mathrm{C}$ for $24 \mathrm{~h}$; Lane 4, Ap containing duplex in $\mathrm{NaOAc}$ (750 mM, pH 5.2) and $\mathrm{NaCNBH}_{3}(250 \mathrm{mM})$ at $37^{\circ} \mathrm{C}$ for $24 \mathrm{~h}$; Lane 5, Ap containing duplex 
in HEPES (50 mM, pH 7.4), $\mathrm{NaCl}(100 \mathrm{mM})$, and spermine $(1 \mathrm{mM})$ at $37^{\circ} \mathrm{C}$ for $24 \mathrm{~h}$. The 5 '-32 P-labeled oligonucleotides in these reactions were resolved by electrophoresis on a $20 \%$ denaturing polyacrylamide gel and the radioactivity in each band quantitatively measured by phosphorimager analysis.

Consistent with our previous thinking, we asked the question of whether the tail being hybridized to the duplex during cross-link formation affected the ability of the guanine residues downstream to form an interstrand cross-link. To answer this question, duplexes were designed to keep the tails either completely hybridized or unhybridized during cross-link formation (duplexes P \& J respectively). It was shown that when the tail is completely hybridized during cross-link formation in duplex $\mathrm{R}$, the guanine residues downstream are not able to do nucleophilic additions to form interstrand cross-links (Figure 3.4.5, Lane 5). However, when the tail is completely unhybridized during cross-link conditions as in duplex $\mathrm{L}$, the guanine residues downstream are able to undergo nucleophilic addition with the dRP-iminium ion to form interstrand cross-links (Figure 3.4.6, Lane 5). 

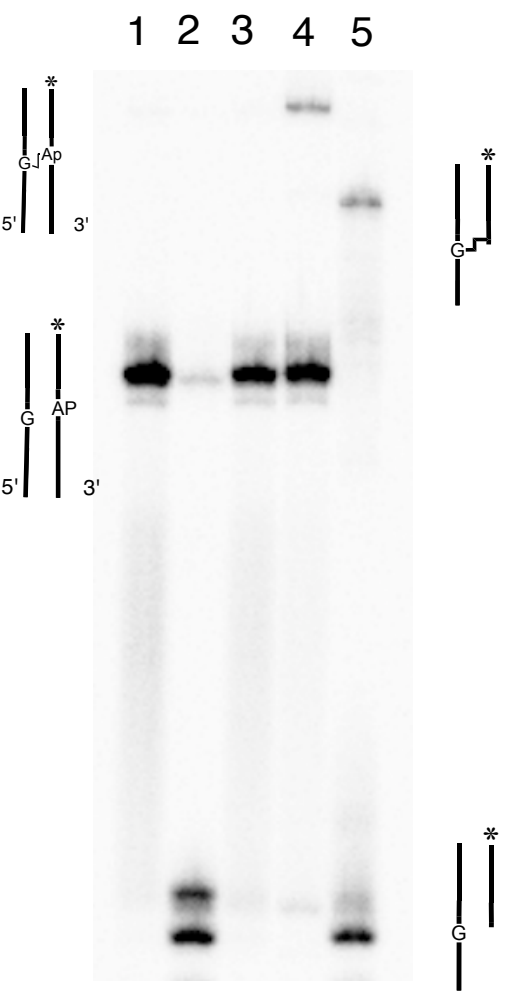

Figure 3.4.5. Formation of the nicked cross-linked duplex R. By incubation of nicked duplex $\mathrm{R}$ in HEPES buffer (50 mM, pH 7.4), $\mathrm{NaCl}(100 \mathrm{mM})$, and spermine (1 mM) at $37^{\circ} \mathrm{C}$. Lane 1 , freshly prepared Ap site size marker; Lane 2, Ap containing duplex subjected to $\mathrm{NaOH}$ work-up $\left(165 \mathrm{mM}, 37^{\circ} \mathrm{C}, 30 \mathrm{~min}\right)$; Lane 3 , Ap containing duplex in HEPES (50 mM, pH 7.4) and $\mathrm{NaCl}(100 \mathrm{mM})$ at $37^{\circ} \mathrm{C}$ for $24 \mathrm{~h}$; Lane 4, Ap containing duplex in NaOAc (750 mM, pH 5.2) and $\mathrm{NaCNBH}_{3}(250 \mathrm{mM})$ at $37^{\circ} \mathrm{C}$ for $24 \mathrm{~h}$; Lane 5, Ap containing duplex in HEPES (50 mM, pH 7.4), $\mathrm{NaCl}(100 \mathrm{mM})$, and spermine (1 $\mathrm{mM}$ ) at $37^{\circ} \mathrm{C}$ for $24 \mathrm{~h}$. The $5^{\prime}{ }^{32} \mathrm{P}$-labeled oligonucleotides in these reactions were resolved by electrophoresis on a $20 \%$ denaturing polyacrylamide gel and the radioactivity in each band quantitatively measured by phosphorimager analysis. 


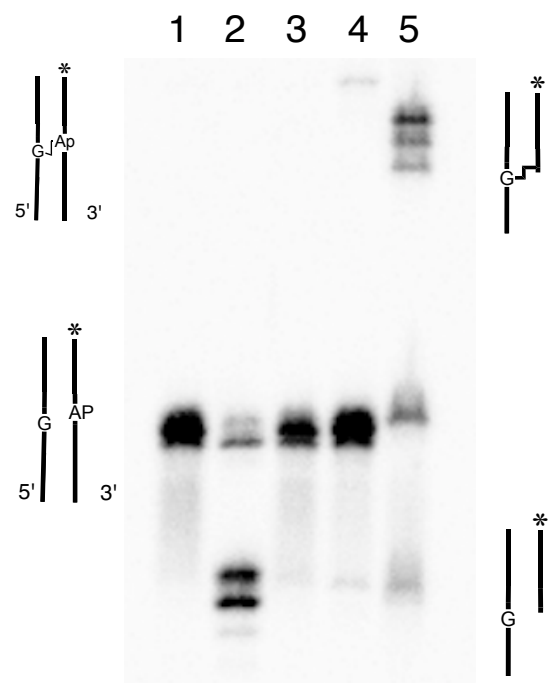

Figure 3.4.6. Formation of the nicked cross-linked duplex L. By incubation of nicked duplex L in HEPES buffer (50 mM, pH 7.4), $\mathrm{NaCl}(100 \mathrm{mM})$, and spermine $(1 \mathrm{mM})$ at $37^{\circ} \mathrm{C}$. Lane 1 , freshly prepared Ap site size marker; Lane 2, Ap containing duplex subjected to $\mathrm{NaOH}$ work-up $\left(165 \mathrm{mM}, 37^{\circ} \mathrm{C}, 30 \mathrm{~min}\right)$; Lane 3 , Ap containing duplex in HEPES (50 $\mathrm{mM}, \mathrm{pH} 7.4)$ and $\mathrm{NaCl}(100 \mathrm{mM})$ at $37^{\circ} \mathrm{C}$ for $24 \mathrm{~h}$; Lane 4, Ap containing duplex in $\mathrm{NaOAc}$ (750 mM, pH 5.2) and $\mathrm{NaCNBH}_{3}(250 \mathrm{mM})$ at $37^{\circ} \mathrm{C}$ for $24 \mathrm{~h}$; Lane 5, Ap containing duplex in HEPES (50 mM, pH 7.4), $\mathrm{NaCl}(100 \mathrm{mM})$, and spermine $(1 \mathrm{mM})$ at $37^{\circ} \mathrm{C}$ for $24 \mathrm{~h}$. The 5'-32 P-labeled oligonucleotides in these reactions were resolved by electrophoresis on a $20 \%$ denaturing polyacrylamide gel and the radioactivity in each band quantitatively measured by phosphorimager analysis. 
We also examined how the cross-linking reaction was affected by different buffers and different amines as potential catalysts to induce strand cleavage at the AP site in duplex A. The cross-linking reactions described above were carried out in HEPES buffer $(50 \mathrm{mM}$, $\mathrm{pH}$ 7.4) containing $\mathrm{NaCl}(100 \mathrm{mM})$ and spermine $(1 \mathrm{mM})$. We found that the yields of spermine-induced ICL formation in Tris- $\mathrm{HCl}(50 \mathrm{mM}, \mathrm{pH}$ 7.4) containing $\mathrm{NaCl}(100 \mathrm{mM})$, sodium phosphate (50 mM, $\mathrm{pH} 7.4)$ containing $\mathrm{NaCl}(100 \mathrm{mM})$, and sodium acetate (750 $\mathrm{mM})$ were comparable $(19 \pm 2 \%, 38 \pm 2 \%$, and $3 \pm 0.2 \%$, respectively) (Figure 3.4.7). Other polyamines such as $N, N^{\prime}$-dimethylethylenediamine $(1 \mathrm{mM})$, putrescine $(1 \mathrm{mM})$, and the tripeptide, Lys-Trp-Lys $(100 \mu \mathrm{M})$ did induce strand cleavage and ICL, generating crosslink yields of $4 \pm 0.3 \%, 1 \pm 0.1 \%$, and $3 \pm 0.5 \%$ respectively) (Figure 3.4 .8 ). Lysine and arginine $(1 \mathrm{mM})$ were relatively ineffective at inducing strand cleavage and ICL formation and did not generate a cross-link (Figure 3.4.8) possibly due to the lack of free ammonium ion associated with the $\mathrm{pH}$ of the solution. 


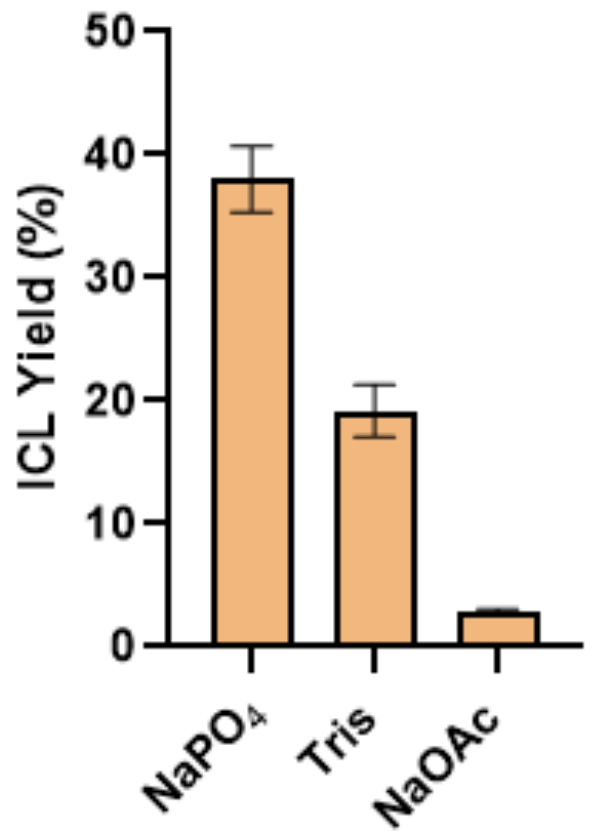

Figure 3.4.7. Interstrand cross-link formation in duplex $A$ in various buffers. 


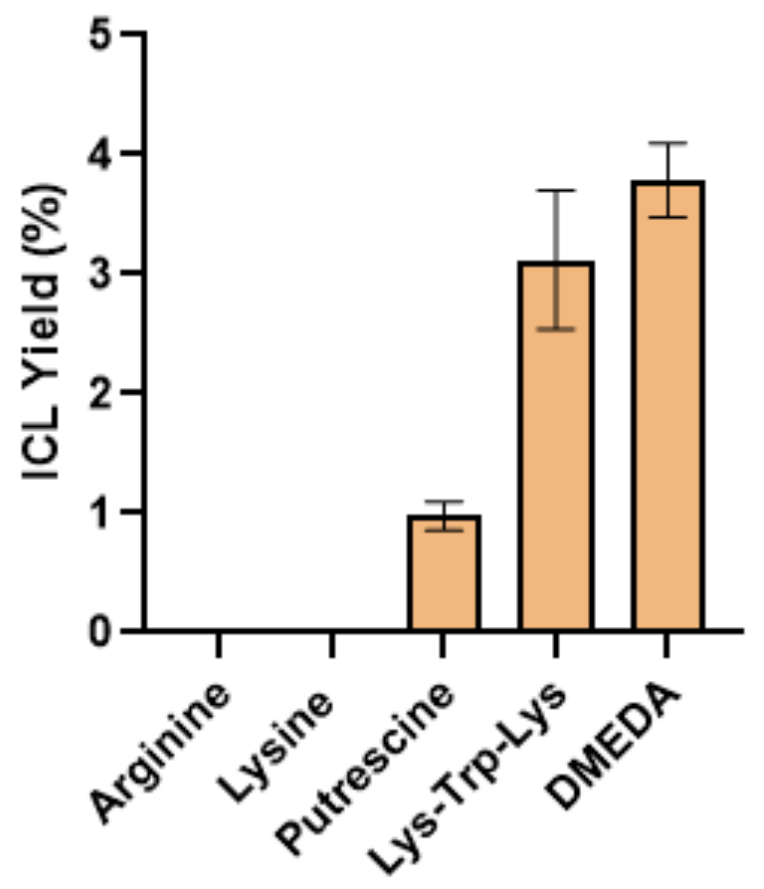

Figure 3.4.8. Interstrand cross-link formation in duplex $\mathrm{A}$ by various amines.

Overall, our results suggest that formation of the dG-dRP ICL arising from aminecatalyzed cleavage of AP sites in duplex DNA occurs under a wide variety of conditions and in many different sequence environments. 


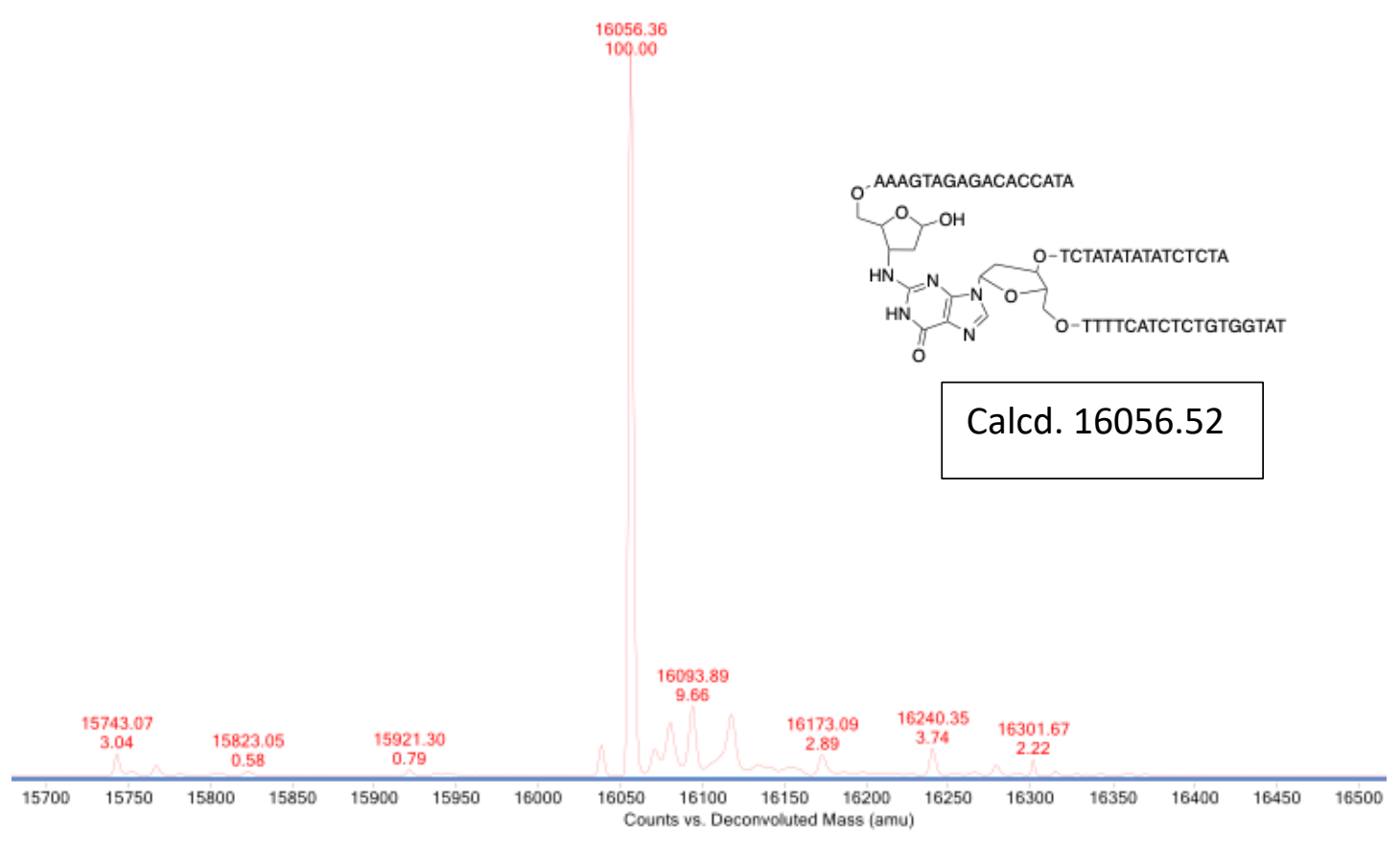

Figure 3.4.9. ESI(-)-QTOF-LC-MS analysis of the cross-linked DNA generated by spermine-mediated cleavage of the AP-containing duplex. Masses shown correspond to the most prominent peak in the isotope envelope. The deconvoluted mass for the most intense signal was $16056.36 \mathrm{amu}$. This result was consistent with a cross-link arising from conjugate addition of a guanine residue to the $\alpha, \beta$-unsaturated strand cleavage product (calcd 16056.52 amu). The major signal (16056.36 amu) was not consistent with an alternate cross-linking product arising from 1,2-addition of a guanine residue to the $\alpha, \beta$ unsaturated cleavage product (calcd 16,038.50 amu). A relatively weak signal at 16,038.34 amu that may correspond to this product was observed. 


\subsection{Conclusion}

Strand breaks at Ap sites in DNA are generated ubiquitously. The result of the strand break generates the reactive 3'dRP lesion. Studies have shown that nucleophilic small molecules can react with this 3'dRP lesion. The work shown in this chapter provides the first evidence of an interstrand cross-link forming from the reaction of an opposing guanine residue (Scheme 3.1.2).

We have shown that the $\mathrm{dG}$-dRP crosslink forms via a reactive 3 'dRP-iminium ion intermediate from the degradation of the Ap site by the polyamine, spermine. This lesion generates a complex lesion, two (or more) modifications located within a 20 base pair (bp) stretch of duplex DNA. Importantly, we provided evidence that the repair of this novel cross-link can be initiated by the base excision repair enzyme, APE1. 


\subsection{Experimental}

Oligonucleotides were purchased from Integrated DNA Technologies (Coralville, IA, USA), $\left[\gamma_{-}{ }^{32} \mathrm{P}\right]-\mathrm{ATP}(6000 \mathrm{Ci} / \mathrm{mmol})$ was purchased from Perkin-Elmer, uracil DNA glycosylase (UDG) were from New England Biolabs (Ipswich, MA, USA), C-18 Sep-Pak cartridges were purchased from Waters (Milford, MA, USA), and BS Poly-prep columns were obtained from BioRad (Hercules, CA, USA), acrylamide/bis-acrlyamide 19:1 (40\% solution, electrophoresis grade) was purchased from Fisher Scientific (Waltham, MA, USA).

\section{Representative procedures for generation of the nicked duplex and its conversion to}

\section{the nicked cross-linked duplex.}

In these experiments, 2'-deoxyuridine-containing oligonucleotides were used as precursors for the enzymatic generation of Ap-containing oligonucleotides. The singlestranded, uracil-containing 2'-deoxy-oligonucleotides were $\alpha$ - $^{32} \mathrm{P}$ 5'-end-labeled using standard procedures, and then annealed to the complimentary strand. The labeled duplex DNA was treated with the UDG (200 units/mL, final concentration) in Tris- $\mathrm{HCl}$ buffer (20 mM, pH 8) containing DTT (1 mM), EDTA (1 mM). After incubation at $37^{\circ} \mathrm{C}$ for 60 min, the UDG enzyme was removed by phenol-chloroform extraction and the DNA ethanol precipitated to remove low molecular weight compounds. The resulting duplex was re-dissolved and incubated in a buffer consisting of HEPES (50 mM, pH 7.4), $\mathrm{NaCl}$ $(100 \mathrm{mM})$, and spermine $(1 \mathrm{mM})$ at $37^{\circ} \mathrm{C}$ for $24 \mathrm{hrs}$. The reaction mixture was then combined with formamide loading buffer and the resulting sample loaded onto a $20 \%$ 
denaturing polyacrylamide gel $(0.4 \mathrm{~mm}$ thick) and the gel electrophoresed for $4 \mathrm{~h}$ at 1600 V. A gel image and the amount of radiolabeled DNA in each band on the gel was obtained by phosphoimager analysis. The formation rate of cross-linked DNA was measured as described above except at specified time points, aliquots were removed and frozen at $-20^{\circ} \mathrm{C}$ prior to gel electrophoresis analysis.

\section{Formation of full-sized cross-link.}

In these experiments, 2'-deoxyuridine-containing oligonucleotides were used as precursors for the enzymatic generation of Ap-containing oligonucleotides. The singlestranded, uracil-containing 2'-deoxy-oligonucleotides were $\alpha-{ }^{32} \mathrm{P}$ 5'-end-labeled using standard procedures, and then annealed to the complimentary strand. The labeled duplex DNA was treated with the UDG (200 units/mL, final concentration) in Tris-HCl buffer (20 mM, pH 8) containing DTT (1 mM), EDTA (1 mM). After incubation at $37^{\circ} \mathrm{C}$ for 60 min, the UDG enzyme was removed by phenol-chloroform extraction and the DNA ethanol precipitated to remove low molecular weight compounds. The resulting duplex was re-dissolved and incubated in a buffer consisting of $\mathrm{NaOAc}(750 \mathrm{mM}, \mathrm{pH} 5.2)$ and $\mathrm{NaCNBH}_{3}(250 \mathrm{mM})$ at $37^{\circ} \mathrm{C}$ for $24 \mathrm{hrs}$. The reaction mixture was then combined with formamide loading buffer and the resulting sample loaded onto a $20 \%$ denaturing polyacrylamide gel $(0.4 \mathrm{~mm}$ thick $)$ and the gel electrophoresed for $4 \mathrm{~h}$ at $1600 \mathrm{~V}$. A gel image and the amount of radiolabeled DNA in each band on the gel was obtained by phosphoimager analysis. 


\section{Reduction of the cross-link in duplex $\mathrm{C}$ by $\mathrm{NaBH}_{4}$}

Duplex DNA containing ${ }^{32} \mathrm{P}-$ labeled, duplex A (Figure 1) was incubated in a buffer composed of HEPES (50 mM, pH 7.0) and $\mathrm{NaCl}(100 \mathrm{mM})$ with $\mathrm{NaBH}_{4}(100 \mathrm{mM})$ at $37^{\circ} \mathrm{C}$ for $4 \mathrm{~h}$. The DNA was then ethanol precipitated, resuspended in formamide loading buffer, and the resulting sample loaded onto a $20 \%$ denaturing polyacrylamide gel $(0.4$ $\mathrm{mm}$ thick) and the gel electrophoresed for $4 \mathrm{~h}$ at $1600 \mathrm{~V}$. A gel image and the amount of radiolabeled DNA in each band on the gel was obtained by phosphoimager analysis.

\section{Enzymatic Digestion}

A $10 \mu \mathrm{L}$ solution containing oligodeoxynucleotides $(50 \mathrm{pmol})$, sodium acetate $(30 \mathrm{mM}$, $\mathrm{pH}$ 5.6), $\mathrm{ZnCl}_{2}(10 \mathrm{mM})$, nuclease $\mathrm{P} 1$ (1 unit), was incubated $37^{\circ} \mathrm{C}$ for $6 \mathrm{~h}$. To the mixture were subsequently added calf intestinal phosphatase $(0.2$ unit $), 4 \mu \mathrm{L}$ of Tris- $\mathrm{HCl}(0.5 \mathrm{M}$, $\mathrm{pH} 8.9$ ), and water to make the total volume of the solution $20 \mu \mathrm{L}$. The digestion mixture was incubated at $37^{\circ} \mathrm{C}$ for $2 \mathrm{~h}$. The enzymes in the digestion mixture were subsequently removed by chloroform extraction. The resulting aqueous layer was dried, reconstituted in doubly distilled water to give a solution of approximately $0.5 \mathrm{pmol} / \mu \mathrm{L}$, and subjected to LC-MS/MS analysis. 


\section{LC-MS/MS and LC-MS/MS/MS Analysis}

A $0.5 \times 250 \mathrm{~mm}$ Zorbax SBC18 column (particle size, $5 \mu \mathrm{m}$, Agilent) was used for the separation of the above digested oligodeoxynucleotides samples, and the flow rate was 8.0 $\mu \mathrm{L} /$ min, which was delivered by using an Agilent 1200 capillary HPLC pump (Agilent Technologies). A solution of $2 \mathrm{mM}$ ammonium bicarbonate ( $\mathrm{pH} 7.0$ ) in water (solution $\mathrm{A}$ ) and methanol (solution B) were used as mobile phases, and a gradient of 5 min $0 \% \mathrm{~B}, 5$ min $0-20 \%$ B and 40 min $20-50 \%$ B was employed for the separation. The effluent from the LC column was directed to an LTQ linear ion-trap mass spectrometer (Thermo Fisher Scientific), which was set up for monitoring the fragmentation of singly protonated $\left([\mathrm{M}+\mathrm{H}]^{+}\right)$ion of the cross-linked dinucleoside remnant in the positive-ion mode.

\section{Iron-EDTA-H $\mathrm{H}_{2} \mathrm{O}_{2}$ footprinting to determine cross-link attachment locations.}

Footprinting was carried out as described previously. In these experiments, the cytosinecontaining strand was 5'-labeled using standard procedures. Labeled DNA was annealed to the uracil-containing complementary strand and treated with UDG to generate the APcontaining duplex described above. The AP-containing duplex ( 500,000 cpm) was incubated either in sodium acetate ( $\mathrm{pH}$ 5) or HEPES ( $\mathrm{pH} 7$ ) buffer for $72 \mathrm{~h}$. The DNA was ethanol precipitated, suspended in formamide loading buffer, and the oligodeoxynucleotides resolved on a $0.4 \mathrm{~mm}$ thick $20 \%$ denaturing polyacrylamide gel. The location of the slow-migrating cross-linked duplex band was visualized using X-ray film, the band excised from the gel, the gel slice crushed, and the gel fragments vortexed in elution buffer $(\mathrm{NaCl}, 200 \mathrm{mM}$; EDTA, $1 \mathrm{mM})$ at room temperature for at least $1 \mathrm{~h}$ to 
extract the DNA. The mixture was filtered through a poly-prep column to remove gel fragments and the filtrate desalted using a C18 Sep-pak column (100 mg size). The resulting solution was evaporated using a Speed-Vac concentrator, the residue redissolved in water $(24 \mu \mathrm{L})$, split evenly into three microcentrifuge tubes, and diluted with $2 \mathrm{x}$ oxidation buffer $(10 \mu \mathrm{L}$ of a solution composed of sodium phosphate, $20 \mathrm{mM}, \mathrm{pH} 7.2$; $\mathrm{NaCl}, 20 \mathrm{mM}$; sodium ascorbate, $2 \mathrm{mM} ; \mathrm{H}_{2} \mathrm{O}_{2}, 1 \mathrm{mM}$ ). To this mixture was added a solution of iron-EDTA $\left(2 \mu \mathrm{L}\right.$, EDTA, $70 \mathrm{mM}$; Fe( $\left.\left(\mathrm{NH}_{4}\right)_{2}\left(\mathrm{SO}_{4}\right)_{2} \bullet 6 \mathrm{H}_{2} \mathrm{O}, 70 \mathrm{mM}\right)$ to start the reaction, the mixture vortexed briefly, and incubated at room temperature for 1,2 , and 3 min before addition of thiourea stop solution $(10 \mu \mathrm{L}$ of a $100 \mathrm{mM}$ solution in water). Hydroxyl radical footprinting reactions, Maxam-Gilbert G, and Maxam-Gilbert A+G reactions were performed on the labeled single-strand to generate marker lanes. The resulting DNA fragments were analyzed using gel electrophoresis as described above.

\section{ESI-QTOF-LC-MS analysis of the cross-linked duplex generated from the AP-}

containing duplex A. LC-MS data were acquired on an Agilent Technologies 6520A Accurate Mass QTOF. Sample was injected onto a C8 trap column (Michrom Bioresources Captrap) at a flow rate of $5 \mu \mathrm{L} / \mathrm{min}$ of $10 \mathrm{mM}$ DMBAA, pH 7.1 over 4 min. and separated by isocratic elution (either $80 \%$ or $42.5 \%$ methanol, $15 \mathrm{mM}$ DMBAA, $\mathrm{pH}$ 7.1) at a flow rate of $0.4 \mu \mathrm{L} / \mathrm{min}$ on a $10 \mathrm{~cm}$ x $75 \mu \mathrm{m} \mathrm{C} 8$ analytical column (fused silica packed with Michrom Bioresources C8, $3.5 \mu \mathrm{m}$ particles). Following the 4 min trap load, separation on the trap/analytical columns continued for $16 \mathrm{~min}$, under isocratic elution conditions. Total run time was $20 \mathrm{~min}$. Mass spectra were acquired using the following parameters: negative-ion mode; VCap $2500 \mathrm{~V}$; mass range 290-3200 m/z; 0.63 
spectra/second; fragmentor at $300 \mathrm{~V}$ ( $250 \mathrm{~V}$ for IDT oligo); internal MS recalibration was achieved using the K/Na adducted Hexakis 1221 Chip Cube High Mass Reference compound ( $\mathrm{m} / \mathrm{z}$ 1279.99). Samples were loaded in sequence as follows: blank (10 mM DMBAA), sample, and blank. Multiply-charged DNA peaks were deconvoluted using the maximum entropy algorithm in Qualitative Analysis software (version B.07.00 Agilent Technologies) with the following parameters: adduct $=$ proton-loss; $\mathrm{m} / \mathrm{z}$ range $=$ $600-1500 \mathrm{~m} / \mathrm{z}$; mass range $=$ expected mass $\pm 2 \mathrm{kDa}$; peak height to calculate mass $=$ $25 \%$. The $\mathrm{m} / \mathrm{z}$ values reported are neutral deconvoluted masses. The cross-linking reaction was carried out as described above. After a $72 \mathrm{~h}$ incubation 20 volumes of ammonium acetate $(2.5 \mathrm{M})$ was added and after $30 \mathrm{~min}$ at room temperature the mixture was and desalted using a C18 Sep-Pak column eluted with HPLC grade methanol and ultrapure, deionized water. 


\section{References}

(1) Crick, F. Central Dogma of Molecular Biology. Nature 1970, 227 (5258), 561-563. https://doi.org/10.1038/227561a0.

(2) Lindahl, T. Instability and Decay of the Primary Structure of DNA. Nature 1993, 362 (6422), 709-715. https://doi.org/10.1038/362709a0.

(3) Gates, K. S. An Overview of Chemical Processes That Damage Cellular DNA: Spontaneous Hydrolysis, Alkylation, and Reactions with Radicals. Chem. Res. Toxicol. 2009, 22 (11), 1747-1760. https://doi.org/10.1021/tx900242k.

(4) De Bont, R.; van Larebeke, N. Endogenous DNA Damage in Humans: A Review of Quantitative Data. Mutagenesis 2004, 19 (3), 169-185.

https://doi.org/10.1093/mutage/geh025.

(5) Chen, H.; Yao, L.; Brown, C.; Rizzo, C. J.; Turesky, R. J. Quantitation of Apurinic/Apyrimidinic Sites in Isolated DNA and in Mammalian Tissue with a Reduced Level of Artifacts. Anal. Chem. 2019, 91 (11), 7403-7410. https://doi.org/10.1021/acs.analchem.9b01351.

(6) Sun, B.; Latham, K. A.; Dodson, M. L.; Lloyd, R. S. Studies on the Catalytic Mechanism of Five DNA Glycosylases: PROBING FOR ENZYME-DNA IMINO INTERMEDIATES (*). J. Biol. Chem. 1995, 270 (33), 19501-19508. https://doi.org/10.1074/jbc.270.33.19501.

(7) Helleday, T.; Eshtad, S.; Nik-Zainal, S. Mechanisms Underlying Mutational Signatures in Human Cancers. Nat. Rev. Genet. 2014, 15 (9), 585-598. https://doi.org/10.1038/nrg3729. 
(8) Friedberg, E. C.; McDaniel, L. D.; Schultz, R. A. The Role of Endogenous and Exogenous DNA Damage and Mutagenesis. Curr. Opin. Genet. Dev. 2004, 14 (1), 5-10. https://doi.org/10.1016/j.gde.2003.11.001.

(9) Kucab, J. E.; Zou, X.; Morganella, S.; Joel, M.; Nanda, A. S.; Nagy, E.; Gomez, C.; Degasperi, A.; Harris, R.; Jackson, S. P.; Arlt, V. M.; Phillips, D. H.; Nik-Zainal, S. A Compendium of Mutational Signatures of Environmental Agents. Cell 2019, 177 (4), 821-836.e16. https://doi.org/10.1016/j.cell.2019.03.001.

(10) McKinnon, P. J. DNA Repair Deficiency and Neurological Disease. Nat. Rev. Neurosci. 2009, 10 (2), 100-112. https://doi.org/10.1038/nrn2559.

(11) Madabhushi, R.; Pan, L.; Tsai, L.-H. DNA Damage and Its Links to Neurodegeneration. Neuron 2014, 83 (2), 266-282. https://doi.org/10.1016/j.neuron.2014.06.034.

(12) Borgesius, N. Z.; de Waard, M. C.; van der Pluijm, I.; Omrani, A.; Zondag, G. C. M.; van der Horst, G. T. J.; Melton, D. W.; Hoeijmakers, J. H. J.; Jaarsma, D.; Elgersma, Y. Accelerated Age-Related Cognitive Decline and Neurodegeneration, Caused by Deficient DNA Repair. J. Neurosci. Off. J. Soc. Neurosci. 2011, 31 (35), 12543-12553. https://doi.org/10.1523/JNEUROSCI.1589-11.2011.

(13) Schumacher, B.; Garinis, G. A.; Hoeijmakers, J. H. J. Age to Survive: DNA Damage and Aging. Trends Genet. TIG 2008, 24 (2), 77-85. https://doi.org/10.1016/j.tig.2007.11.004.

(14) Menck, C. F.; Munford, V. DNA Repair Diseases: What Do They Tell Us about Cancer and Aging? Genet. Mol. Biol. 2014, 37 (1 Suppl), 220-233. 
(15) Hoeijmakers, J. H. J. DNA Damage, Aging, and Cancer. N. Engl. J. Med. 2009, 361 (15), 1475-1485. https://doi.org/10.1056/NEJMra0804615.

(16) Cline, S. D. Mitochondrial DNA Damage and Its Consequences for Mitochondrial Gene Expression. Biochim. Biophys. Acta 2012, 1819 (9-10), 979-991. https://doi.org/10.1016/j.bbagrm.2012.06.002.

(17) Potenski, C. J.; Klein, H. L. How the Misincorporation of Ribonucleotides into Genomic DNA Can Be Both Harmful and Helpful to Cells. Nucleic Acids Res. 2014, 42 (16), 10226-10234. https://doi.org/10.1093/nar/gku773.

(18) Barnes, D. E.; Lindahl, T. Repair and Genetic Consequences of Endogenous DNA Base Damage in Mammalian Cells. Annu. Rev. Genet. 2004, 38, 445-476. https://doi.org/10.1146/annurev.genet.38.072902.092448.

(19) Pham, P.; Bransteitter, R.; Goodman, M. F. Reward versus Risk: DNA Cytidine Deaminases Triggering Immunity and Disease. Biochemistry 2005, 44 (8), 27032715. https://doi.org/10.1021/bi047481+.

(20) Marnett, L. J.; Burcham, P. C. Endogenous DNA Adducts: Potential and Paradox. Chem. Res. Toxicol. 1993, 6 (6), 771-785. https://doi.org/10.1021/tx00036a005.

(21) Tubbs, A.; Nussenzweig, A. Endogenous DNA Damage as a Source of Genomic Instability in Cancer. Cell 2017, 168 (4), 644-656. https://doi.org/10.1016/j.cell.2017.01.002.

(22) Lindahl, T.; Barnes, D. E. Repair of Endogenous DNA Damage. Cold Spring Harb. Symp. Quant. Biol. 2000, 65, 127-133. https://doi.org/10.1101/sqb.2000.65.127. 
(23) Lindahl, T. The Croonian Lecture, 1996: Endogenous Damage to DNA. Philos. Trans. R. Soc. Lond. B. Biol. Sci. 1996, 351 (1347), 1529-1538. https://doi.org/10.1098/rstb.1996.0139.

(24) Lindahl, T. The Intrinsic Fragility of DNA (Nobel Lecture). Angew. Chem. Int. Ed Engl. 2016, 55 (30), 8528-8534. https://doi.org/10.1002/anie.201602159.

(25) Eccles, L. J.; O’Neill, P.; Lomax, M. E. Delayed Repair of Radiation Induced Clustered DNA Damage: Friend or Foe? Mutat. Res. 2011, 711 (1-2), 134-141. https://doi.org/10.1016/j.mrfmmm.2010.11.003.

(26) Georgakilas, A. G.; O’Neill, P.; Stewart, R. D. Induction and Repair of Clustered DNA Lesions: What Do We Know so Far? Radiat. Res. 2013, 180 (1), 100-109. https://doi.org/10.1667/RR3041.1.

(27) Mehta, A.; Haber, J. E. Sources of DNA Double-Strand Breaks and Models of Recombinational DNA Repair. Cold Spring Harb. Perspect. Biol. 2014, 6 (9), a016428. https://doi.org/10.1101/cshperspect.a016428.

(28) Lindahl, T.; Nyberg, B. Rate of Depurination of Native Deoxyribonucleic Acid. Biochemistry 1972, 11 (19), 3610-3618. https://doi.org/10.1021/bi00769a018.

(29) Wilson, D. M.; Takeshita, M.; Grollman, A. P.; Demple, B. Incision Activity of Human Apurinic Endonuclease (Ape) at Abasic Site Analogs in DNA. J. Biol. Chem. 1995, 270 (27), 16002-16007. https://doi.org/10.1074/jbc.270.27.16002.

(30) Whitaker, A. M.; Freudenthal, B. D. APE1: A Skilled Nucleic Acid Surgeon. DNA Repair 2018, 71, 93-100. https://doi.org/10.1016/j.dnarep.2018.08.012. 
(31) Chou, K.-M.; Cheng, Y.-C. An Exonucleolytic Activity of Human Apurinic/Apyrimidinic Endonuclease on 3' Mispaired DNA. Nature 2002, 415 (6872), 655-659. https://doi.org/10.1038/415655a. 


\section{Chapter 4}

\section{Facile synthesis of DNA duplexes containing a chemically-defined, derivatizable, covalent cross-link}

\subsection{Introduction}

DNA is vital to cellular function. ${ }^{1}$ Therefore, maintaining the integrity of the structure of DNA is of utmost importance. Damage to the DNA is unavoidable and can be detrimental to organisms. ${ }^{2,3,4}$ The ability to repair the damage to DNA is paramount to maintain DNA structure and function. ${ }^{5,6,7}$ However, due to the unavoidable and extensive nature of damage to the DNA, DNA repair mechanisms are often complex and not fully understood. Understanding these vital cellular functions is an important area of research and the development of tools that can assist in the area is vital.

Methods for a chemical synthesis of DNA duplexes containing site-specific, chemically-defined interstrand cross-links have potential applications many areas including structural biology. The ability to install a chemically defined, high yielding interstrand cross-link from commercially available reagents with a handle that can be linked with a variety of tags, such as biotin, can be a useful tool to study interactions of proteins with DNA.

In this chapter, I will describe the facile installation of an interstrand DNA crosslink that contains a derivatizable ethylamine "handle" (Scheme 4.1.1). The approach employs reductive amination reactions to cross-link two Ap sites on opposing strands of a DNA duplex with a triamine linker. It is further shown that these cross-linked duplexes can be derivatized with an activated ester to install a biotin tag (Scheme 4.1.1). 


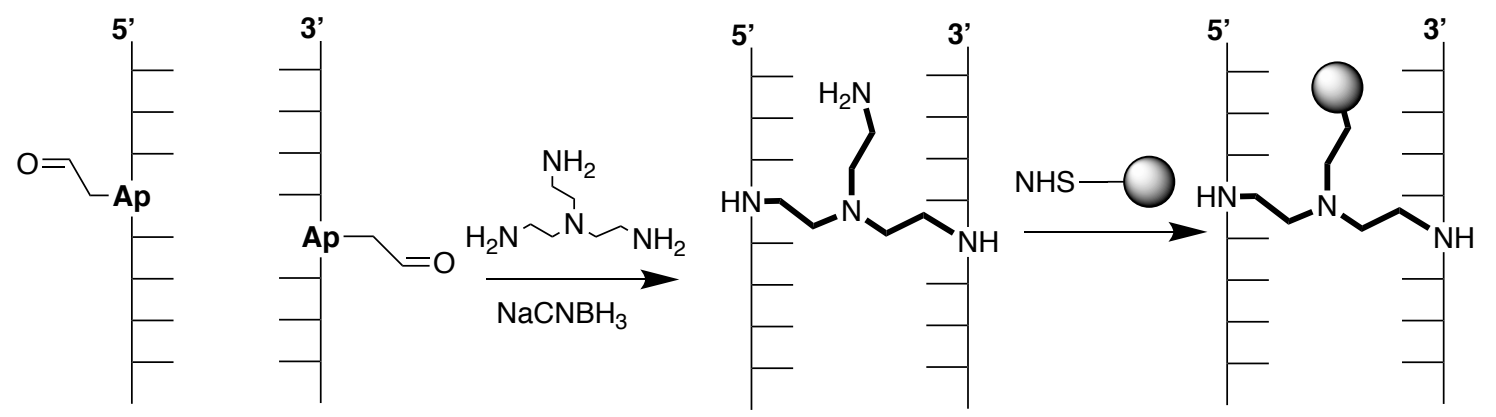

Scheme 4.1.1. Synthesis of a DNA interstrand cross-link containing an ethylamine handle that is tagged with biotin.

\subsection{Interstrand Cross-Link Formation}

$$
\mathbf{X}=\mathbf{A p}
$$

A 5'-ATACCACATAGATGAATXCAGACATATACACAGAT 3' -TATGGTGTATCTACTTAXGTCTGTATATGTGTCTA

B 5'-ATACCACATAGATGATTXCAGACATATACACAGAT $3^{\prime}$-TATGGAGTATCTACTAXCGTCTGTATATGTGTCTA

C 5'-ATACCACATAGATGTTTXCAGACATATACACAGAT $3^{\prime}$-TATGGAGTATCTACAXACGTCTGTATATGTGTCTA

D 5'-ATACCACATAGATGTTTXCAGACATATACACAGAT 3 ' -TATGGAGTATCTACXAACGTCTGTATATGTGTCTA

E 5'-ATACCACCTAGATGTTTXCGTACATATACACAGAT 3' -TATGGAGXATCTACAAACGCATGTATATGTGTCTA

Figure 4.2.1. Duplexes used in this study 


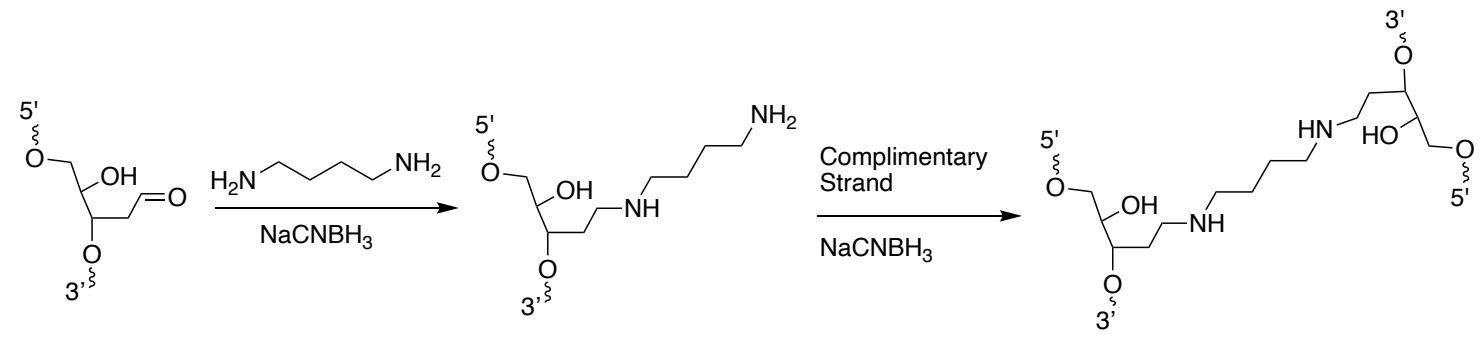

Scheme 4.2.1. Formation of interstrand cross-link with a 1,4-diaminobutane linker.

Forming an interstrand cross-link with an Ap site via reductive amination has been shown by the Gates group with an opposing guanine residue on the complimentary strand. ${ }^{8,9}$ We wanted to synthesize a chemically defined interstrand cross-link using a diamino linker and reductive amination where Ap sites were installed on both strands of DNA that could potentially be used to functionalize the cross-link to install tags onto the cross-link. We first needed to study the effect of how long the linker needed to be which still resulted in a high yield of cross-link and how far apart the opposing Ap sites could be in the oligomer duplex.

The effect of linker length was studied using three different linker lengths: 1,4diaminobutane, 1,5-diaminopentane, and 1,6-diaminohexane (Figure 4.2.2) using duplex B (Figure 4.2.1). All three linker lengths gave fairly similar results with the 1,6diaminohexane giving the lowest percent yield (Figure 4.2.2). Along with the length of the linker, the distance between the opposing Ap sites was important to determine to give 
maximal cross-link yield. Ap sites being directly opposed and offset by 1, 2, 3, and 10 base pairs were studied using the 1,4-diaminobutane linker (Figure 4.2.3). The studies suggested that using the duplex where the Ap sites were offset by one base pair gave the highest percent yield (Figure 4.2.3).

\section{Effect of Linker on Cross-Link Yield}

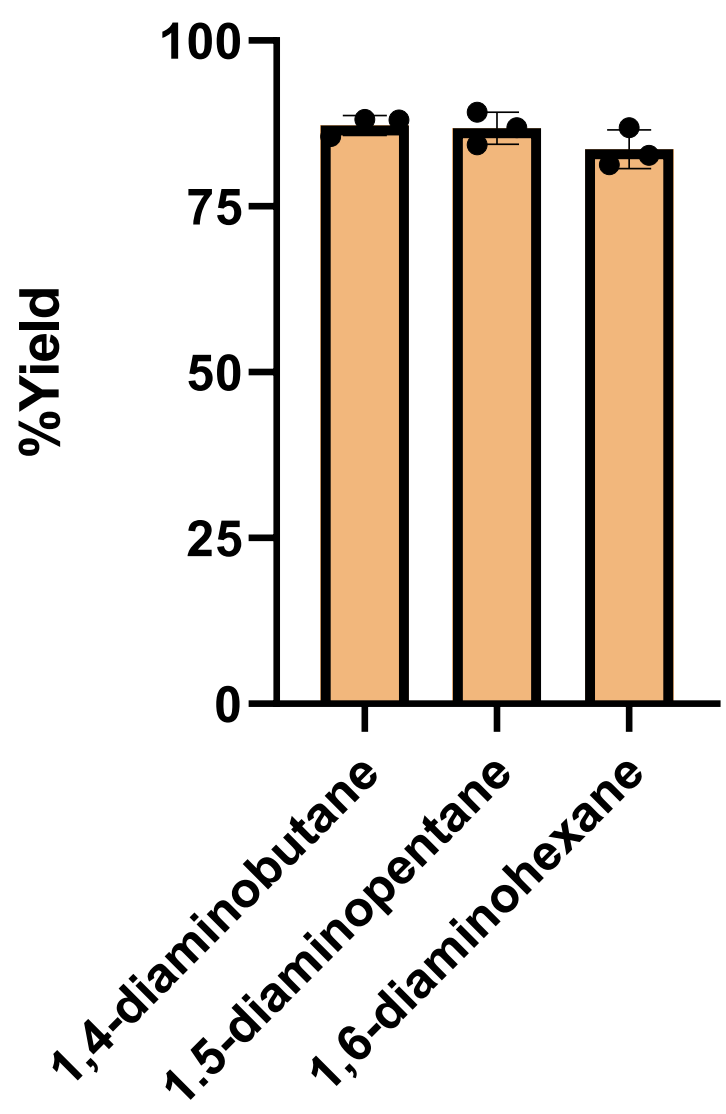

Figure 4.2.2. Effect of linker size on cross-link formation. 


\section{Efffect of Cross-Link Yield with 1,4-diaminobutane by Distance Between Ap Sites}

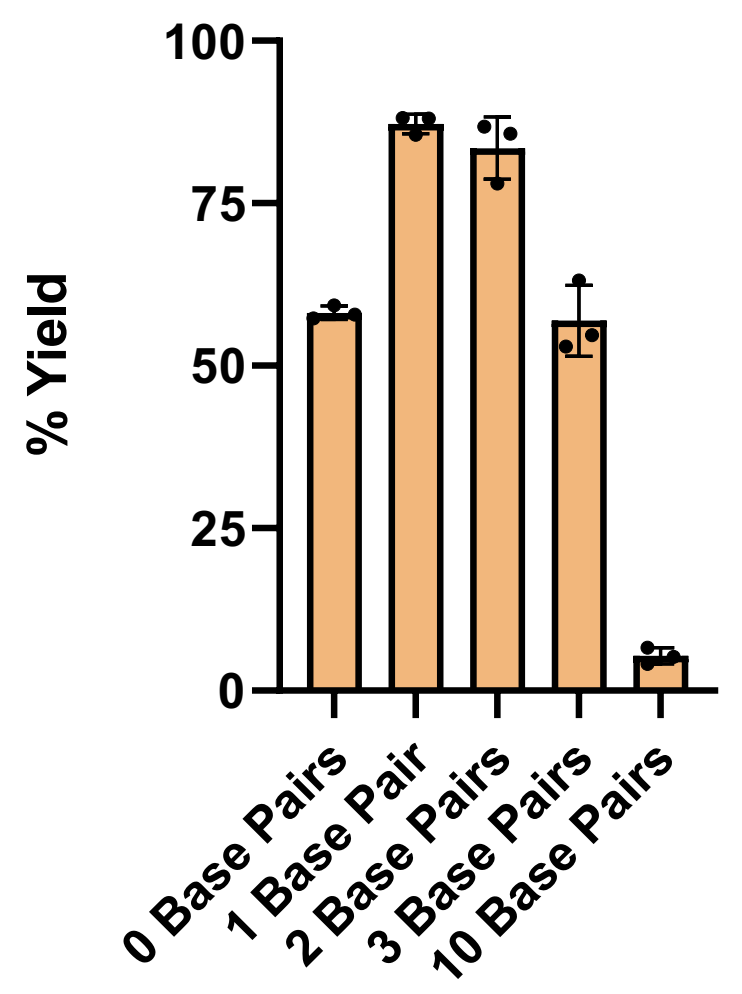

Figure 4.2.3. Effect of Distance between opposing Ap sites on cross-link formation.

The cross-link formation with 1,4-diaminobutane and using duplex B where the Ap sites are offset by one base pair is shown in Figure 4.2.4. Lane 1 is the single stranded Ap site size marker. Lane 2 is a piperidine work-up to show where single strand cleavage site size marker. Lane 3 is the single stranded Ap site treated with 1,4-diaminobutane in reductive amination conditions $\left(250 \mathrm{mM} \mathrm{NaCNBH}_{3}\right)$ to show the monoadduct. Lane 4 is 
cross-linking conditions where the complimentary strand with the Ap site installed under reductive amination conditions $(250 \mathrm{mM} \mathrm{NaCNBH} 3)$ to give the slow migrating crosslink band. 


\section{4}
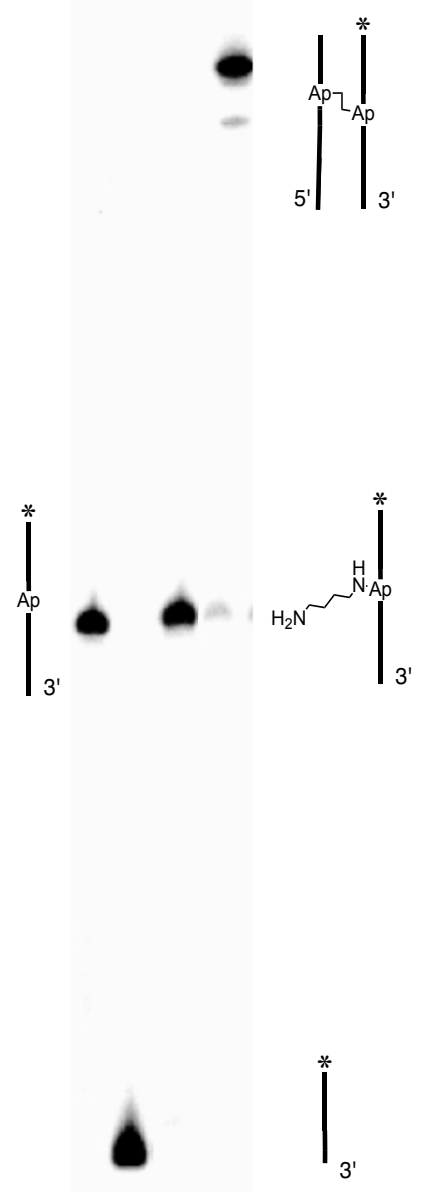

Figure 4.2.4. Formation of the cross-linked duplex. By incubation of duplex B with the 1,4-diaminobutane linker in HEPES buffer (50 mM, pH 7.4), $\mathrm{NaCl}(100 \mathrm{mM})$, and $\mathrm{NaCNBH}_{3}(250 \mathrm{mM})$ at $37^{\circ} \mathrm{C}$. Lane 1, freshly prepared Ap site size marker; Lane 2, Ap containing duplex subjected to piperidine work-up ( $\left.1 \mathrm{M}, 95^{\circ} \mathrm{C}, 25 \mathrm{~min}\right)$; Lane 3; single strand with Ap site with the 1,4-diaminobutane linker in HEPES buffer (50 mM, pH 7.4), $\mathrm{NaCl}(100 \mathrm{mM})$, and $\mathrm{NaCNBH}_{3}(250 \mathrm{mM})$ at $37^{\circ} \mathrm{C}$ for 12 hours; Lane 4; single strand with the 1,4-diaminobutane linker with the Ap-containing 
complimentary strand in HEPES buffer (50 mM, pH 7.4), $\mathrm{NaCl}(100 \mathrm{mM})$, and $\mathrm{NaCNBH}_{3}(250 \mathrm{mM})$ at $37^{\circ} \mathrm{C}$ for 24 hours. The $5^{\prime}-{ }^{32} \mathrm{P}$-labeled oligonucleotides in these reactions were resolved by electrophoresis on a $20 \%$ denaturing polyacrylamide gel and the radioactivity in each band quantitatively measured by phosphorimager analysis.

Analysis of the 1,4-diaminobutane interstrand cross-link with duplex B by Nanospray ESI(-)-MS revealed a major signal at 21311.82 amu (Figure 4.2.5). This result combined with the PAGE analysis above allowed us to suggest a reasonable structure for the interstrand cross-link (Figure 4.2.5). 


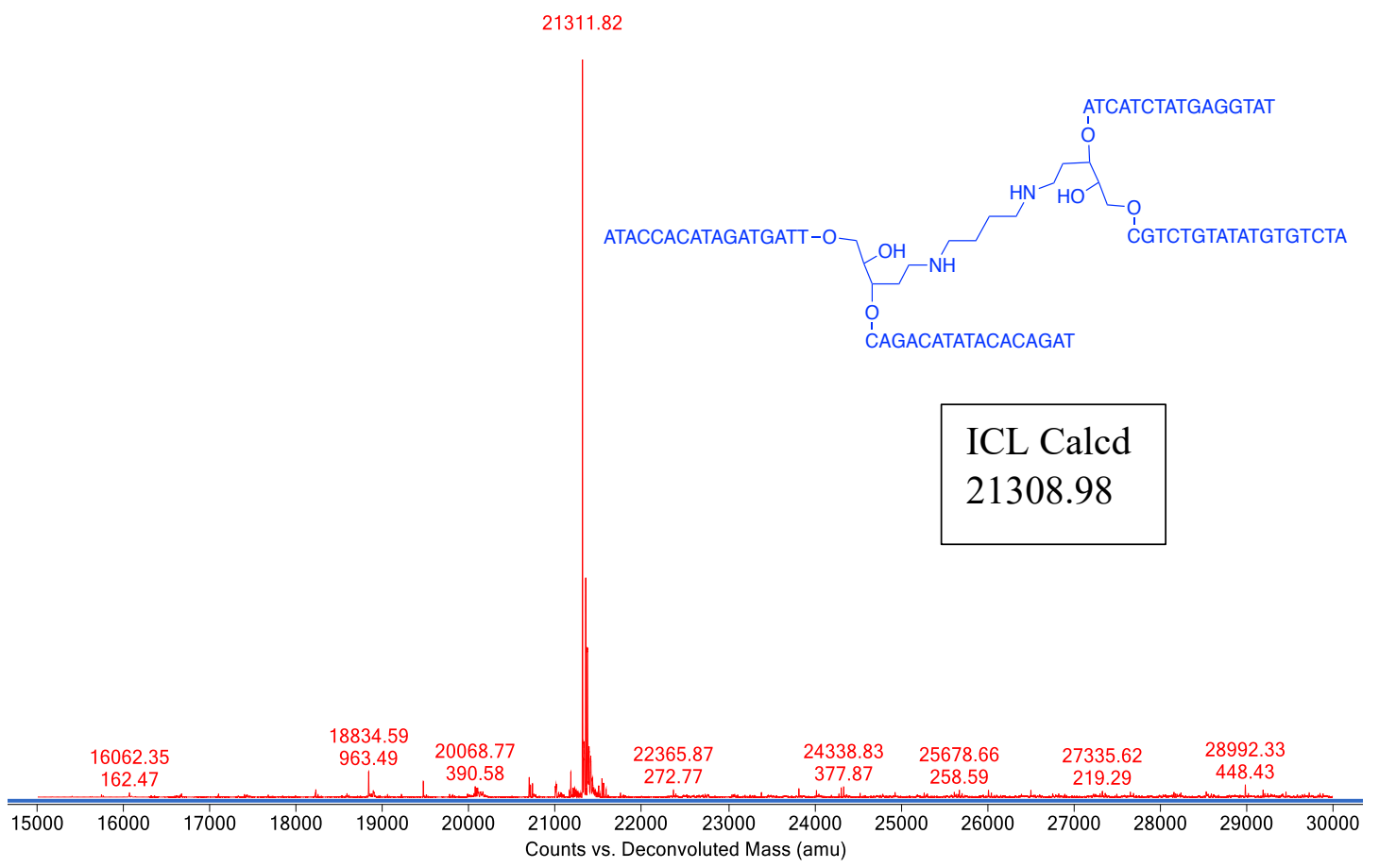

Figure 4.2.5. ESI(-)-TOF-MS analysis of the 1,4-diaminobutane interstrand cross-

link. Masses shown correspond to the most prominent peak in the isotope envelope for each species. Calculated molecular mass for the cross-link is $21308.98 \mathrm{amu}$. 


\subsection{Cross-Link Formation with Derivatizable Amino Handle}

Once it was confirmed that an interstrand cross-link can be formed with opposing Ap sites, we wanted to functionalize the cross-link by adding a nucleophilic 'handle' to the cross-link that we could derivatize. It was important for the new linker to by symmetric so the cross-link structure is defined. We determined that the Tris(2aminoethyl)amine linker would be feasible as it is symmetric and commercially available with a good nucleophilic 'handle' that could be functionalized down the line (Scheme 4.3.1).
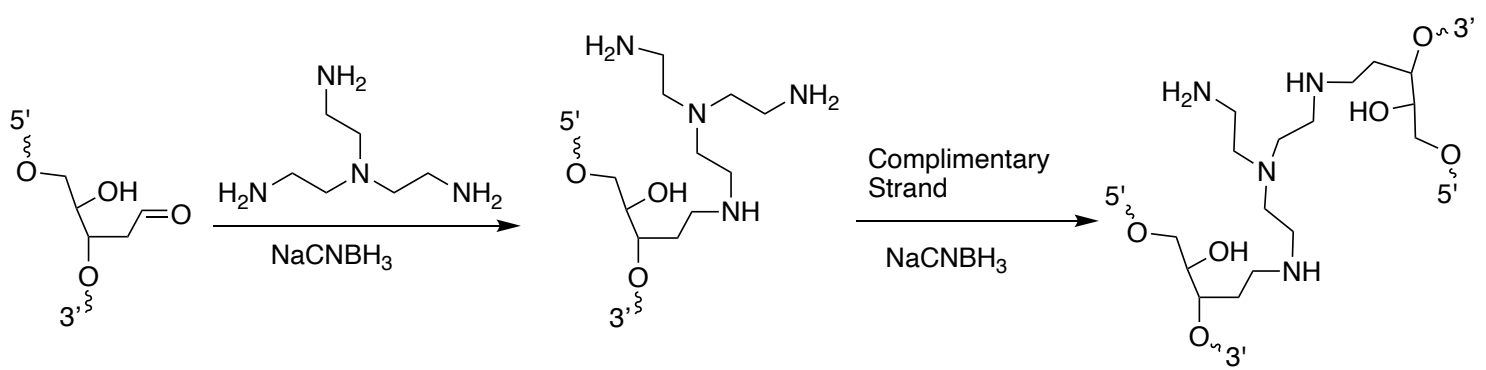

Scheme 4.3.1. Synthesis of an interstrand cross-link containing the tris(2aminoethyl)amine linker 
The cross-link formation with the tris(2-aminoethyl)amine linker and duplex B where the Ap sites are offset by one base pair is shown in Figure 4.3.1. Lane 1 is the single stranded Ap site size marker. Lane 2 is a piperidine work-up to show single strand cleavage site size marker. Lane 3 is the single stranded Ap site treated with tris(2aminoethyl)amine in reductive amination conditions $\left(250 \mathrm{mM} \mathrm{NaCNBH}_{3}\right)$ to show the monoadduct. Lane 4 is cross-linking conditions where the complimentary strand with the Ap site installed under reductive amination conditions $(250 \mathrm{mM} \mathrm{NaCNBH}$ ) to give the slow migrating cross-link band. 

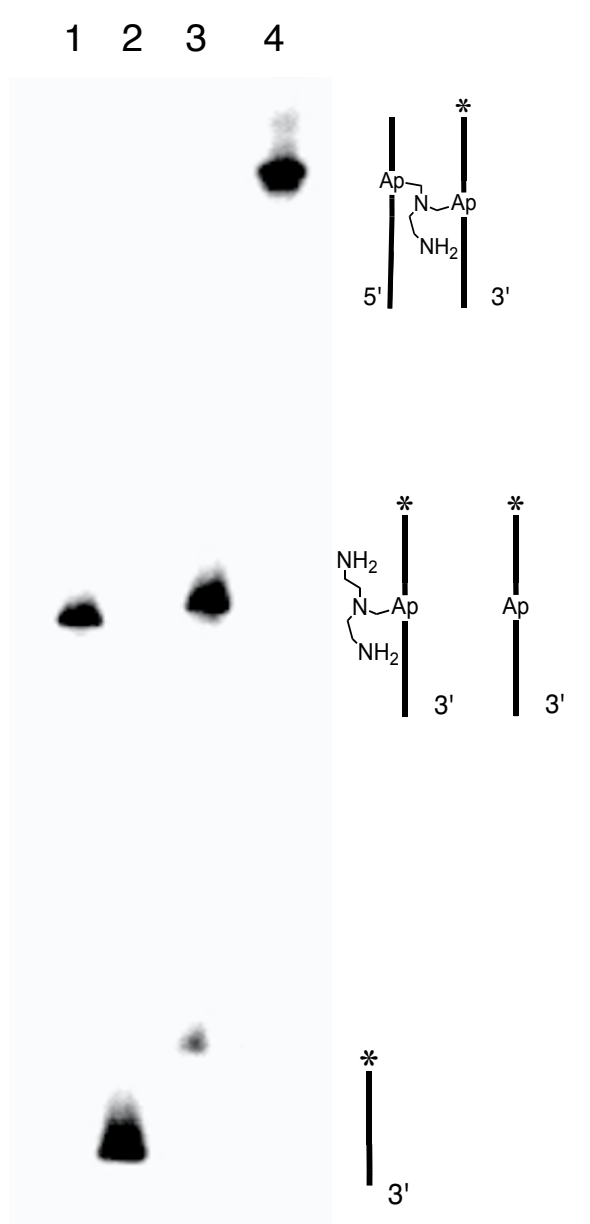

Figure 4.3.1. Formation of the cross-linked duplex. By incubation of duplex B the Tris(2-aminoethyl)amine linker in HEPES buffer (50 mM, pH 7.4), $\mathrm{NaCl}(100 \mathrm{mM})$, and $\mathrm{NaCNBH}_{3}(250 \mathrm{mM})$ at $37^{\circ} \mathrm{C}$. Lane 1, freshly prepared Ap site size marker; Lane 2, Ap containing duplex subjected to piperidine work-up ( $\left.1 \mathrm{M}, 95^{\circ} \mathrm{C}, 25 \mathrm{~min}\right)$; Lane 3; single stranded Ap with Tris(2-aminoethyl)amine linker in HEPES buffer (50 mM, $\mathrm{pH}$ 7.4), $\mathrm{NaCl}(100 \mathrm{mM})$, and $\mathrm{NaCNBH}_{3}(250 \mathrm{mM})$ at $37^{\circ} \mathrm{C}$ for 12 hours; Lane 4; duplex B with Tris(2-aminoethyl)amine linker and the Ap-containing complimentary strand in HEPES buffer (50 mM, pH 7.4), $\mathrm{NaCl}(100 \mathrm{mM})$, and $\mathrm{NaCNBH}_{3}(250 \mathrm{mM})$ 
at $37^{\circ} \mathrm{C}$ for 24 hours. The $5^{\prime}-{ }^{32} \mathrm{P}$-labeled oligonucleotides in these reactions were resolved by electrophoresis on a $20 \%$ denaturing polyacrylamide gel and the radioactivity in each band quantitatively measured by phosphorimager analysis.

Analysis of the tris(2-aminoethyl)amine interstrand cross-link with duplex B by Nanospray ESI(-)-MS revealed a major signal at 21369.78 amu (Figure 4.3.2). This result combined with the PAGE analysis above allowed us to suggest a reasonable structure for the interstrand cross-link (Figure 4.3.2).

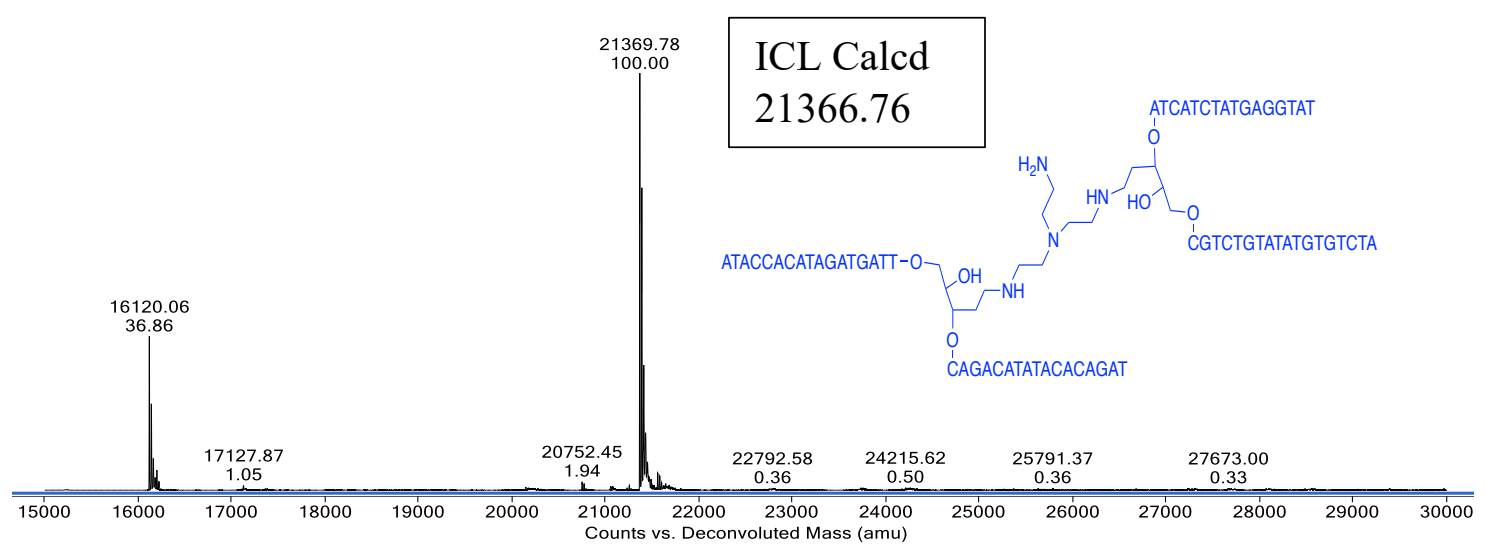

Figure 4.3.2. ESI(-)-TOF-MS analysis of the tris(2-aminoethyl)amine interstrand cross-link. Masses shown correspond to the most prominent peak in the isotope envelope for each species. Calculated molecular mass for the cross-link is $21366.76 \mathrm{amu}$. 


\subsection{Conjugating a Biotin Tag onto the Interstrand Cross-Link}

Once the interstrand cross-link using the Tris(2-aminoethyl)amine linker was confirmed we wanted to work on using the nucleophilic amine handle to add tags to the cross-link. To test the ability to add a 'tag' to the cross-link to the nucleophilic amino handle, we decided to test the hypothesis using a biotin NHS ester molecule to add to the cross-link (Scheme 4.4.1). Once the cross-link was synthesized, it was incubated with the NHS ester biotin tag. Analysis of the biotin tagged Tris(2aminoethyl)amine interstrand cross-link with duplex B by Nanospray ESI(-)-MS revealed a major signal at 21843.85 amu (Figure 4.4.1). This result allowed us to suggest a reasonable structure for the biotin tagged interstrand cross-link (Figure 4.4.1). 


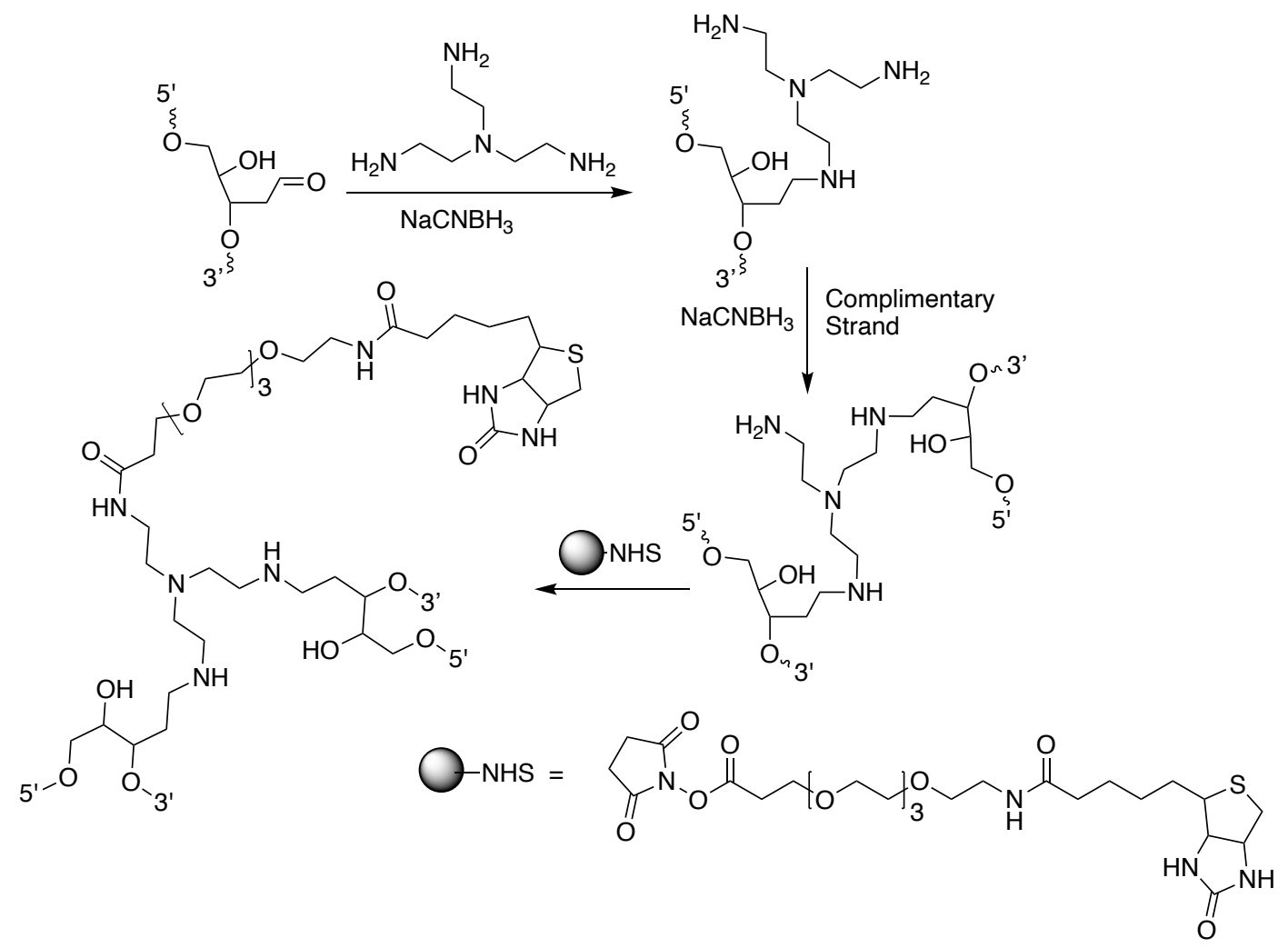

Scheme 4.4.1. Formation of interstrand cross-link with a tris(2-aminoethyl)amine

linker and subsequent formation of interstrand cross-link with a biotin label. 


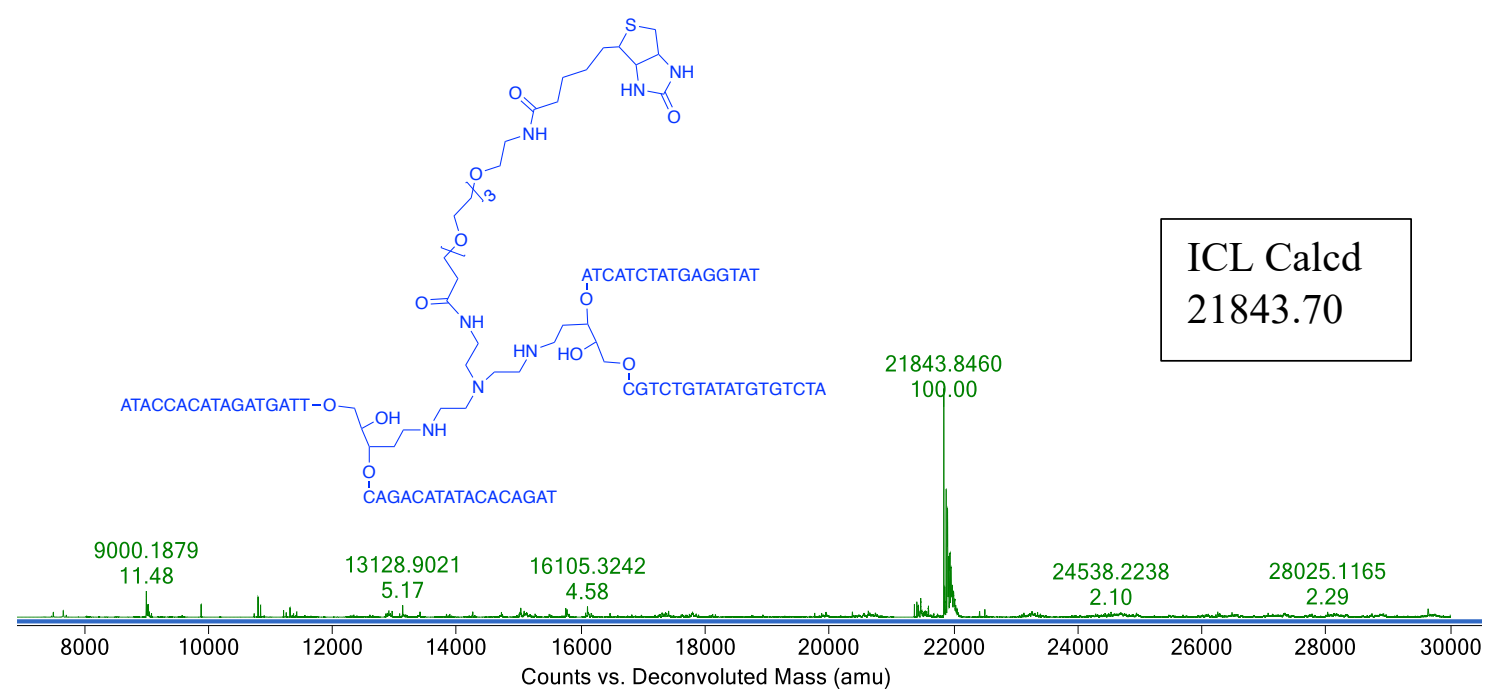

Figure 4.4.1. ESI(-)-TOF-MS analysis of the biotin tagged Tris(2-aminoethyl)amine interstrand cross-link. Masses shown correspond to the most prominent peak in the isotope envelope for each species. Calculated molecular mass for the cross-link is $21843.70 \mathrm{amu}$.

Biotin has a strong affinity for the protein, streptavidin. Streptavidin's affinity for biotin is one of the strongest non-covalent bonds in nature due to the many non-covalent interactions between streptavidin and biotin. ${ }^{10,11,12}$ To help confirm the biotin labeled cross-link described above, a pull down assay was designed to test the biotin labeled cross-links affinity for streptavidin. Once the biotin labeled cross-link was synthesized, the cross-link was incubated with streptavidin. The results of which are shown in Figure 4.4.2. In lane 1 is the cross-linked duplex size marker. In lane 2 is the cross-linked duplex 
treated with streptavidin. In lane 3 is the biotin containing cross-linked duplex size marker. In lane 4 is the biotin containing cross-linked duplex with streptavidin.

$\begin{array}{llll}1 & 2 & 3 & 4\end{array}$

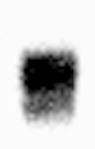

Figure 4.4.2. Pulldown of biotin containing cross-linked duplex B with streptavidin.

Lane 1, cross-linked duplex B size marker; Lane 2, cross-linked duplex B treated with streptavidin (5.68 nanomoles) at $37^{\circ} \mathrm{C}$ for 12 hours; Lane 3, biotin containing crosslinked duplex B size marker; Lane 4, biotin containing cross-linked duplex B with streptavidin (5.68 nanomoles) at $37^{\circ} \mathrm{C}$ for 12 hours. The $5^{\prime}-{ }^{32} \mathrm{P}$-labeled oligonucleotides in these reactions were resolved by electrophoresis on a $10 \%$ non-denaturing polyacrylamide gel and the radioactivity in each band quantitatively measured by phosphorimager analysis. 


\subsection{Conclusions}

DNA is a highly complex and vital macromolecule. Due to the complexity, interactions with proteins and other molecules are not fully understood. The results described above identified a high yielding, chemically defined, site specific, interstrand cross-link with the ability to tag biotin onto the cross-link.

Incubation of the dU containing strands with UDG allowed us to install the Ap sites on both strand of DNA and the use of reductive amination allowed us to install various amine linkers and synthesize the interstrand cross-link. These amine linkers were then utilized to install a biotin tag through the use of NHS ester biotin.

Overall, our findings revealed that the Ap-Ap cross-link is high yielding and can be used to install tags using the click chemistry of NHS-ester molecules that can be used to do pull-down assays with proteins- which could potentially be an important tool for studying DNA-protein interactions. 


\subsection{Experimental}

Oligonucleotides were purchased from Integrated DNA Technologies (Coralville, IA, USA $),\left[\gamma^{32} \mathrm{P}\right]$-ATP $(6000 \mathrm{Ci} / \mathrm{mmol})$ was purchased from Perkin-Elmer, uracil DNA glycosylase (UDG) were from New England Biolabs (Ipswich, MA, USA), C-18 Sep-Pak cartridges were purchased from Waters (Milford, MA, USA), and BS Poly-prep columns were obtained from BioRad (Hercules, CA, USA), acrylamide/bis-acrlyamide 19:1 (40\% solution, electrophoresis grade) was purchased from Fisher Scientific (Waltham, MA, USA), all other chemical reagents were purchased from Sigma-Aldrich (St. Louis, MO, USA).

\section{Representative procedures for generation of cross-linked duplex containing a 1,4- diaminobutane linker.}

In these experiments, 2'-deoxyuridine-containing oligonucleotides were used as precursors for the enzymatic generation of Ap-containing oligonucleotides. The singlestranded, uracil-containing 2'-deoxy-oligonucleotides were $\alpha-{ }^{32} \mathrm{P} 5$ '-end-labeled using standard procedures. The labeled single stranded DNA was treated with the UDG (200 units/mL, final concentration) in Tris- $\mathrm{HCl}$ buffer $(20 \mathrm{mM}, \mathrm{pH}$ 8) containing DTT (1 $\mathrm{mM})$, EDTA $(1 \mathrm{mM})$. After incubation at $37^{\circ} \mathrm{C}$ for $2 \mathrm{~h}$, the UDG enzyme was removed by phenol-chloroform extraction and the DNA ethanol precipitated to remove low molecular weight compounds. The resulting Ap containing single strand was re-dissolved and incubated in a buffer consisting of HEPES (50 mM, pH 7.4), $\mathrm{NaCl}(100 \mathrm{mM}), 1,4-$ diaminobutane $(10 \mathrm{mM})$ and $\mathrm{NaCNBH}_{3}(250 \mathrm{mM})$ at $37^{\circ} \mathrm{C}$ for $12 \mathrm{hrs}$. The unlabeled complimentary strand was treated with UDG (200 units/mL, final concentration) in Tris- 
$\mathrm{HCl}$ buffer (20 mM, pH 8) containing DTT (1 mM), EDTA (1 mM). After incubation for $2 \mathrm{hr}$, the UDG enzyme was removed by by phenol-chloroform extraction and the DNA ethanol precipitated to remove low molecular weight compounds. The labeled linker containing single strand was incubated with the unlabeled, Ap-containing complimentary strand in HEPES (50 mM, pH 7.4), $\mathrm{NaCl}(100 \mathrm{mM})$, and $\mathrm{NaCNBH}_{3}(250 \mathrm{mM})$ at $37^{\circ} \mathrm{C}$ for $24 \mathrm{~h}$.

The reaction mixture was then combined with formamide loading buffer and the resulting sample loaded onto a $20 \%$ denaturing polyacrylamide gel ( $0.4 \mathrm{~mm}$ thick $)$ and the gel electrophoresed for $4 \mathrm{~h}$ at $1600 \mathrm{~V}$. A gel image and the amount of radiolabeled DNA in each band on the gel was obtained by phosphoimager analysis.

\section{Representative procedures for generation of cross-linked duplex containing a} triamino linker.

In these experiments, 2'-deoxyuridine-containing oligonucleotides were used as precursors for the enzymatic generation of Ap-containing oligonucleotides. The single-

stranded, uracil-containing 2'-deoxy-oligonucleotides were $\alpha-{ }^{32} \mathrm{P} 5$ '-end-labeled using standard procedures. The labeled single stranded DNA was treated with the UDG (200 units/mL, final concentration) in Tris- $\mathrm{HCl}$ buffer $(20 \mathrm{mM}, \mathrm{pH} 8)$ containing DTT (1 $\mathrm{mM})$, EDTA $(1 \mathrm{mM})$. After incubation at $37^{\circ} \mathrm{C}$ for $2 \mathrm{~h}$, the UDG enzyme was removed by phenol-chloroform extraction and the DNA ethanol precipitated to remove low molecular weight compounds. The resulting Ap containing single strand was re-dissolved and incubated in a buffer consisting of HEPES (50 mM, pH 7.4), $\mathrm{NaCl}(100 \mathrm{mM})$, Tris(2- 
aminoethyl)amine $(10 \mathrm{mM})$ and $\mathrm{NaCNBH}_{3}(250 \mathrm{mM})$ at $37^{\circ} \mathrm{C}$ for $12 \mathrm{hrs}$. The unlabeled complimentary strand was treated with UDG (200 units/mL, final concentration) in Tris$\mathrm{HCl}$ buffer (20 mM, pH 8) containing DTT (1 mM), EDTA (1 mM). After incubation for $2 \mathrm{hr}$, the UDG enzyme was removed by by phenol-chloroform extraction and the DNA ethanol precipitated to remove low molecular weight compounds. The labeled linker containing single strand was incubated with the unlabeled, Ap-containing complimentary strand in HEPES (50 mM, pH 7.4), $\mathrm{NaCl}(100 \mathrm{mM})$, and $\mathrm{NaCNBH}_{3}(250 \mathrm{mM})$ at $37^{\circ} \mathrm{C}$ for $24 \mathrm{~h}$.

The reaction mixture was then combined with formamide loading buffer and the resulting sample loaded onto a $20 \%$ denaturing polyacrylamide gel ( $0.4 \mathrm{~mm}$ thick $)$ and the gel electrophoresed for $4 \mathrm{~h}$ at $1600 \mathrm{~V}$. A gel image and the amount of radiolabeled DNA in each band on the gel was obtained by phosphoimager analysis.

\section{Representative procedures for generation of cross-linked duplex containing a triamino linker and a biotin handle.}

The cross-linked duplex with a trimamino linker was synthesized as described above and The resulting cross-lin $(\sim 500,000 \mathrm{cpm})$ were ethanol precipitated, resuspended in formamide loading buffer, and resolved on a $2 \mathrm{~mm}$ thick $20 \%$ denaturing polyacrylamide gel. The cross-linked duplex band was visualized using X-ray film, the band excised from the gel, the gel slice crushed, and the gel pieces vortex-mixed in a buffer composed of HEPES (50 mM, pH 7.4) containing $\mathrm{NaCl}(100 \mathrm{mM})$ at room temperature for $1 \mathrm{~h}$. The mixture was filtered through a Poly-Prep column to remove gel fragments and the DNA ethanol precipitated. 
Biotin NHS ester $(3 \mathrm{mM})$ was reacted with the cross-linked oligonucleotide overnight at $4^{\circ} \mathrm{C}$ in sodium bicarbonate buffer $(12.5 \mathrm{mM}, \mathrm{pH} 8.0)$. The reaction mixture was then ethanol precipitated.

\section{Representative procedures for generation of cross-linked duplex containing a triamino linker and a biotin handle with a streptavidin assay.}

The cross-linked duplex with a trimamino linker with a biotin handle was synthesized as described above. The cross-linked oligonucleotide with the biotin handle was reacted with streptavidin (5.68 nanomoles) and reacted overnight at $37^{\circ} \mathrm{C}$. The reaction mixture was then combined with formamide loading buffer and the resulting sample loaded onto a $10 \%$ non-denaturing polyacrylamide ( $2 \mathrm{~mm}$ thick) and the gel electrophoresed for $2 \mathrm{~h}$ at $200 \mathrm{~V}$. A gel image and the amount of radiolabeled DNA in each band on the gel was obtained by phosphoimager analysis.

\section{ESI-QTOF-LC-MS analysis of the Oligonucleotides.}

LC-MS data were acquired on an Agilent Technologies 6520A Accurate Mass QTOF. Samples were analyzed according to the protocol of Studzinska and Buszewski, ${ }^{40}$ with slight modifications as outlined. Sample was injected onto a C8 trap column (Michrom Bioresources Captrap) at a flow rate of $5 \mu \mathrm{L} / \mathrm{min}$ of $10 \mathrm{mM}$ DMBAA, $\mathrm{pH} 7.1$ over $4 \mathrm{~min}$. and separated by isocratic elution (either $80 \%$ or $42.5 \%$ methanol, $15 \mathrm{mM}$ DMBAA, $\mathrm{pH} 7.1$ ) at a flow rate of $0.4 \mu \mathrm{L} / \mathrm{min}$ on a $10 \mathrm{~cm} \times 75 \mu \mathrm{m} \mathrm{C} 8$ analytical column (fused silica packed with Michrom Bioresources C8, $3.5 \mu \mathrm{m}$ particles). Following the 4 min trap load, separation on the trap/analytical columns continued for 16 min, under 
isocratic elution conditions. Total run time was $20 \mathrm{~min}$. Mass spectra were acquired using the following parameters: negative-ion mode; VCap $2500 \mathrm{~V}$; mass range 290-3200 $\mathrm{m} / \mathrm{z} ; 0.63 \mathrm{spectra} / \mathrm{sec}$ d ; fragmentor at $300 \mathrm{~V}$ ( $250 \mathrm{~V}$ for IDT oligo); internal MS recalibration was achieved using the K/Na adducted Hexakis 1221 Chip Cube High Mass Reference compound ( $\mathrm{m} / \mathrm{z}$ 1279.99). Samples were loaded in sequence as follows: blank (10 mM DMBAA), sample, and blank. Multiply-charged DNA peaks were deconvoluted using the maximum entropy algorithm in Qualitative Analysis software (version B.07.00 Agilent Technologies) with the following parameters: adduct $=$ proton-loss; $\mathrm{m} / \mathrm{z}$ range $=$ $600-1500 \mathrm{~m} / \mathrm{z}$; mass range $=$ expected mass $\pm 2 \mathrm{kDa}$; peak height to calculate mass $=$ $25 \%$. The $\mathrm{m} / \mathrm{z}$ values reported are neutral deconvoluted masses. The cross-linking reaction was carried out as described above. After a $72 \mathrm{~h}$ incubation 20 volumes of ammonium acetate $(2.5 \mathrm{M})$ was added and after $30 \mathrm{~min}$ at room temperature the mixture was and desalted using a C18 Sep-Pak column eluted with HPLC grade methanol and ultrapure, deionized water. 


\section{References}

(1) Crick, F. Central Dogma of Molecular Biology. Nature 1970, 227 (5258), 561-563. https://doi.org/10.1038/227561a0.

(2) Schumacher, B.; Garinis, G. A.; Hoeijmakers, J. H. J. Age to Survive: DNA Damage and Aging. Trends Genet. TIG 2008, 24 (2), 77-85. https://doi.org/10.1016/j.tig.2007.11.004.

(3) Borgesius, N. Z.; de Waard, M. C.; van der Pluijm, I.; Omrani, A.; Zondag, G. C. M.; van der Horst, G. T. J.; Melton, D. W.; Hoeijmakers, J. H. J.; Jaarsma, D.; Elgersma, Y. Accelerated Age-Related Cognitive Decline and Neurodegeneration, Caused by Deficient DNA Repair. J. Neurosci. Off. J. Soc. Neurosci. 2011, 31 (35), 12543-12553. https://doi.org/10.1523/JNEUROSCI.1589-11.2011.

(4) Menck, C. F.; Munford, V. DNA Repair Diseases: What Do They Tell Us about Cancer and Aging? Genet. Mol. Biol. 2014, 37 (1 Suppl), 220-233.

(5) Tubbs, A.; Nussenzweig, A. Endogenous DNA Damage as a Source of Genomic Instability in Cancer. Cell 2017, 168 (4), 644-656. https://doi.org/10.1016/j.cell.2017.01.002.

(6) Lindahl, T.; Barnes, D. E. Repair of Endogenous DNA Damage. Cold Spring Harb. Symp. Quant. Biol. 2000, 65, 127-133. https://doi.org/10.1101/sqb.2000.65.127.

(7) Barnes, D. E.; Lindahl, T. Repair and Genetic Consequences of Endogenous DNA Base Damage in Mammalian Cells. Annu. Rev. Genet. 2004, 38, 445-476. https://doi.org/10.1146/annurev.genet.38.072902.092448. 
(8) Dutta, S.; Chowdhury, G.; Gates, K. S. Interstrand Cross-Links Generated by Abasic Sites in Duplex DNA. J. Am. Chem. Soc. 2007, 129 (7), 1852-1853. https://doi.org/10.1021/ja067294u.

(9) Johnson, K. M.; Price, N. E.; Wang, J.; Fekry, M. I.; Dutta, S.; Seiner, D. R.; Wang, Y.; Gates, K. S. On the Formation and Properties of Interstrand DNA-DNA CrossLinks Forged by Reaction of an Abasic Site with the Opposing Guanine Residue of 5'-CAp Sequences in Duplex DNA. J. Am. Chem. Soc. 2013, 135 (3), 1015-1025. https://doi.org/10.1021/ja308119q.

(10) Stayton, P. S.; Freitag, S.; Klumb, L. A.; Chilkoti, A.; Chu, V.; Penzotti, J. E.; To, R.; Hyre, D.; Le Trong, I.; Lybrand, T. P.; Stenkamp, R. E. Streptavidin-Biotin Binding Energetics. Biomol. Eng. 1999, 16 (1), 39-44. https://doi.org/10.1016/S1050-3862(99)00042-X.

(11) Helm, C. A.; Knoll, W.; Israelachvili, J. N. Measurement of Ligand-Receptor Interactions. Proc. Natl. Acad. Sci. U. S. A. 1991, 88 (18), 8169-8173.

(12) Weber, P. C.; Ohlendorf, D. H.; Wendoloski, J. J.; Salemme, F. R. Structural Origins of High-Affinity Biotin Binding to Streptavidin. Science 1989, 243 (4887), $85-88$. 


\section{Chapter 5}

\section{Conclusion and directionality of research}

\subsection{Introduction}

This thesis has involved the study of the Ap site, a highly electrophilic lesion in DNA, and the reactivity and repair of it and its derivatives. A firm understanding of the Ap site and the lesions it can form with nucleophiles is important to understand the profound biological consequences of the Ap site. This chapter will serve to discuss the future direction of this research.

\subsection{Directionality of research}

Chapter two shows the reaction between an Ap site and multiple nucleophiles, including glutathione (Scheme 2.2.1), 1-aminohydantoin (Scheme 2.3.1), and carbidopa (Scheme 2.4.1) and its ability to form adducts. The ability for the DNA repair enzyme, APE1 was also studied for its potential to initiate the repair process for these monoadduct Ap lesions (Scheme 2.1.1). This chapter was able to show that these lesions formed and was able to inhibit APE1 repair, but more work needs to be done. 


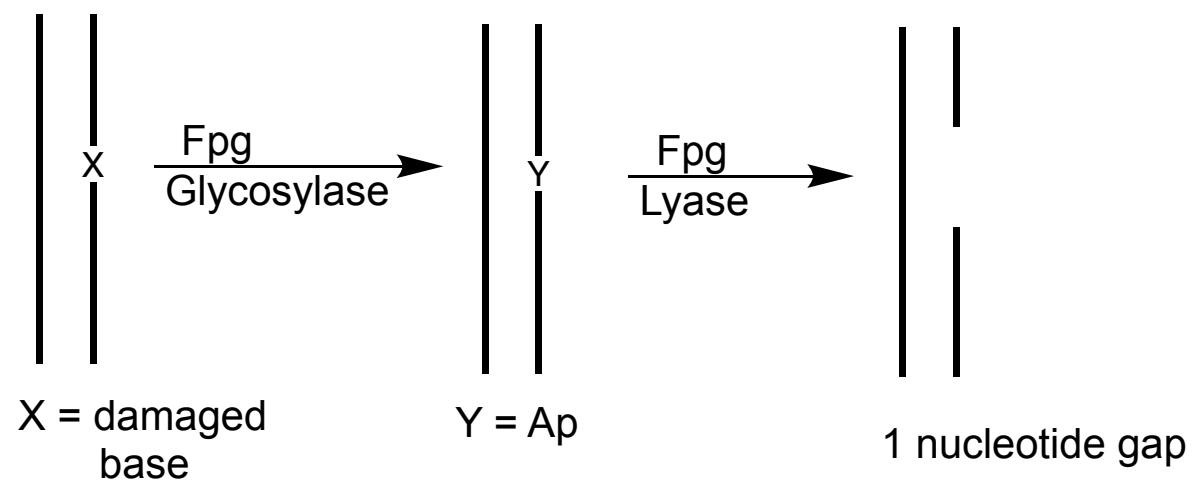

\section{Scheme 5.1.1. Fpg removes damaged base and leaves a single strand break with its lyase activity.}

The stability of these lesions as well as the ability of other repair enzymes such as Fpg is an area that could be studied further. Fpg is a base repair enzyme which removes a wide range of oxidized DNA bases (Scheme 5.1.1). ${ }^{1}$ These studies can help elucidate the reactivity and activity of these lesions.

\subsection{Conclusions}

Ap sites represent a ubiquitous, yet not fully understood, electrophilic lesion in DNA. If these lesions are not repaired, it can result in neurodegeneration, aging, and cancer. ${ }^{2,3,4,5,6,7,8}$ Chapter two goes into the chemistry of forming lesions with the Ap site and the 3 'dRP end group. Chapter three goes into detail of forming an interstrand crosslink at a single strand break in DNA between the 3'dRP group and an opposing guanine nucleobase. Chapter four describes a facile synthesis for a DNA duplex containing a chemically defined, derivatizable interstrand cross-link. 
The research performed in this thesis is all founded on the principle that Ap sites are a class of highly electrophilic, reactive lesions. I used the techniques of bio-organic, organic, and analytical chemistry to study the chemistry of the Ap site. 


\section{References}

(1) Boiteux, S.; O’Connor, T. R.; Laval, J. Formamidopyrimidine-DNA Glycosylase of Escherichia Coli: Cloning and Sequencing of the Fpg Structural Gene and Overproduction of the Protein. EMBO J. 1987, 6 (10), 3177-3183.

(2) McKinnon, P. J. DNA Repair Deficiency and Neurological Disease. Nat. Rev. Neurosci. 2009, 10 (2), 100-112. https://doi.org/10.1038/nrn2559.

(3) Madabhushi, R.; Pan, L.; Tsai, L.-H. DNA Damage and Its Links to Neurodegeneration. Neuron 2014, 83 (2), 266-282.

https://doi.org/10.1016/j.neuron.2014.06.034.

(4) Borgesius, N. Z.; de Waard, M. C.; van der Pluijm, I.; Omrani, A.; Zondag, G. C. M.; van der Horst, G. T. J.; Melton, D. W.; Hoeijmakers, J. H. J.; Jaarsma, D.; Elgersma, Y. Accelerated Age-Related Cognitive Decline and Neurodegeneration, Caused by Deficient DNA Repair. J. Neurosci. Off. J. Soc. Neurosci. 2011, 31 (35), 12543-12553. https://doi.org/10.1523/JNEUROSCI.1589-11.2011.

(5) Schumacher, B.; Garinis, G. A.; Hoeijmakers, J. H. J. Age to Survive: DNA Damage and Aging. Trends Genet. TIG 2008, 24 (2), 77-85. https://doi.org/10.1016/j.tig.2007.11.004.

(6) Menck, C. F.; Munford, V. DNA Repair Diseases: What Do They Tell Us about Cancer and Aging? Genet. Mol. Biol. 2014, 37 (1 Suppl), 220-233.

(7) Hoeijmakers, J. H. J. DNA Damage, Aging, and Cancer. N. Engl. J. Med. 2009, 361 (15), 1475-1485. https://doi.org/10.1056/NEJMra0804615. 
(8) Cline, S. D. Mitochondrial DNA Damage and Its Consequences for Mitochondrial Gene Expression. Biochim. Biophys. Acta 2012, 1819 (9-10), 979-991. https://doi.org/10.1016/j.bbagrm.2012.06.002. 
Kurt L. Housh was born in Cambridge, MA. He and his family moved to Round Rock, TX where they settled and spent most of his childhood. He earned a bachelor's degree in biochemistry from Missouri Southern State University, during which he did undergraduate research in an organic chemistry lab. He gained a fascination with medicinal chemistry during this time. He joined the lab of Dr. Gates as a graduate student in 2016. He obtained his Ph.D. in 2021, after which he took a position as a postdoctoral researcher for the drug company NUBAD, LLC in Greenville, SC. 